\title{
META-ANÁLISE DE PARÂMETROS GENÉTICOS DE CARACTERÍSTICAS DE CRESCIMENTO EM BOVINOS DE CORTE SOB ENFOQUES CLÁSSICO E BAYESIANO
}

\section{JULIANA DI GIORGIO GIANNOTTI}

\author{
Tese apresentada à Escola Superior de Agricultura "Luiz \\ de Queiroz”, Universidade de São Paulo, para obtenção \\ do título de Doutor em Agronomia, Área de \\ Concentração: Ciência Animal e Pastagens.
}

P I R A C I C A B A

Estado de São Paulo - Brasil

Julho - 2004 


\title{
META-ANÁLISE DE PARÂMETROS GENÉTICOS DE CARACTERÍSTICAS DE CRESCIMENTO EM BOVINOS DE CORTE SOB ENFOQUES CLÁSSICO E BAYESIANO
}

\section{JULIANA DI GIORGIO GIANNOTTI}

Engenheiro Agrônomo

\author{
Orientador: Prof. Dr. IRINEU UMBERTO PACKER
}

\begin{abstract}
Tese apresentada à Escola Superior de Agricultura "Luiz de Queiroz”, Universidade de São Paulo, para obtenção do título de Doutor em Agronomia, Área de Concentração: Ciência Animal e Pastagens.
\end{abstract}

P I R A C I C A B A

Estado de São Paulo - Brasil

Julho - 2004 
Dados Internacionais de Catalogação na Publicação (CIP)
DIVISÃO DE BIBLIOTECA E DOCUMENTAÇÃO - ESALQ/USP

Giannotti, Juliana Di Giorgio

Meta-análise de parâmetros genéticos de características de crescimento em bovinos de corte sob enfoques clássico e bayesiano

$86 \mathrm{p}$.

Tese (doutorado) - - Escola Superior de Agricultura Luiz de Queiroz, 2004.

Bibliografia.

1. Bovino de corte 2. Inferência-Bayesiana (Inferência estatística) 3.

Melhoramento genético animal 4. Parâmetro genético I. Título

CDD 636.213

"Permitida a cópia total ou parcial deste documento, desde que citada a fonte - O autor" 
Edegar Giannotti e Thaïs Helena de Jorge Giannotti, meus queridos pais, pelo afeto, compreensão, incentivo $e$ principalmente por tudo o que são e representam para mim, a vocês DEDICO este trabalho. 


\section{AGRADECIMENTOS}

Faço aqui meus intensos e sinceros AGRADECIMENTOS para:

Professor Irineu Umberto Packer, pela confiança e orientação.

Pesquisadora e grande amiga Maria Eugênia Zerlotti Mercadante, pelas correções e sugestões nos trabalhos.

Professores Antônio Augusto Franco Garcia, César Gonçalves Lima e Roseli Aparecida Leandro, pelas contribuições nos trabalhos.

Conselho Nacional de Desenvolvimento Científico e Tecnologico (CNPq), pelo apoio financeiro.

Professores e Funcionários dos departamentos de Ciências Exatas, Ciências Florestais e Zootecnia, pelo apoio, ensinamentos transmitidos e estrutura fornecida.

Todos os colegas da pós-graduação, pela amizade.

Alexandre Di Giorgio Giannotti, pelo bom exemplo de conduta de vida.

Família Cândido Xavier, pela carinhosa acolhida.

Alexandre Cândido Xavier, pelo amor, companheirismo e corajosas leituras dos trabalhos.

Todas as pessoas que direta ou indiretamente contribuíram para a realização deste trabalho. 


\section{SUMÁRIO}

Página

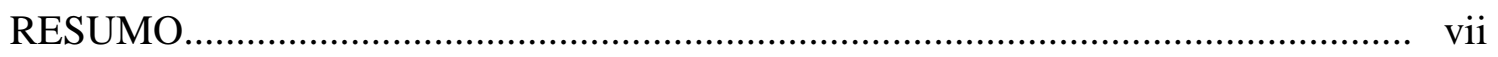

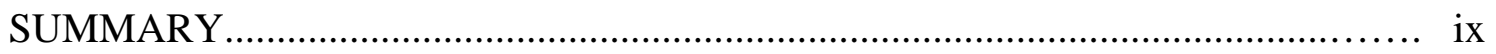

$1 \quad$ INTRODUÇÃO

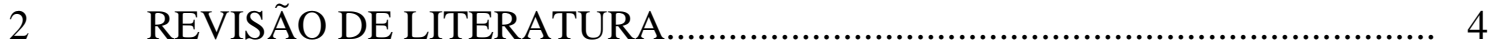

2.1 Definição e origem do termo................................................................. 4

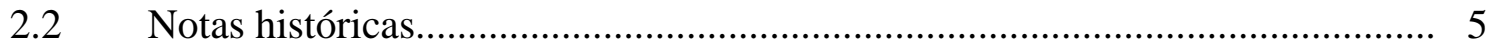

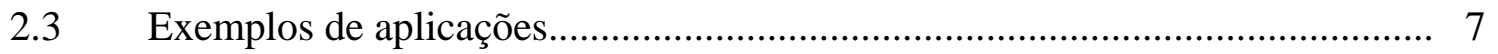

2.4 Propósitos e problemas da meta-análise...................................................... 8

2.5 Metodologia estatística para combinar estudos......................................... 10

2.5.1 Metodologia estatística para combinar testes de hipóteses........................... 10

2.5.2 Metodologia estatística para combinar estimativas.................................... 11

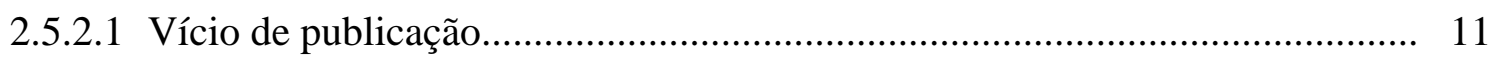

2.5.2.2 Teste de homogeneidade.................................................................. 12

2.5.2.3 Modelos de efeito fixo e aleatório.......................................................... 12

2.5.2.4 Obtenção da estimativa combinada.......................................................... 14

2.6 Programas computacionais para implementação de meta-análise.................. 14

3 META-ANÁLISE DAS ESTIMATIVAS DE HERDABILIDADE PARA CARACTERÍSTICAS DE CRESCIMENTO EM BOVINOS DE CORTE.... 16

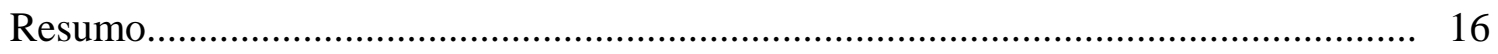

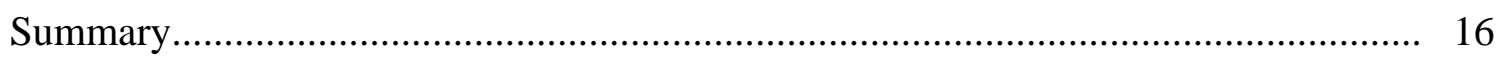




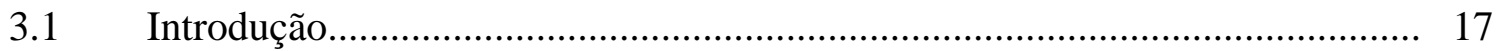

3.2 Material e Métodos........................................................................................ 19

3.3 Resultados e Discussão.............................................................................. 23

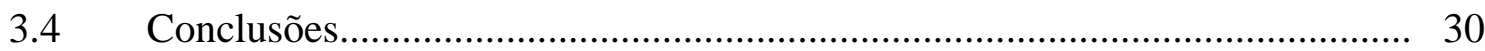

4 ANÁLISE DE AGRUPAMENTO PARA IMPLEMENTAÇÃO DA METAANÁLISE EM ESTIMATIVAS DE HERDABILIDADE PARA CARACTERÍSTICAS DE CRESCIMENTO EM BOVINOS DE CORTE.... 31

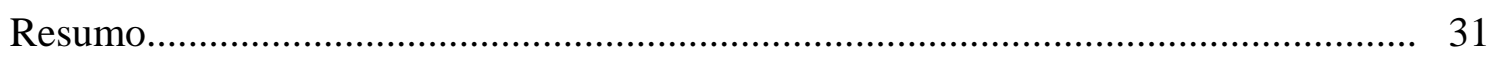

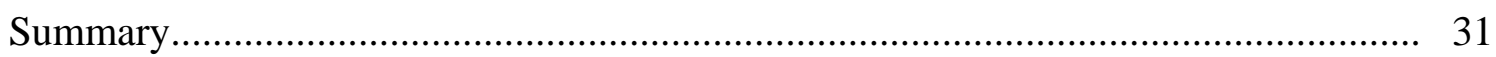

4.1 Introdução.................................................................................. 32

4.2 Material e Métodos....................................................................................... 34

4.3 Resultados e Discussão.............................................................................. 37

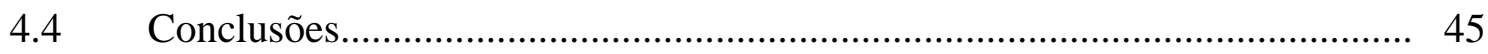

5 META-ANÁLISE SOB ENFOQUE BAYESIANO DE ESTIMATIVAS DE HERDABILIDADE E COEFICIENTES DE CORRELAÇÃO PARA CARACTERÍSTICAS DE CRESCIMENTO EM BOVINOS DE CORTE.... 46

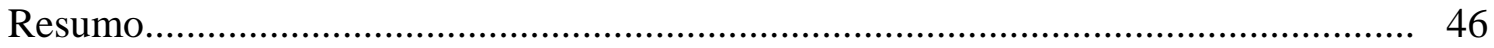

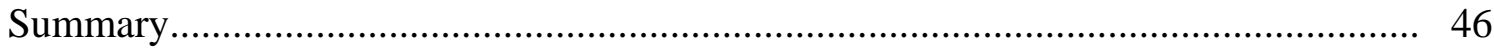

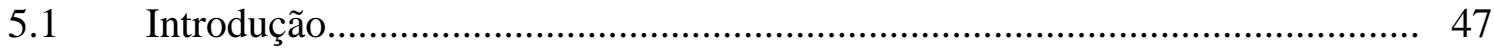

5.2 Material e Métodos................................................................................ 49

$5.3 \quad$ Resultados e Discussão.............................................................................. 53

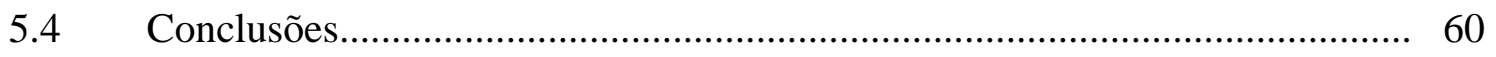

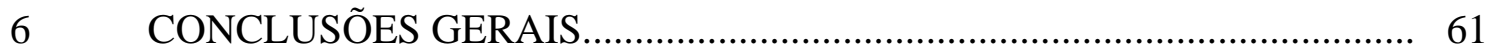

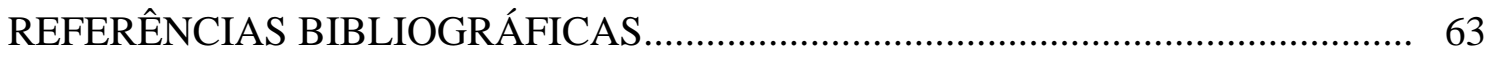

BIBLIOGRAFIA UTILIZADA NA META-ANÁLISE............................................. 73 


\title{
META-ANÁLISE DE PARÂMETROS GENÉTICOS DE CARACTERÍSTICAS DE CRESCIMENTO EM BOVINOS DE CORTE SOB ENFOQUES CLÁSSICO E BAYESIANO
}

\author{
Autora: JULIANA DI GIORGIO GIANNOTTI \\ Orientador: Prof. Dr. IRINEU UMBERTO PACKER
}

\section{RESUMO}

O crescente volume de publicações científicas gerado pelo desenvolvimento das pesquisas e as conclusões, algumas vezes destoantes, obtidas em diferentes trabalhos versando sobre um mesmo tema, são as duas principais motivações de pesquisadores em compilar informações publicadas. Em vista disso, procedimentos estatísticos, dentre os quais destaca-se a meta-análise, vêm sendo desenvolvidos para obtenção de uma resposta única e confiável para um conjunto de resultados publicados.No melhoramento genético animal há um grande número de trabalhos contendo estimativas de herdabilidade de características de crescimento em bovinos de corte. Através de pesquisa bibliográfica foram encontrados, em 186 artigos publicados, 869 estimativas de herdabilidade de efeito direto, 186 estimativas de herdabilidade de efeito materno e 123 estimativas do coeficiente de correlação genética entre os efeitos direto e materno, das características de crescimento peso ao nascimento, peso a desmama, peso aos 365 dias e peso aos 550 dias em bovinos de corte de origem indiana. De posse deste conjunto de dados, foram realizadas meta-análises, dentro de cada uma das quatro características de crescimento, cujo objetivo principal foi obter uma resposta combinada, para estes 
parâmetros genéticos, sob enfoques clássico e bayesiano. No enfoque clássico conduziram-se as meta-análises utilizando modelos fixo e aleatório, em que dois estimadores, o de máxima verossimilhança restrita e o proposto por DerSimonian \& Laird, foram empregados para estimar a variância entre os estudos. Também foi realizada meta-análise de acordo com a técnica de agrupamento de Ward. Sob o enfoque bayesiano, as meta-análises foram conduzidas utilizando-se um modelo hierárquico e, a variância entre os estudos, foi obtida via simulação através do modelo proposto. As estimativas combinadas de herdabilidade de efeito direto variaram de 0,18 a 0,33, nos diferentes grupos formados a partir da análise de agrupamento, sendo sempre menores àquelas obtidas para peso à desmama e sempre maiores àquelas obtidas para peso aos 550 dias. As estimativas combinadas de herdabilidade de efeito materno foram 0,09 para peso ao nascimento, 0,13 para peso à desmama, 0,12 para peso aos 365 dias e 0,05 para peso aos 550 dias. As estimativas combinadas para correlação entre os efeitos diretos e maternos foram de -0,16 para peso ao nascimento, à desmama e aos 550 dias e -0,20 para peso aos 365 dias. Os três métodos utilizados para estimar a variância entre os estudos, o da máxima verossimilhança restrita, o proposto por DerSimonian \& Laird e o Bayesiano, conduziram a valores distintos para esta variância, sendo sempre maiores os valores obtidos através do método Bayesiano e sempre menores os obtidos por DerSimonian \& Laird. Porém, os valores das estimativas combinadas para herdabilidades de efeito direto, obtidas através destes três estimadores, muito próximos, para as quatro características. Devido ao fato de comparar e combinar resultados de estudos distintos, permitindo inferir sobre um conjunto de resultados publicados, recomenda-se a meta-análise, como procedimento estatístico, para obtenção de valores combinados das estimativas de herdabilidade de efeito direto, materno e suas correlações, nas características de crescimento em bovinos de corte. 


\title{
META-ANALYSIS OF GENETIC PARAMETERS OF GROWTH TRAITS ON BEEF CATTLE UNDER CLASSIC AND BAYESIAN APPROACH
}

\author{
Author: JULIANA DI GIORGIO GIANNOTTI \\ Adviser: Prof. Dr. IRINEU UMBERTO PACKER
}

\section{SUMMARY}

The increasing volume of research publications as a consequence of scientific development and eventually with divergent conclusions obtained in different studies about the same subject are the two main motivations for compiling the information of these works. Statistical procedures, particularly the meta-analysis, were developed in order to obtain a unique and realistic answer from a set of published results. In the field of animal breeding there is a large amount of research work on heritability estimates for growth traits in beef cattle. A total of 186 articles was found in literature, reporting 869 direct heritability estimates, 186 maternal heritability estimates and 123 direct-maternal genetic correlation for birth weight, weaning weight, weight at 365 and at 550 days of age in zebu beef cattle. Based on this data set, meta-analysis, under Classic and Bayesian approaches, were performed in order to obtain a pooled estimate of those genetic parameters for each trait. Regarding the Classic approach, the meta-analysis were performed using a random effect model, where two estimators, the Restricted Maximum Likelihood and the one proposed by DerSimonian \& Laird were used to evaluate the variance between studies. Also, it was performed a meta-analysis using the method of cluster analysis of Ward to group the estimates. Under the Bayesian approach, the meta- 
analysis was performed using a hierarchical model and the variances between the studies, were obtained by simulation using the proposed model. The pooled estimates for direct heritabilities ranged from 0.18 to 0.33 for the different groups composed by the cluster analysis. The lower values were obtained for weaning weight and higher values were obtained for weight at 550 days of age. The pooled estimates for maternal heritabilities were 0.09 for birth weight, 0.13 for weaning weight, 0.12 for weight at 365 days of age and 0.05 for weight at 550 days of age. The pooled estimates for directmaternal genetic correlations were -0.16 for birth weight, weaning weight and weight at 550 days of age and -0.20 for weight at 365 days of age. The three methods, Restricted Maximum likelihood, the estimator proposed by DerSimonian \& Laird and the Bayesian, used to estimate the variance between studies lead to different values, the greater ones obtained by Bayesian method and the lower by DerSimonian \& Laird. In general, pooled estimates values for direct heritabilities, obtained by those three estimators, were very close. Meta-analysis is recommended as a statistical procedure to compare and combine results from different studies in order to obtain pooled values of direct and maternal heritabilities and direct-maternal genetic correlations of growth traits of beef cattle. 


\section{INTRODUÇÃO}

O número de revistas e artigos científicos publicados atualmente é tão grande, que, muitas vezes, a quantidade de informação gerada pode dificultar a tomada de decisão de alguns pesquisadores sobre determinado tema. Estima-se que existam acima de 890000 revistas científicas publicadas em todo o mundo (Ferreira \& Krzyzanowski, 2003). Pode-se citar alguns exemplos da coleção de artigos científicos em instituições no Brasil, nas bibliotecas da Escola Superior de Agricultura "Luiz de Queiroz", com publicações mais direcionadas às ciências agrárias, e da Universidade Federal de Viçosa, com publicações abrangendo um número maior de áreas, o número de periódicos colocados à disposição da comunidade é de, respectivamente, 2957 e 6271, a CAPES e o SIBI-USP disponibilizam, respectivamente, 7024 e 5053 revistas científicas eletrônicas.

Em virtude deste aumento do volume de informação científica gerado, há de se esperar a coincidência de assuntos estudados em alguns destes artigos, havendo, também, a possibilidade de discordância nas suas conclusões.

Tal fato pode ser exemplificado com diferentes artigos publicados na área de melhoramento animal, em trabalhos cujo objetivo é estimar herdabilidades de efeitos direto e materno, e a correlação entre estes efeitos, para determinadas características de crescimento em bovinos de corte. Para estimativas de herdabilidade de efeito direto na característica peso ao nascimento em bovinos de corte, os valores encontrados por Cárdenas et al. (2001) e Tawah et al. (1993), foram 0,09 e 0,65, respectivamente. Para estimativas de herdabilidade de efeito materno na característica peso ao nascimento em bovinos de corte, os valores encontrados por Albuquerque \& Meyer (2001) e Reyes et al. (1994), foram 0,01 e 0,25, respectivamente. Características com valores de 
estimativas de herdabilidade abaixo de 0,20 são consideradas pouco herdáveis, entre 0,20 e 0,40 moderadamente herdáveis, e superiores a 0,40 altamente herdáveis (Bourdon, 2000). Deste modo, impera a dúvida da estimativa de herdabilidade para efeito direto da característica peso ao nascimento ser pouco ou muito herdável, e da estimativa de herdabilidade para efeito materno da característica peso ao nascimento ser pouco ou moderadamente herdável. Quanto a correlação entre os efeitos direto e materno, para a característica peso ao nascimento, os valores encontrados por Tawah et al. (1993) e Salles (1995) foram, respectivamente, -0,93 e 0,12. O coeficiente de correlação indica a associação entre duas variáveis, variando de -1 a 1 , sendo que: valores próximos a -1 indicam forte associação negativa entre variáveis; zero indica ausência de associação; e valores próximos a 1 indicam forte associação positiva entre variáveis. De posse destes dois resultados, a dúvida que prevalece, nesta situação, é a existência de uma associação negativa forte entre as herdabilidades de efeito direto e materno ou a existência de uma associação positiva fraca entre elas.

Assim, para nortear uma conclusão, a média obtida a partir de diferentes resultados já existentes pode ser uma solução interessante. Porém, para a obtenção de um valor médio que represente, da maneira mais fiel possível, os vários resultados de diferentes pesquisas, diversos fatores devem ser considerados na análise, dentre eles a variabilidade existente entre os estudos, que pode ser proveniente, por exemplo, de diferentes tipos de manejo alimentar (a pasto, confinado, semi-confinado), diferentes raças, sexo, métodos distintos de estimação dos parâmetros envolvidos, dados oriundos de vários países etc. Um procedimento estatístico que propõe estimar, e se preciso incluir na análise conjunta, a variância entre os estudos é a meta-análise.

A meta-análise pode ser definida como o procedimento estatístico que consiste em uma revisão quantitativa e resumida de resultados de estudos distintos, mas relacionados (Glass, 1976). Seus objetivos são, principalmente, comparar, e possivelmente combinar, os resultados de diferentes trabalhos publicados, acarretando em alguma conclusão geral sobre o tema em estudo. 
Koots et al. (1994a) consideram que o número de estimativas de herdabilidade publicadas, para algumas características de crescimento em bovinos de corte, é suficiente para que exista a pretensão, entre os pesquisadores da área de melhoramento animal, de resumir tais parâmetros genéticos e realizar inferências considerando valores combinados.

Neste contexto, em que existe tanto um grande número de artigos publicados contendo estimativas de herdabilidade para características de crescimento em bovinos de corte, quanto conclusões destoantes para uma mesma característica, devido a ampla variação de resultados apresentados na literatura para estas estimativas, os objetivos principais deste trabalho são:

a) obter estimativas combinadas, através da meta-análise, para estimativas de herdabilidades de efeito direto e materno, e a correlação entre estes efeitos, nas características de crescimento, peso ao nascimento, peso à desmama, peso aos 365 dias e peso aos 550 dias, em bovinos de corte de origem indiana;

b) realizar análise de agrupamento, dentro das características peso ao nascimento, peso à desmama, peso aos 365 dias e peso aos 550 dias, considerando como variáveis raça, país, método de estimação, número de animais e a estimativa de herdabilidade;

c) verificar a influência, na estimativa combinada, de três estimadores da variância entre os estudos: o proposto por DerSimonian \& Laird (1986); o da Máxima Verossimilhança Restrita; e o Bayesiano. 


\section{REVISÃO DE LITERATURA}

A meta-análise é o procedimento estatístico que permite obter uma medida comum entre várias pesquisas distintas, todavia relacionadas. Pode-se verificar a grande e crescente coleção de artigos publicados nas diversas áreas do conhecimento, gerando interesse dos pesquisadores de realizar a síntese destes resultados, uma vez que pode ocorrer divergência das conclusões em trabalhos enfocando o mesmo tema. Este procedimento é particularmente útil quando os estudos ou ensaios individuais são muito pequenos para fornecer isoladamente uma resposta confiável e conclusiva (Fagard et al., 1996).

A aplicação da meta-análise originou-se na pesquisa educacional, teve aceitação imediata em medicina e o seu emprego tem se estendido a várias áreas, podendo-se observar o crescimento da sua utilização. Apesar de ter sido bem recebida, o procedimento sofre críticas e há alguns problemas quanto ao seu emprego, principalmente em relação à natureza diversa dos estudos a serem sintetizados e ao alcance da revisão de literatura dos artigos a serem incluídos na análise.

\subsection{Definição e origem do termo}

O nome "meta-análise" foi sugerido e definido por Glass (1976), pesquisador da área da ciências sociais, mais precisamente da pesquisa educacional, como “a análise de uma grande coleção de resultados de análises provenientes de estudos individuais, tendo como propósito completar o que foi encontrado”. Este termo pode ser considerado adequado pois, "meta" implica em algo que ocorreu depois ou em sucessão, mais organizado ou realizado de maneira mais especializada (Egger \& Smith, 1997). Apesar 
de existirem outros termos na língua inglesa para designar este tipo de análise, tais como “overview”, “data pooling”, “pooling”, “literature syntesis”, “data syntesis”, “quantitative syntesis” e “quantitative review” (Dickersin \& Berlin, 1992), o termo “meta-analysis” já está estabelecido (Gaver et al., 1992). Assim, o termo utilizado na língua portuguesa é meta-análise (Costa, 1999; Fortulan, 1999; Giannotti, 2000; Bini et al., 2001; Martins, 2001).

\subsection{Notas históricas}

A síntese de informações de dados coletados sob diferentes condições, e até mesmo precisões, para produzir conclusões mais abrangentes não é recente. Stigler (1986) descreve a origem do método dos mínimos quadrados, no início do século XIX, como uma tentativa de resolver o problema da utilização de observações astronômicas, coletadas de observatórios distintos, para estimar a órbita dos cometas e determinar arcos meridianos na geodésia.

Gaver et al. (1992) descrevem a proposta, no início do século XX, de determinar a relação entre mortalidade e inoculação com uma vacina para febre entérica, usando dados de cinco estudos pequenos e independentes. Calcularam-se estimativas da correlação entre inoculação e mortalidade em cada uma das amostras e, então, obteve-se a correlação combinada entre as amostras, pois “os ensaios individuais eram muito pequenos para permitir qualquer opinião definitiva”. Esta estimativa combinada foi utilizada para avaliar a eficácia da vacina, comparando-a com valores padrões de correlações de outras vacinas.

Trabalhos importantes quanto a reunião de estudos distintos surgiram na área agronômica, nos primeiros anos do século XX, onde duas direções distintas foram tomadas para combinar evidências: uma utilizando o nível de significância estatística entre os estudos (Fisher, 1932); e outra o efeito dos tratamentos entre os estudos (Hedges \& Olkin, 1985). 
Entre os anos de 1945 e 1970 existem poucos artigos publicados sobre o tema de combinar resultados provenientes de estudos distintos até que, em meados de 1970, principalmente na área das ciências sociais, houve um aumento no número de artigos publicados sobre meta-análise (Olkin, 1995). Entre os anos de 1980 e 1990 surgiram os

primeiros livros textos sobre este assunto. Tais livros enfocam principalmente discussões, exemplos de casos de estudos e metodologias estatísticas para implementar uma meta-análise, dentre os quais citam-se Glass et al. (1981), Rosenthal (1984), Hedges \& Olkin (1985), Cooper (1990) e Hunter \& Schmidt (1990). Livros textos mais recentes também exploram este tema tanto dentro de capítulos (Scheiner \& Gurevitch, 1993; Kirby, 1993; Gelman et al., 2004) quanto na íntegra (Petitti, 1994; Wang \& Bushman, 1999; Arthur et al., 2001).

Assim como houve um aumento na publicação de livros textos sobre este tema, o número de artigos publicados nas várias áreas da pesquisa também teve um crescimento a partir de 1976 (Figura 1).

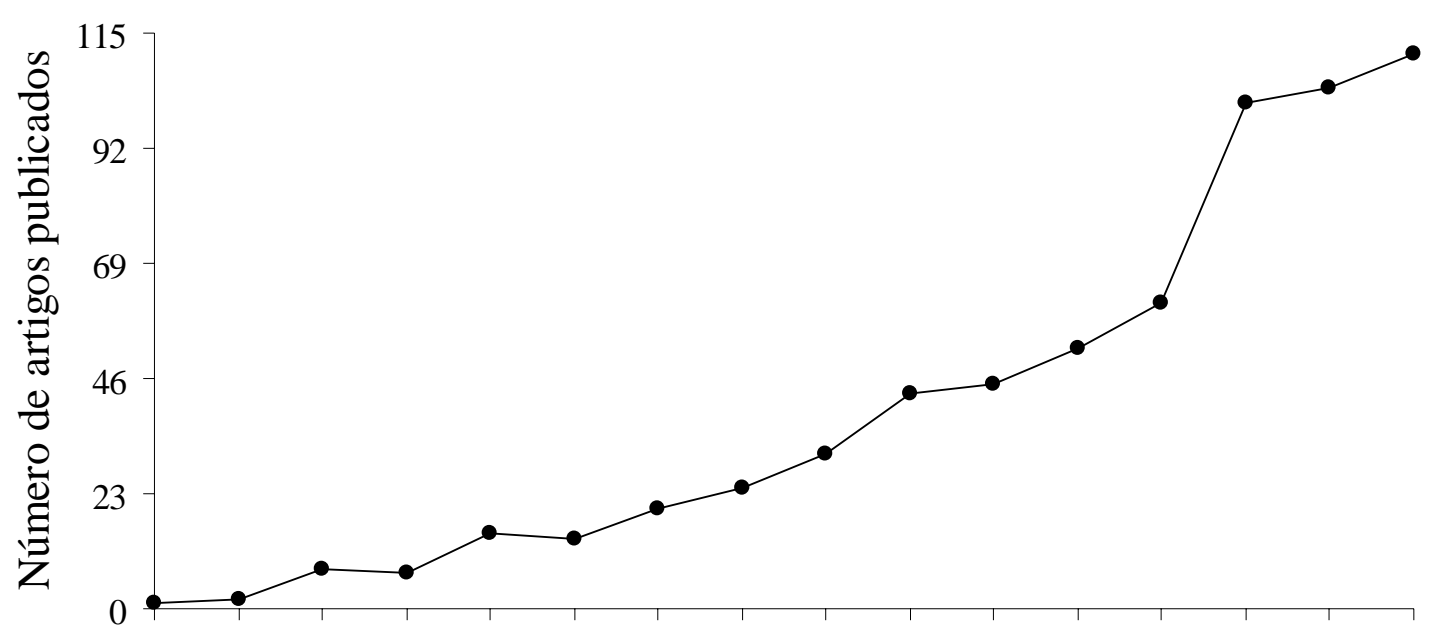

1988198919901991199219931994199519961997199819992000200120022003

Ano

Figura 1- Número de publicações sobre o tema meta-análise na base de dados internacional $\mathrm{CAB}$ 
Uma investigação feita na base de dados internacional CAB, em que são indexados trabalhos de ciências agrárias, zootécnicas, florestais, ambientais, biológicas e afins, usando com as palavras-chave "meta-analysis" e "meta-analise", entre os anos de 1976 e 2003, mostra que o número de artigos em periódicos sobre esse tema, aumentou no decorrer deste período (Figura 1). Observa-se que o maior número de artigos ocorreu em 2003, com 111 publicações.

\subsection{Exemplos de aplicações}

A aplicação da meta-análise ocorreu primeiramente na área das ciências sociais, como citado anteriormente, mais precisamente em educação. A motivação principal para a reunião de resultados neste contexto foi em virtude de alguns artigos publicados sobre um mesmo tema estarem gerando conclusões contraditórias. Deste modo, combinar resultados de artigos distintos, poderia auxiliar nas tomadas de decisão quanto à melhor técnica a ser recomendada (Glass, 1976).

Na área médica, a meta-análise conseguiu aceitação imediata em virtude, principalmente, da possibilidade da obtenção de um tamanho amostral grande, pela reunião de estudos menores, proporcionando uma resposta mais precisa (Egger \& Smith, 1997). Assim, existem inúmeros artigos de aplicação da meta-análise em medicina, podendo ser citado, como um exemplo clássico, o trabalho de Canner (1987). Este autor compara seis ensaios clínicos multicêntricos, nos Estados Unidos e Europa, sobre a utilização e efeito de aspirina e placebo no tratamento de pacientes que sofreram ataque do coração. Este trabalho foi abordado na avaliação de diferentes metodologias e enfoques em meta-análise por Goodman (1989), Gaver et al. (1992), Normand (1995), DuMouchel (1996), Costa (1999) e Brockwell \& Gordon (2001).

Além da medicina e ciências sociais o emprego da meta-análise se estendeu a outras áreas da pesquisa, com aplicações bastante diversas, como por exemplo: 
a) Agronomia: Olkin \& Shaw (1995) compararam o controle químico e o biológico de determinada praga em morango; Martins (2001) estudou a influência da aplicação de diferentes dosagens de vinhaça na produção de cana-de-açúcar, em solos arenosos e argilosos;

b) Ecologia: Gurevitch \& Hedges (1993) realizaram estudo sobre o aumento no número e no tamanho de diferentes espécies de microorganismos em ambientes terrestres, marinhos e lacustres; Curtis \& Wang (1998) estudaram os efeitos da elevação do $\mathrm{CO}_{2}$ sobre plantas lenhosas;

c) Genética e Melhoramento: Devin et al. (1997) conduziram uma meta-análise bayesiana sobre a herdabilidade do quociente de inteligência em humanos; Goffinet \& Gerber (2000) estudaram a possibilidade de combinar locos de características quantitativas (QTL) em dados simulados apresentando um exemplo de aplicação em milho; Roughsedge et al. (2001) estudaram componentes genéticos diretos e maternos para características de importância econômica em raças cruzadas de bovinos de corte; Giannotti (2001) sumarizaram estimativas de correlação genética entre pesos ao nascer e à desmama em bovinos de corte;

d) Zootecnia: Oetzel (1991) estudou a influência que diferentes composições nutricionais das dietas para gado leiteiro promovem na redução da febre do leite nos animais; Cameron (1998) estudou o comportamento da amamentação como um preditor do consumo de leite; Beckett \& Lean (1997) e Peters et al. (2000) estudaram o efeito do hormônio liberador de gonadotrofina ( $\mathrm{GnRH})$ na ovulação e prenhês em gado leiteiro.

\subsection{Propósitos e problemas da meta-análise}

O mérito alcançado na condução da meta-análise é a obtenção de uma resposta única para diversos estudos distintos. O interesse em encontrar uma medida resumida se dá, principalmente, devido ao grande número de artigos científicos publicados nas diversas áreas da pesquisa, trazendo, em algumas situações, trabalhos sobre um mesmo 
assunto porém com conclusões contraditórias (Olkin, 1992). Os métodos estatísticos empregados na meta-análise asseguram a obtenção de uma resposta combinada precisa, uma vez que há um aumento do número de observações e, conseqüentemente, do poder estatístico. Existe ainda a possibilidade de examinar a variabilidade entre os estudos, podendo-se realizar uma análise de subgrupo, e há meios tanto de responder questões que não foram atribuídas de início aos estudos individuais, quanto generalizar as conclusões para um conjunto de estudo (Fagard et al., 1996).

Apesar da meta-análise ser uma solução bastante interessante para diversas situações, há ainda muitas controvérsias quanto a sua utilização. Houwelingen (1997) refere-se a este procedimento como "um pesadelo e uma solução humana pobre para o problema de analisar medidas resumidas de publicações relacionadas”, defendendo a situação ideal de ter acesso aos dados originais. Admite, contudo, a dificuldade de analisar e mesmo acessar as informações originais de todas as pesquisas, apoiando desta maneira, a idéia de combinar evidências provenientes de origens distintas, modelando, necessariamente, a variância existente entre os estudos.

Menos críticos quanto ao uso deste procedimento estatístico, mas preocupados com a natureza diversa dos diferentes estudos, tanto em termos de delineamento como dos métodos empregados na realização de cada um deles, DerSimonian \& Laird (1986) propõem um método para incorporar a variância entre os estudos na análise.

Embora os estudos a serem combinados envolvam o mesmo assunto, há, muitas vezes, diferenças entre eles, o que é denominado heterogeneidade entre os estudos, sendo este um dos problemas correntes em meta-análise. A solução encontrada para resolver essa questão foi incorporar na análise a variabilidade existente entre os estudos (Li \& Begg, 1994; Li, 1995).

Outros problemas incidentes quanto à formulação de uma meta-análise são a seleção dos estudos a ser incorporada na análise, a correlação existente entre as estimativas a serem combinadas e o vício de publicação, conhecido como "file drawer problem”, compreendendo a dificuldade ao acesso a todos os artigos do assunto em 
pauta (Rosenthal, 1984). Este último pode ser considerado, juntamente com a heterogeneidade das estimativas, os principais problemas presentes em meta-análise (Begg \& Mazumdar, 1994; Silliman, 1997). Há uma concordância entre os usuários da meta-análise que, quanto mais abrangente for a revisão de literatura sobre o tema em questão, menor será o vício de publicação. Assim, tal revisão deverá incluir, além dos artigos publicados em periódicos, aqueles presentes em anais de congresso, publicações pessoais, dissertações e teses.

\subsection{Metodologia estatística para combinar estudos}

O trabalho de meta-análise pode ser dividido em duas linhas de conduta, condicionadas à informação obtida nos estudos originais, consistindo de resultados de testes de hipótese ou estimativas (médias, correlações, razões entre grupos etc) (Hedges, 1992).

Neste contexto, seja uma coleção de $k$ estudos independentes nos quais o i-ésimo estudo tem como estimativa $y_{i}$, variância $\hat{s}_{i}^{2}$ e como parâmetro $\alpha_{i}$.

\subsubsection{Metodologia estatística para combinar testes de hipóteses}

Quando os dados dos estudos a serem combinados forem provenientes de testes estatísticos, pode-se estimar uma resposta única, se nos artigos estiverem presentes os pvalores ou meios para calculá-los. A utilização de resultados de testes de hipótese para combinar estudos foi, possivelmente, o primeiro procedimento estatístico desenvolvido para tal objetivo (Hedges \& Olkin, 1985).

Existem diferentes métodos de combinar os p-valores tais como: os métodos baseados na distribuição Uniforme; o método da Normal inversa; o método Logit; e o método do Qui-quadrado inverso proposto por Fisher (1932). Este último, é talvez o mais utilizado. Essas metodologias para combinar p-valores de estudos distintos, assim como suas limitações, estão amplamente descritos em Hedges \& Olkin (1985) e Hedges (1992). 


\subsubsection{Metodologia estatística para combinar estimativas}

Quando os estudos a serem combinados têm delineamentos e estruturas de resultados similares, e fornecem estimativas como diferenças médias entre grupos de tratamento e de controle, coeficientes de correlação, razões entre grupos tratamento e controle (por exemplo razão de risco, “odds ratio” e risco relativo), e herdabilidades, estes poderão ser sintetizados, através de meta-análise, se estiverem presentes nos estudos originais informações como a variância da estimativa e o tamanho da amostra (Hedges \& Olkin, 1985).

De posse das estimativas a serem sintetizadas as principais etapas para implementar uma meta-análise são: verificar a existência ou não de vício de publicação; testar a homogeneidade entre os estudos; modelar a variação e adotar um modelo para a análise; obter uma estimativa comum (Hedges, 1992).

\subsubsection{Vício de publicação}

O vício de publicação pode ser detectado pelo gráfico de funil, que avalia a dispersão dos efeitos estimados contra o tamanho da amostra. Tal dispositivo baseia-se no fato de estimativas mais precisas estarem relacionadas a amostras de tamanho grande, assim, resultados de estudos pequenos serão plotados na parte inferior do gráfico. $\mathrm{Na}$ ausência de influência, a dispersão dos pontos será semelhante a de um funil invertido e simétrico. Se existir uma forma assimétrica no gráfico, poderá haver influência dos estudos selecionados (Egger \& Smith, 1998). Porém, quando a meta-análise inclui poucos estudos é difícil determinar a forma exata do gráfico e conseqüentemente, se há ou não vício de publicação. Deste modo Wang \& Bushman (1999) propuseram a utilização do gráfico de quantil-quantil (“qqplot”) para verificar se há vício de publicação. Este dispositivo gráfico consiste em plotar cada estimativa padronizada contra o valor observado na distribuição normal padronizada, e indicará a ausência de vício se os pontos se alinharem ao longo da reta que passa pela origem e se aproximadamente $68 \%$ das estimativas estiverem entre -1 e 1 . 


\subsubsection{Teste de homogeneidade}

Uma das questões mais importantes em meta-análise é a verificação da homogeneidade entre os estudos. Esta suposição é testada pela hipótese $H_{0}: y_{1}=y_{2}=\ldots=y_{k}$, contra a hipótese de que pelo menos uma estimativa de difere das demais, através da estatística $Q \sim \chi_{k-1}^{2}$ (Cochran, 1937), dada por: $Q=\sum_{i=1}^{k} w_{i}\left(y_{i}-\hat{\mu}\right)^{2}$, em que $w_{i}=1 / \hat{s}_{i}^{2} \quad$ e $\hat{\mu}=\sum_{i=1}^{k} w_{i} y_{i} / \sum_{i=1}^{k} w_{i}$. O resultado significativo do teste estatístico implica que a variação nas estimativas entre os estudos é maior do que aquela esperada pelo acaso, ou seja, rejeita-se a hipótese de que as estimativas não diferem entre si (Wang \& Bushman, 1999).

\subsubsection{Modelos de efeito fixo e aleatório}

De acordo com o resultado obtido no teste de homogeneidade opta-se por um modelo de efeito fixo ou aleatório. A decisão pelo modelo de efeito fixo é tomada quando não há heterogeneidade significativa entre os estudos, ou seja, há variabilidade apenas dentro dos estudos e não entre eles. E, caso haja heterogeneidade significativa entre os estudos, deve-se optar pelo modelo de efeito aleatório, no qual estão presentes as variâncias dentro e entre os estudos.

Nos modelos de efeito fixo assume-se que a estimativa combinada é um valor fixo, enquanto nos modelos de efeito aleatório essa estimativa é uma variável aleatoriamente distribuída com média e variância próprias. Quando se utiliza o modelo de efeito fixo pode-se fazer generalizações para um universo de estudos com características similares e, quando se utiliza o modelo de efeito aleatório, pode-se fazer generalizações a um universo de estudos diversos. Deste modo, a generalização é maior nos modelos de efeito aleatório, o poder estatístico destes é menor do que o de efeito fixo (Wang \& Bushman, 1999). 
Em geral no modelo de efeito fixo assume-se que $\alpha_{i}=\mu$, portanto pode ser descrito como: $y_{i}=\mu+e_{i}$ em que $y_{i} \sim \operatorname{Normal}\left(\mu, s_{i}^{2}\right), \mu$ representa o valor da estimativa combinada, dada por $\hat{\mu}=\sum_{i=1}^{k} w_{i} y_{i} / \sum_{i=1}^{k} w_{i}$ com $w_{i}=1 / \hat{s}_{i}^{2}, e_{i}$ representa o erro aleatório $e_{i} \sim \operatorname{Normal}\left(0, s_{i}^{2}\right)$.

O modelo de efeito aleatório assume um efeito básico diferente para cada estudo e leva isto em consideração, como causa de variação adicional (Egger et al., 1997a). Em contraste com o modelo de efeito fixo, o modelo de efeito aleatório concebe os estudos observados como tendo sido retirados de uma grande população de estudos. O modelo de efeito fixo é um caso especial do aleatório em que a variância entre os estudos é nula.

Deste modo, no modelo de efeito aleatório assume-se que as $y_{i}$ são distintas, e o modelo pode então ser descrito como: $y_{i}=\mu^{*}+\varepsilon_{i}+e_{i}$, em que $y i \sim \operatorname{Normal}\left(\mu^{*}, s_{i}^{2}+\tau^{2}\right)$, $\mu^{*}$ representa o valor da estimativa combinada, dada por $\hat{\mu}^{*}=\sum_{i=1}^{k} w_{i}^{*} y_{i} / \sum_{i=1}^{k} w_{i}^{*}$ com $w_{i}^{*}=1 /\left(\hat{s}_{i}^{2}+\hat{\tau}^{2}\right), e_{i} \sim \operatorname{Normal}\left(0, s_{i}^{2}\right)$ é o erro aletatório, $\varepsilon_{i} \sim \operatorname{Normal}\left(0, \tau^{2}\right)$ é o erro aletatório e $\tau^{2}$ é a variância entre os estudos.

Quando se adota o modelo de efeito aleatório, existe a necessidade de estimar a variância entre os estudo $\left(\tau^{2}\right)$, o que pode ser feito através de três métodos:

a) Máxima Verossimilhança Restrita: este é um método para estimar componentes de variância num modelo linear. Consiste em usar a distribuição marginal para $\boldsymbol{y}$ (vetor das observações) e maximizar a função do log-verossimilhança em um processo iterativo. O algoritmo “EM” (“Expectation Maximization”) (Dempster et al., 1977), pode ser utilizado para encontrar o valor que maximiza tal função.

b) DerSimonian \& Laird (1986): este é um método não iterativo e consiste em obter a $\tau^{2}$ através da equação $\hat{\tau}_{D L}^{2}=\operatorname{máx}\left\{0,(Q-(k-1)) /\left(\sum_{i=1}^{k} w_{i}-\left(\sum_{i=1}^{k} w_{i}^{2} / \sum_{i=1}^{k} w_{i}\right)\right)\right\}$. 
c) Bayesiano: neste método adota-se um modelo hierárquico em que se especifica distribuições a priori para os parâmetros de interesse e, as inferências são feitas através dos resultados da integração da distribuição a posteriori conjunta, para a obtenção das distribuições marginais dos parâmetros. Em virtude dos cálculos envolvidos nesta integração serem geralmente complexos, há que se empregar, muitas vezes, métodos de aproximação, como as técnicas de simulação com aplicação dos métodos de amostragem Gibbs e Metrópolis Hastings. Tais técnicas fornecem estimativas pontuais e por intervalo dos parâmetros de interesse do modelo (Gelfand \& Smith, 1990).

\subsubsection{Obtenção da estimativa combinada}

Tendo optado por um dos modelos disponíveis, de efeito fixo ou aleatório, a

estimativa combinada é obtida através da equação: $\hat{\mu}^{*}=\sum_{i=1}^{k} w_{i}^{*} y_{i} / \sum_{i=1}^{k} w_{i}^{*}$, sendo que no modelo de efeito fixo a variância entre os estudos é nula $\left(\hat{\tau}^{2}=0\right)$ (Wang \& Bushman, 1999).

\subsection{Programas computacionais para implementação de meta-análise}

Existem à disposição do usuário, uma série de programas computacionais para a realização da meta-análise. Alguns foram desenvolvidos exclusivamente para este fim, como o META Program Information (Kenny, 2002), o Comprehensive Meta-Analysis (Borenstein et al., 2002a) e o POWER PRECISION (Borenstein et al., 2002b), disponíveis gratuitamente na internet, e outros podem ser utilizados com algumas adaptações ou programações específicas.

Planilhas eletrônicas como o EXCEL e o STATSDIRECT (STATSDIRECT Ltd., 2002), este último com uma opção específica para meta-análise, também podem ser utilizadas na sua aplicação. Guveritch \& Hedges (1993), realizaram uma meta-análise utilizando o EXCEL, com aproximações tanto para um modelo de efeito fixo quanto para um de efeito aleatório. 
Normand (1995) discute o uso de três programas: o DSTAT (Johnson \& Mullen, 2002); o TRUE EPISTAT (Epistat services, 2002); e o FAST*PRO (Eddy \& Hasselblad, 2002), tendo este último a vantagem de realizar tanto uma análise para um modelo de efeito fixo quanto aleatório. Os dois primeiros fazem apenas a aproximação para um modelo de efeito fixo.

Kirby (1993), propõe a utilização do SYSTAT para realizar uma meta-análise. Este programa pode ser utilizado tanto no sistema operacional compatível com MS-DOS quanto para MACINTOSH, e, com programação adequada, faz os cálculos e gráficos necessários para a análise combinada de dados.

Wang \& Bushman (1999) e Arthur et al. (2001) publicaram livros, com programas e macros, para a utilização do programa estatístico SAS na realização de uma meta-análise. Esses autores consideram que, apesar do SAS não ser especialmente delineado para realizar este tipo de análise, ele é uma das melhores opções, no momento, já que um bom software para procedimentos de meta-análise, deve ter capacidade de manejar um banco de dados, realizar cálculos necessários envolvidos numa meta-análise e utilizar dispositivos gráficos para ilustração. Outros autores também preconizam o uso do SAS como uma opção para a realização de uma meta-análise (Dear, 1994; Berkey et al., 1995; Kuss \& Koch; 1996; Normand, 1999; St-Pierre, 2001; Houwelingen et al., 2002). Os principais procedimentos utilizados por esses autores neste programa são o MIXED (SAS, 1996), o IML (SAS, 1990a) e o GLM (SAS, 1990b).

Para a realização da meta-análise sob o enfoque Bayesiano os principais programas computacionais utilizados são: o WinBUGS (Spiegelhalter et al., 2004); o R (R Development Core Team, 2004); e a "library” do R denominada CODA (Best et al., 2004), todos disponíveis gratuitamente na internet. Em programas computacionais que permitem programação é também possível implementar uma meta-análise Bayesiana. Fortulan (1999) utilizou o MINITAB (Minitab, 2002) e o MATLAB (Murphy, 2002) para este fim. 


\section{META-ANÁLISE DAS ESTIMATIVAS DE HERDABILIDADE PARA CARACTERÍSTICAS DE CRESCIMENTO EM BOVINOS DE CORTE}

\section{Resumo}

Um conjunto de 869 estimativas de herdabilidade de características de crescimento, pesos ao nascimento, desmama, 365 e 550 dias, obtidas em bovinos de corte de raças indianas, procedentes de 186 artigos publicados, foi compilado e sumarizado utilizando a meta-análise. Dados foram analisados de acordo com modelos fixo e aleatório, sendo considerados fatores estatisticamente significativo, nas quatro características, raça e método de estimação, sendo que este último deve ser considerado na síntese dessas estimativas. Resultados indicaram que não ocorre homogeneidade das variâncias entre estimativas obtidas em diferentes estudos. Os valores das estimativas combinadas das herdabilidades, para as características peso ao nascimento, peso à desmama, peso aos 365 dias e peso aos 550 dias, obtidos foram: 0,30 $\pm 0,01 ; 0,23 \pm 0,01$; $0,27 \pm 0,01$; e $0,31 \pm 0,01$, respectivamente. O procedimento da meta-análise pode ser recomendado para resumir informações sobre parâmetros genéticos de populações bovinas.

\section{Summary}

A total of 869 heritability estimates for birth and weaning weight and weight at 365 and 550 days of age of zebu beef cattle, from 186 published articles, were compiled and summarized using meta-analysis. Data were analyzed under fixed and random models in order to verify the factors which affect the weighted heritability estimates. Results showed heterogeneity of variances among the heritability estimates from 
different studies and the estimation method as the only significant factor which affected the heritability estimates of the four traits. The pooled heritability estimates for birth weight, weaning weight, weight at 365 days of age and weight at 550 days of age were $0.30 \pm 0.01,0.23 \pm 0.01,0.27 \pm 0.01$ and $0.31 \pm 0.01$, respectively. Meta-analysis procedures, under random model, can be recommended to summarize genetic parameters estimates of beef cattle populations.

\subsection{Introdução}

A meta-análise pode ser definida como um procedimento estatístico que consiste de uma revisão quantitativa e resumida de resultados de estudos distintos, mas relacionados (Glass, 1976). Os métodos estatísticos empregados na meta-análise asseguram a obtenção de uma estimativa combinada e precisa sobretudo, em virtude, do aumento do número de observações, e conseqüentemente do poder estatístico e da possibilidade de examinar a variabilidade entre os estudos (Fagard et al., 1996).

Na pesquisa científica, é crescente o número de artigos similares conduzidos e publicados nas diversas áreas do conhecimento, gerando interesse, muitas vezes, de realizar síntese destes resultados (Fagard et al., 1996). Deste modo, a aplicação da metaanálise tem aumentado em vários campos das ciências (Cooper, 1990) tais como: agronomia (Olkin \& Shaw, 1995); ciências sociais (Glass, 1976); ecologia (Gurevitch \& Hedges, 1993); engenharia (Pickard et al., 1998); medicina (Canner, 1987; Normand, 1999); melhoramento animal (Giannotti et al., 2002) e zootecnia (Beckett \& Lean, 1997).

Assim como vem ocorrendo em muitas áreas, existe, em melhoramento animal, o anseio de sumarizar o conhecimento adquirido no formato de revisão. Tal pretensão se dá, principalmente, em virtude do aumento do conhecimento científico nesta área, e da necessidade do pesquisador em entender as relações biológicas, de ambiente e de comportamento animal (St-Pierre, 2001). 
Ainda no contexto do melhoramento animal, são freqüentes as revisões bibliográficas cujo objetivo é obter uma estimativa combinada, proveniente de resultados de estudos individuais. Deste modo, estimativas de parâmetros genéticos de populações bovinas, tais como correlações genéticas e fenotípicas, herdabilidade e heterose, são compiladas e resumidas, para diversas características de interesse econômico na produção animal. Nestas revisões, utilizam-se diferentes critérios para obter uma estimativa combinada, entre eles uma média ponderada pelo inverso da variância (Koots et al., 1994ab; Lôbo et al., 2000) ou do desvio padrão (Mohiuddin et al., 1993; Mercadante et al., 1995) individual de cada estimativa do parâmetro genético, e uma análise de regressão linear múltipla com aplicação de análise de agrupamento (Roughsedge et al., 2001). Porém, apesar de algumas dessas revisões realizarem pesquisa bibliográfica abrangente, obterem uma medida resumida comum para diferentes estudos e ponderarem pelo inverso da variância, em nenhuma delas foi considerada a variância existente entre os estudos. Os procedimentos estatísticos empregados em meta-análise propõem considerar o efeito da variação existente entre esses estudos para a obtenção da estimativa combinada (Brockwell \& Gordon, 2001). A variação entre os estudos é proveniente, por exemplo, de diferentes tipos de manejo alimentar (a pasto, confinado, semi-confinado), diferentes raças, sexo, métodos distintos de estimação dos parâmetros envolvidos, dados oriundos de vários países etc (Koots et al., 1994a).

A herdabilidade é um parâmetro populacional essencial na avaliação genética animal e no delineamento de programas de melhoramento animal, sendo definida como uma medida do grau de semelhança dos filhos, em relação ao desempenho de seus pais, para determinada característica (Bourdon, 2000). Sua obtenção pode ser afetada por alguns fatores como raça, origem dos dados (país), método de estimação e época de publicação, dentre outros. O número de trabalhos publicados contendo estimativas de herdabilidade $\left(\hat{h}^{2}\right)$, para características de crescimento em bovinos de corte, é suficientemente grande para conduzir análises com o objetivo de determinar quais 
fatores afetam essas características e fazer recomendações considerando valores combinados apropriados (Koots et al., 1994a).

Os objetivos do presente trabalho foram: i) desenvolver e aplicar a metodologia da meta-análise ao problema de resumir informações das estimativas de herdabilidade $\left(\hat{h}^{2}\right)$ para as características peso ao nascimento (PN), peso à desmama (PD), peso aos 365 dias (P365) e peso aos 550 dias (P550) em bovinos de corte de origem indiana; ii) estimar a variância entre os estudos, e incorporá-la na obtenção das estimativas combinadas das herdabilidades $\left(\hat{h}_{+}^{2}\right)$ para as quatro características; iii) identificar os fatores que afetam as $\hat{h}^{2}$ ponderadas.

\subsection{Material e Métodos}

Os dados utilizados neste trabalho referem-se a $869 \hat{h}^{2}$ das características de crescimento PN, PD, P365 e P550, obtidas em populações de bovinos de corte de origem indiana, sendo 182 de PN, 331 de PD, 153 de P365 e 203 de P550. Sendo estas, procedentes de 186 artigos publicados, dos quais 102 estão presentes no trabalho de revisão realizado por Mercadante et al. (1995) e 84 são provenientes de pesquisa bibliográfica realizada para a atualização destes dados, do ano de 1995 até 2002. Tal pesquisa englobou anais de congressos, teses e dissertações e base de dados como CAB e AGRIS, onde as palavras chaves utilizadas foram: “nelore”; “nellore”; "zebu”; "bos indicus”; e “heritabili*”.

A meta-análise da coleção das $\hat{h}^{2}$ envolveu os seguintes passos: análise exploratória do conjunto de dados; verificação das pressuposições estatísticas requeridas; realização do teste de homogeneidade; estimação da variância entre os estudos; obtenção da estimativa combinada.

A análise do conjunto de dados visa detectar tanto a presença de vício de publicação, isto é, se a pesquisa bibliográfica não foi bastante abrangente, quanto à 
presença de observações discrepantes. O vício de publicação foi examinado através do gráfico de funil, que consiste de um diagrama de dispersão das $\hat{h}^{2}$ contra o tamanho da amostra $(N)$. É baseado no fato da $i$-ésima estimativa de herdabilidade $\left(\hat{h}_{i}^{2}, i=1,2, \ldots, k\right.$, sendo $k$ o número de $\hat{h}^{2}$ publicada para cada característica) ser tanto mais precisa quanto maior for o $N$, e de estudos com menores $N$ serem prevalecentes em qualquer pesquisa de literatura. Na ausência de vício de publicação, a forma do gráfico será semelhante a um funil invertido e simétrico (Egger \& Smith, 1998). As observações discrepantes foram detectadas através do "box-plot".

A validade dos procedimentos utilizados na meta-análise requer que as suposições de normalidade e independência das estimativas a serem combinadas sejam satisfeitas (Hedges \& Olkin, 1985). A independência das estimativas é em parte garantida, em virtude dessas serem obtidas de diferentes trabalhos publicados, já a normalidade deve ser testada. O teste de Shapiro-Wilk, cuja hipótese de nulidade expressa que os dados em questão têm distribuição normal, foi utilizado para verificar a suposição de normalidade (Shapiro \& Wilk, 1965). Na ausência de normalidade os dados foram transformados utilizando-se o algoritmo sugerido por Box \& Cox (1964), cujo parâmetro de transformação, $\lambda$, é selecionado pelo método da máxima verossimilhança. Esta técnica envolve a realização de uma série de análises de variância, para vários valores de $\lambda$, transformados como: $y_{i}^{\lambda}=\left(y^{\lambda}-1\right) / \lambda$, para $\lambda \neq 0$, em que $y_{i}$ é a variável resposta em estudo (neste trabalho, as $\hat{h}^{2}$ ). A estimativa de $\lambda$ que produzir menor soma de quadrados do resíduo na análise de variância, será utilizada para transformar os dados, aproximando-os da normalidade (Peltier et al., 1998). O parâmetro $\lambda$ foi estimado utilizando a macro boxglm do SAS (Friendly, 2003).

A informação da variância $\left(s_{i}^{2}\right)$ associada a $\hat{h}_{i}^{2}$ é essencial em um estudo deste tipo, pois será usada na obtenção da estimativa combinada. Entretanto, alguns estudos não fornecem a $s_{i}^{2}$ da $\hat{h}_{i}^{2}$ e, para o cálculo destas, foram utilizadas as seguintes 
equações: $\hat{s}_{i}^{2}=32 \hat{h}_{i}^{2} / N$, quando a $\hat{h}_{i}^{2}$ foi estimada a partir de modelo animal ou touro; e $\hat{s}_{i}^{2}=2 / \sqrt{N}$, quando a $\hat{h}_{i}^{2}$ foi estimada a partir de regressão progênie-pai ou regressão progênie-mãe ( Koots et al., 1994a; Falconer \& Mackay, 1996).

Há duas formas de combinar as informações, as quais diferem quanto à modelagem da variação existente entre as estimativas. Um modelo de efeito fixo pressupõe homogeneidade entre as estimativas, enquanto um modelo de efeito aleatório considera a variabilidade existente entre elas. A decisão, com relação a qual modelo adotar, é tomada através do teste de homogeneidade. Assim, de posse das $\hat{h}^{2}$ e $s_{i}^{2}$, foi testada a hipótese $H_{0}: \hat{h}_{1}^{2}=\hat{h}_{2}^{2}=\ldots=\hat{h}_{k}^{2}$, contra a hipótese de que pelo menos uma estimativa de herdabilidade diferia das demais. Este teste é baseado na estatística $Q \sim \chi_{k-1}^{2}$, dada por $Q=\sum_{i=1}^{k} w_{i}\left(\hat{h}_{i}^{2}-\hat{h}_{+}^{2}\right)^{2}$, em que $w_{i}=1 / s_{i}^{2}$ e $\hat{h}_{+}^{2}=\sum_{i=1}^{k} w_{i} \hat{h}_{i}^{2} / \sum_{i=1}^{k} w_{i}$ (Hedges \& Olkin, 1985), sendo realizado através do procedimento GLM (SAS, 1990b). A rejeição de $H_{0}$ sugere a não existência da homogeneidade entre as $\hat{h}^{2}$, adotando-se, assim, um modelo de efeito aleatório, em que a variância existente entre os estudos $\left(\tau^{2}\right)$, deve ser estimada e incluída na obtenção da estimativa combinada das herdabilidades ( $\hat{h}_{+}^{2}$ ) (Wang \& Bushman, 1999).

O modelo de efeito aleatório adotado teve como estrutura $h_{i}^{2}=h_{+}^{2}+\varepsilon_{i}+e_{i}$, em que: $\hat{h}_{i}^{2}$ representa o valor da $i$-ésima herdabilidade de determinada característica; $e_{i}$ é o erro aleatório $\left(e_{i} \stackrel{\text { indep. }}{\sim} \operatorname{Normal}\left(0, s_{i}^{2}\right)\right) ; h_{+}^{2}$ representa o valor da estimativa combinada das herdabilidades; $\varepsilon_{i}$ é o erro aleatório $\left(\varepsilon_{i}{ }^{i n d e p .} \operatorname{Normal}\left(0, \tau^{2}\right)\right.$ ). Nota-se que o modelo de efeito fixo é um caso particular do modelo de efeito aleatório em que $\tau^{2}=0$ (Brockwell \& Gordon, 2001). 
A variância entre estudos foi estimada pelo método da Máxima Verossimilhança Restrita $(M V R)$ em que o estimador $\hat{\tau}^{2}$ é solução para $\hat{\tau}^{2}=\sum_{i=1}^{k} w_{i}^{2^{*}}\left[\frac{k}{k-1}\left(\hat{h}_{i}^{2}-\hat{h}_{i}^{2^{*}}\right)^{2}-s_{i}^{2}\right] / \sum_{i=1}^{k} w_{i}^{2^{*}}$, através do procedimento MIXED (SAS, 1996). Assim, a estimativa combinada das herdabilidades, quando existe heterogeneidade entre os estudos, será encontrada a partir da equação: $\hat{h}_{+}^{2 *}=\sum_{i=1}^{k} w_{i}^{*} h_{i}^{2} / \sum_{i=1}^{k} w_{i}^{*}$, em que a ponderação é $w_{i}^{*}=1 /\left(s_{i}^{2}+\hat{\tau}^{2}\right)$.

O desvio padrão combinado, associado a $\hat{h}_{+}^{2}$, foi estimado através de: $s_{+}=\sqrt{1 / \sum_{i=1}^{k}\left(1 / w_{i}^{*}\right)}$, quando se trabalha com um modelo de efeito aleatório, ou utilizando $w_{i}$ ao invés de $w_{i}^{*}$, no modelo de efeito fixo (Koots et al., 1994a).

Realizados os procedimentos de meta-análise, isto é, obtidos os valores de $\hat{\tau}^{2}$ e $\hat{h}_{+}^{2}$ para as quatro características, deu-se prosseguimento à análise para identificar quais fatores (raça, método de estimação e país) afetaram significativamente as $\hat{h}^{2}$ ponderadas por $w_{i}$ ou $w_{i}^{*}$. Para tanto, realizou-se uma análise utilizando o método de mínimos quadrados, considerando o seguinte modelo:

$$
\hat{h}_{i j k l}^{2}=\mu+R_{i}+M_{j}+P_{k}+e_{i j k l}
$$

em que:

$\hat{h}_{i j k l}^{2}$ é a estimativa de herdabilidade ponderada para determinada característica;

$R_{i}$ é a raça, $i=1,2, \ldots, 15$ para $\mathrm{PN} ; i=1,2, \ldots, 14$ para $\mathrm{PD} ; i=1,2, \ldots, 10$ para $\mathrm{P} 365$ e $\mathrm{P} 550$ (Afrikaner, Bali, Boran, Brahman, Bunaji, Gir, Gobra, Gudali, Guzerá, Indu, Kedah, Mashona, Nelore, Sahiwal, Tabapuã, Wakna e Zebu); 
$M_{j}$ é o método de estimação, $j=1,2,3$ para PN, PD e P550; $j=1,2$ para P365 e (modelo animal, touro e regressão pai progênie);

$P_{k}$ é o país, $k=1,2, \ldots, 16$ para PN e PD; $k=1,2, \ldots, 11$ para P365; e $k=1,2, \ldots, 12$ para P550 (África do Sul, Austrália, Brasil, Camarão, Colômbia, Costa Rica, Cuba, Estados Unidos, Etiópia, Guatemala, Guiana, Malásia, México, Nigéria, Paquistão, Senegal, Tanzânia, Venezuela e Zimbabue);

$e_{i j k m}$ é o erro aleatório suposto homocedástico, independente e normalmente distribuído.

\subsection{Resultados e Discussão}

Pôde-se observar, nas quatro características, que as $\hat{h}^{2}$ (Figura 2) apresentam distribuição assimétrica à direita, possuem a maior parte de seus valores com $\hat{h}^{2}$ de até 0,35, existem poucos valores abaixo de 0,10 e acima de 0,60.

Os valores mais baixos das $\hat{h}^{2}$ foram encontrados na característica PD e os mais elevados na característica P550. Foram detectadas como discrepantes as $\hat{h}^{2}$ cujos valores foram acima de 0,69 para PN e P365, 0,60 para PD e 0,79 para P550. Apesar destes valores serem discrepantes nas amostras das quatro características, nenhum critério de exclusão será imposto sobre eles, pois, nos trabalhos originais, os autores fizeram considerações das razões pelas quais obtiveram valores elevados de herdabilidade para características de crescimento. Tal procedimento concorda com o adotado por Lôbo et al. (2000). 


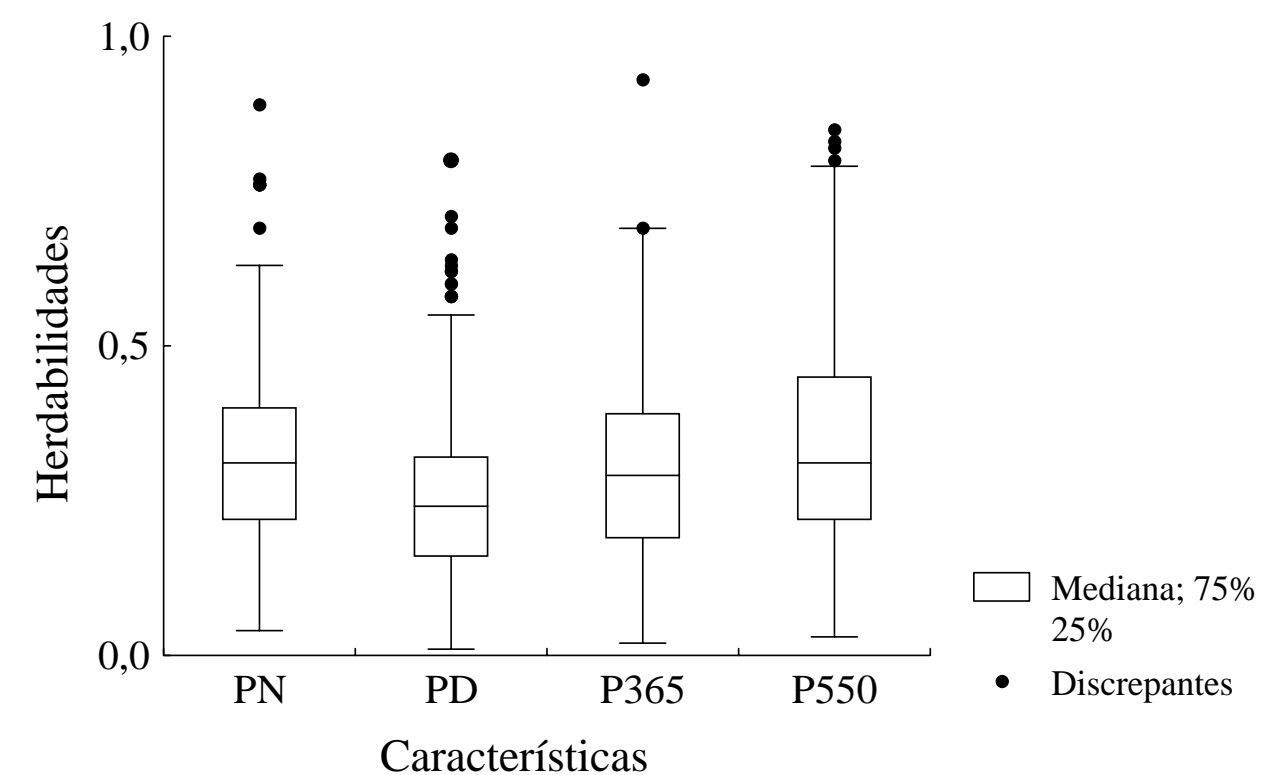

Figura 2- Box-plot das estimativas de herdabilidade $\left(\hat{h}^{2}\right)$ para as características peso ao nascimento (PN), peso à desmama (PD), peso aos 365 dias (P365) e peso aos 550 dias (P550)

Através dos gráficos de funil (Figura 3), é possível afirmar que não houve vício de publicação na pesquisa bibliográfica realizada uma vez que para as quatro características em estudo, os gráficos apresentaram formas aproximadas de funil invertido, expressando assim a abrangência da revisão de literatura para a inclusão dos estudos contendo as $\hat{h}^{2}$ na análise. Ainda por este gráfico observou que, nas quatro características, os tamanhos amostrais $(N)$ referentes às $\hat{h}^{2}$ apresentam maior concentração de valores entre 300 e 15000, tendo poucos abaixo de 100 e acima de 50000 .

Os valores da estatística do teste de Shapiro-Wilk para normalidade foram: 0,96

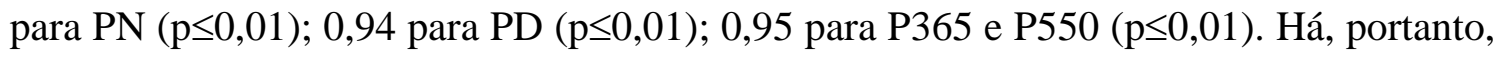
forte evidência que os dados em questão não seguem uma distribuição normal, havendo 
a necessidade de transformação desses dados para aproximar a normalidade e garantir o poder dos testes estatísticos.

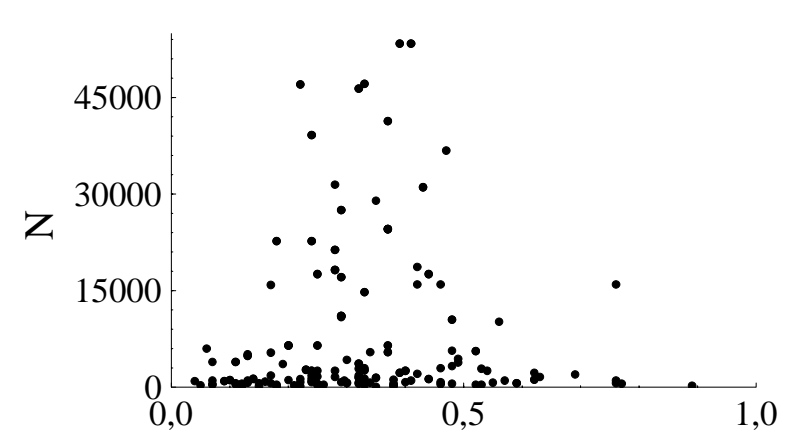

Herdabilidades PN

(a)

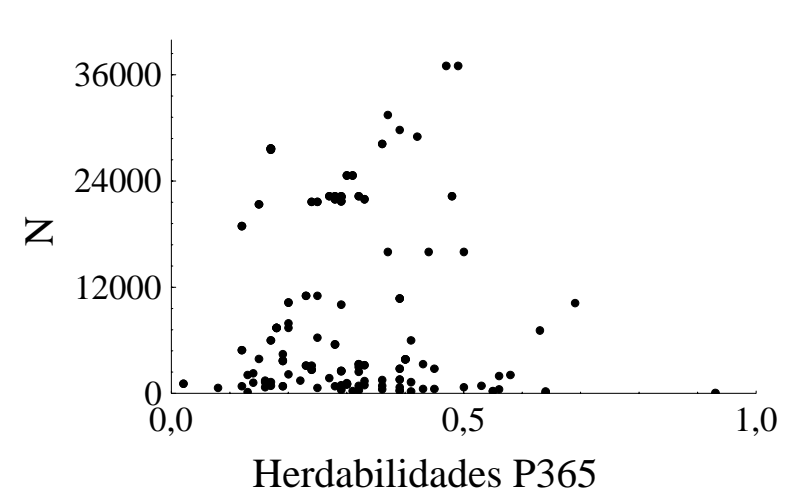

(c)

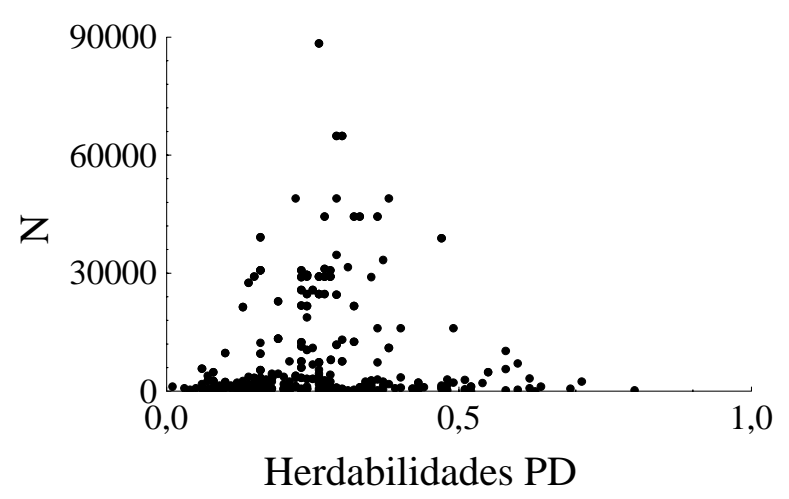

(b)

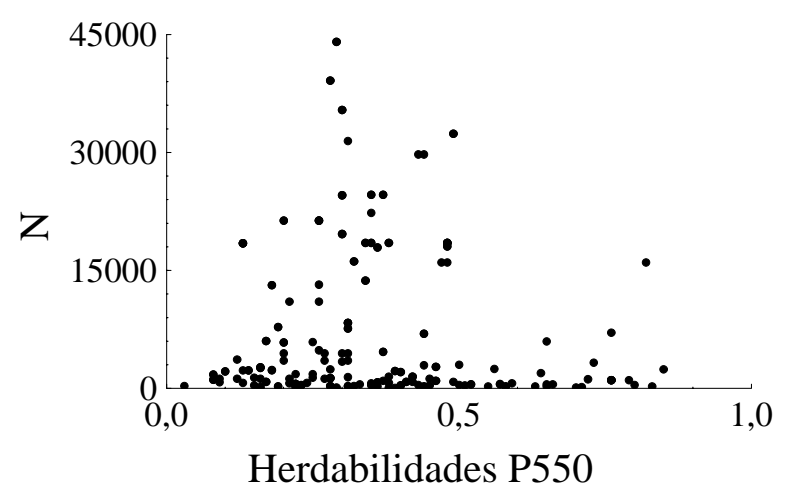

(d)

Figura 3- Gráficos de funil das estimativas de herdabilidade para as características: (a) peso ao nascimento (PN); (b) peso à desmama (PD); (c) peso aos 365 dias (P365); (d) peso aos 550 dias (P550)

A transformação das $\hat{h}^{2}$ foi feita utilizando a macro boxglm do SAS (Friendly, 2003) e o valor de $\lambda$ que promoveu a minimização da soma de quadrados do resíduo do modelo foi 0,40 para as quatro características. Assim, a transformação se deu elevando cada uma das $\hat{h}^{2}$ à potência de $\lambda=0,40$. O teste de Shapiro-Wilk para normalidade foi 
realizado para as $\hat{h}^{2}$ transformadas e o valor da estatística do teste foi $0,99(\mathrm{p}>0,05)$ para as quatro características, evidenciando a decisão de não rejeição da hipótese de normalidade, considerando um nível mínimo de significância de 0,05.

O prosseguimento da análise se deu com o teste de homogeneidade, utilizando as $\hat{h}^{2}$ transformadas, cujos valores da estatística deste teste estão dispostos na Tabela 1. A hipótese de homogeneidade entre as $\hat{h}^{2}$ transformadas é rejeitada para as quatro características $(\mathrm{p} \leq 0,01)$ e, nestas condições, um modelo de efeito aleatório é mais adequado.

Tabela 1. Estatística $Q$ para homogeneidade, com respectivo nível de significância, e grau de liberdade (G.L.), para as estimativas de herdabilidade transformadas, nas características peso ao nascimento (PN), peso à desmama (PD), peso aos 365 dias (P365) e peso aos 550 dias (P550)

\begin{tabular}{ccc}
\hline Característica & G.L. & $Q$ \\
\hline PN & 181 & $619,65^{* *}$ \\
PD & 330 & $1205,20^{* *}$ \\
P365 & 152 & $669,12^{* *}$ \\
P550 & 202 & $744,01^{* *}$ \\
\hline
\end{tabular}

${ }^{* *}=$ Significativo pelo teste de homogeneidade, ao nível de $1 \%(\mathrm{p} \leq 0,01)$.

Assim, para adotar um modelo de efeito aleatório, estimou-se a variância entre os estudos $\left(\hat{\tau}^{2}\right)$, através do método da máxima verossimilhança restrita, resultando em: 0,0069 para PN; 0,0059 para PD; 0,0070 para P365; e 0,0084 para P550. Deste modo, as $\hat{h}^{2}$ foram combinadas utilizando-se a ponderação $w_{i}^{*}$.

Os valores das $\hat{h}_{+}^{2}$ e seus respectivos $\hat{s}_{+}$, para as características PN, PD, P365 e P550, estão apresentados na Tabela 2. 
Tabela 2. Estimativas de herdabilidades combinadas $\left(\hat{h}_{+}^{2}\right)$, com respectivo desvio padrão $\left(\hat{s}_{+}\right)$, para as características peso ao nascimento (PN), peso à desmama (PD), peso aos 365 dias (P365) e peso aos 550 dias (P550)

\begin{tabular}{ccccc}
\hline $\begin{array}{c}\text { Estimativa } \\
\text { combinada }\end{array}$ & PN & \multicolumn{2}{c}{ Característica } \\
\hline$\hat{h}_{+}^{2}$ & 0,30 & 0,23 & 0,27 & 0,31 \\
$\hat{s}_{+}$ & 0,01 & 0,01 & 0,01 & 0,01 \\
\hline
\end{tabular}

A magnitude das $\hat{h}^{2}$ é importante pois, se uma característica é altamente herdável pode-se afirmar que animais com alto, ou baixo, desempenho, tenderão a produzir filhos com alto, ou baixo, desempenho. Por outro lado, se uma característica não é muito herdável, registros de desempenho dos pais revelarão pouco sobre o desempenho da progênie. São consideradas pouco herdáveis estimativas com valores abaixo de 0,20, moderadamente herdáveis estimativas com valores entre 0,20 e 0,40, e altamente herdáveis estimativas com valores superiores a 0,40 (Bourdon, 2000). Assim, as $\hat{h}_{+}^{2}$ obtidas neste trabalho podem ser consideradas moderadamente herdáveis, havendo, então, ressalvas quanto a observar registros dos pais e inferir sobre o desempenho da progênie.

Quando se compara as $\hat{h}_{+}^{2}$ obtidas neste trabalho com outros trabalhos verifica-se que estes valores estão bastante próximos. Bourdon (2000) considera como referência os valores 0,40 para PN e P365, 0,30 para PD e 0,65 para P550. Koots et al. (1994a) utilizando a ponderação $w_{i}$, para combinar $\hat{h}^{2}$ para características de crescimento em bovinos de corte de raças zebuínas, européias e cruzamentos, obtiveram $\hat{h}_{+}^{2}$ de

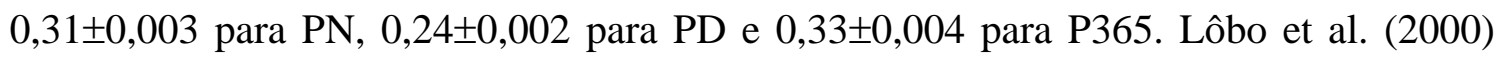
também utilizando a ponderação $w_{i}$, para combinar $\hat{h}^{2}$ para características de crescimento em bovinos de corte de raças zebuínas, européias e cruzamentos, obtiveram 


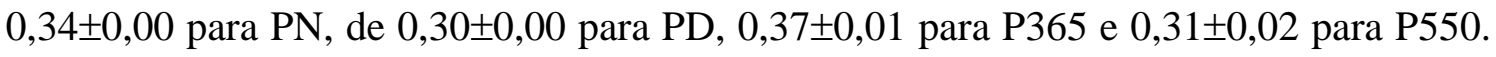
Verifica-se, através destes valores que, exceto para o valor de referência da estimativa de herdabilidade para P550, que foi superior ao obtido neste trabalho, tanto os valores de referência de herdabilidade quanto as $\hat{h}_{+}^{2}$, obtidas por estes autores, apresentaram valores bastante próximos aos encontrados no presente trabalho. Ressalta-se, ainda, que os desvios padrões mais baixos encontrados pelos autores na obtenção das $\hat{h}_{+}^{2}$ podem ser decorrentes da utilização da ponderação $w_{i}$, a qual não adiciona a variância entre os estudos à variância individual das estimativas de herdabilidade.

Na análise de mínimos quadrados, os fatores que afetaram de maneira estatisticamente significativa $(\mathrm{p} \leq 0,05)$ as $\hat{h}^{2}$ ponderadas por $w_{i}^{*}$ foram: raça e método de estimação, nas quatro características; e país, nas características PD e P550.

Koots et al. (1994a) utilizando um modelo com os fatores raça, país, origem dos dados (dados de experimentos ou de campo), manejo alimentar (pasto ou confinado), método de estimação, sexo e época de publicação dos resultados, verificaram efeito estatisticamente significativo $(\mathrm{p} \leq 0,01)$ dos fatores: raça e sexo para as $\hat{h}^{2}$ ponderadas da característica PN; raça, método e sexo para as $\hat{h}^{2}$ ponderadas da característica PD; e manejo alimentar para as $\hat{h}^{2}$ ponderadas da característica P365. Entretanto, os autores esperavam que o método de análise fosse significativo para muitas das características analisadas. Nas análises de modelo animal, quando a matriz de relações aditivas é completa e vai até a população base, as estimativas de variância não são afetadas pela seleção e são, portanto, maiores que aquelas estimadas por outros métodos. Já as causas do efeito de país não estão claras e alguns países podem ter $\hat{h}^{2}$ mais altas devido a diferentes práticas de manejo. Koots et al. (1994a) ressaltam ainda um provável confundimento entre raça e país, fato também notado no presente trabalho.

Lôbo et al. (2000), utilizando um modelo com os fatores método de estimação e grupo genético, encontraram significância estatística $(\mathrm{p} \leq 0,05)$ somente para os fatores 
grupo genético nas características PN e P365, e método de estimação na característica PD.

Tabela 3. Estimativas combinadas das herdabilidades e número de estimativas entre parênteses das características peso ao nascimento (PN), peso à desmama (PD), peso aos 365 dias (P365) e peso aos 550 dias (P550) por raça, país e método de estimação (modelos animal-MA, touro-TOURO, e regressão pai progênie-RPP)

\begin{tabular}{|c|c|c|c|c|c|c|c|c|c|}
\hline \multirow{2}{*}{ Raça } & \multicolumn{4}{|c|}{ Característica } & \multirow{2}{*}{ País } & \multicolumn{4}{|c|}{ Característica } \\
\hline & PN & PD & P365 & P550 & & PN & PD & P365 & P550 \\
\hline Afrikaner & $0,52(2)$ & $0,23(2)$ & $0,17(2)$ & $0,17(2)$ & África do Sul & $0,52(2)$ & $0,23(2)$ & $0,17(2)$ & $0,17(2)$ \\
\hline Bali & $0,22(1)$ & $(0)$ & (0) & $(0)$ & Austrália & $(0)$ & $0,43(9)$ & $0,30(3)$ & $0,35(24)$ \\
\hline Boran & $0,17(6)$ & $0,22(2)$ & $(0)$ & $(0)$ & Brasil & 0,31 (138) & $0,24(254)$ & 0,27 (138) & 0,31 (156) \\
\hline Brahman & 0,26 (20) & $0,21(53)$ & $0,28(8)$ & $0,29(35)$ & Camarões & 0,47 (4) & $0,28(4)$ & (0) & (0) \\
\hline Bunaji & (0) & $0,34(2)$ & (0) & (0) & Colômbia & $0,24(2)$ & $0,18(5)$ & (0) & 0,15 (1) \\
\hline Gir & $0,36(8)$ & $0,19(10)$ & $0,21(2)$ & $0,17(3)$ & Costa Rica & (0) & $0,27(1)$ & $(0)$ & (0) \\
\hline Gobra & $0,14(2)$ & $0,26(2)$ & $0,35(2)$ & $0,18(4)$ & Cuba & $0,21(4)$ & $0,11(14)$ & $0,19(2)$ & $0,31(1)$ \\
\hline Gudali & $0,33(3)$ & 0,15 (3) & $0,37(1)$ & $0,31(1)$ & EUA & $0,36(3)$ & 0,25 (11) & $0,13(1)$ & $0,22(1)$ \\
\hline Guzerá & $0,17(22)$ & $0,21(33)$ & 0,21 (19) & 0,19 (18) & Etiópia & $0,11(2)$ & $0,22(2)$ & (0) & (0) \\
\hline Indu & $0,24(1)$ & 0,07 (1) & (0) & (0) & Guatemala & (0) & $0,26(2)$ & (0) & (0) \\
\hline Kedah & $0,18(1)$ & (0) & (0) & (0) & Guiana & 0,35 (1) & $0,57(2)$ & $0,93(1)$ & (0) \\
\hline Mashona & (0) & $0,28(3)$ & (0) & (0) & Malásia & $0,20(2)$ & (0) & (0) & (0) \\
\hline Nelore & $0,32(105)$ & $0,24(201)$ & 0,27 (107) & 0,32 (129) & México & 0,27 (3) & 0,37 (4) & $0,30(1)$ & $0,72(1)$ \\
\hline Sahiwal & $0,06(1)$ & (0) & $0,41(1)$ & 0,65 (1) & Nigéria & $0,28(1)$ & $0,31(1)$ & 0,37 (1) & $0,31(1)$ \\
\hline Tabapuã & $0,33(5)$ & $0,23(11)$ & $0,23(7)$ & 0,19 (6) & Paquistão & $0,06(1)$ & (0) & $0,41(1)$ & 0,65 (1) \\
\hline Wakwa & $0,62(2)$ & $0,29(2)$ & $(0)$ & (0) & Senegal & $0,14(2)$ & $0,32(2)$ & $0,35(2)$ & $0,18(4)$ \\
\hline \multirow[t]{3}{*}{ Zebu } & $0,53(3)$ & $0,24(6)$ & $0,40(4)$ & $0,54(4)$ & Tanzânia & $0,39(4)$ & $(0)$ & $(0)$ & $(0)$ \\
\hline & & & & & Venezuela & 0,25 (11) & $0,11(12)$ & $0,50(1)$ & $0,18(9)$ \\
\hline & & & & & Zimbábue & $0,28(2)$ & 0,27 (6) & (0) & $0,24(2)$ \\
\hline Método & PN & PD & P365 & P550 & & & & & \\
\hline MA & 0,31 (89) & 0,24 (196) & $0,27(102)$ & $0,31(135)$ & & & & & \\
\hline TOURO & 0,29 (83) & $0,21(123)$ & $0,26(51)$ & $0,29(62)$ & & & & & \\
\hline RPP & $0,22(10)$ & $0,19(12)$ & & $0,21(6)$ & & & & & \\
\hline
\end{tabular}

As estimativas combinadas das herdabilidades calculadas utilizando a ponderação $w_{i}^{*}$ e divididas por raça, país e método de estimação, para as quatro características em estudo PN, PD, P365 e P550, estão expostas na Tabela 3. Para os 
fatores raça e país, apesar de terem sido obtidas $\hat{h}_{+}^{2}$, em muitas situações, estas não representam uma média ponderada e sim uma estimativa pontual, uma vez que se tem apenas uma estimativa de herdabilidade para muitas raças e países, dificultando, assim,

uma conclusão mais geral para estes fatores. Já para o fator método, as $\hat{h}_{+}^{2}$ obtidas com modelo animal foram mais altas que as estimadas pelos outros dois métodos, conforme esperado.

\subsection{Conclusões}

A meta-análise é um procedimento recomendável para a obtenção de valores médios de estimativas de herdabilidade em características de crescimento em bovinos de corte de origem indiana, sendo indispensável, porém, apropriada análise do conjunto de dados a serem resumidos, pois as pressuposições requeridas validarão os resultados finais.

A variabilidade existente entre as estimativas de herdabilidade é importante e influencia na obtenção dos valores médios destas, devendo ser considerada na análise.

O método de estimação da herdabilidade e a raça dos animais foram os fatores significativos sobre as estimativas de herdabilidade ponderadas das quatro características, sendo que o primeiro deve ser considerado na síntese dessas estimativas. 


\section{ANÁliSE DE AGRUPAMENTO PARA IMPLEMENTAÇÃO DA META- ANÁLISE EM ESTIMATIVAS DE HERDABILIDADE PARA CARACTERÍSTICAS DE CRESCIMENTO EM BOVINOS DE CORTE}

\section{Resumo}

No presente trabalho, foram compiladas 869 estimativas de herdabilidade, provenientes de 186 artigos publicados, das características peso ao nascimento, peso à desmama, peso aos 365 dias e peso aos 550 dias, de bovinos de corte de origem indiana, as quais foram divididas em grupos, em cada uma das quatro características, utilizando o método de agrupamento de Ward, e combinadas, dentro de cada grupo, através da metaanálise. Foram utilizados dois métodos, o da máxima verossimilhança restrita e o proposto por DerSimonian e Laird, para estimar a variância presente entre os estudos, tendo o primeiro apresentado valores superiores para esta variância. Pôde-se observar, para todas as características, que os grupos compostos por animais da raça Nelore presentes, na sua maioria, no Brasil, apresentaram estimativas combinadas de herdabilidade maiores que os demais grupos.

\section{Summary}

In this paper, 869 heritability estimates for birth weight, weaning weight, weight at 365 days of age and weight at 550 days of age, from 186 published articles, were compiled, divided in groups using the Ward method of cluster analysis, and pooled by meta-analysis. Restricted maximum likelihood and DerSimonian and Laird methods were used to estimate the variance between studies. It was observed, for all traits, that 
the first method showed higher variances estimates and that groups formed by Nelore breed showed greater pooled heritability estimates than others ones.

\subsection{Introdução}

A herdabilidade de uma característica é a proporção da variação fenotípica que é devida à variância genética aditiva existente na população. É um parâmetro essencial em programas de melhoramento genético pois indica quanto das diferenças existentes no desempenho para uma característica são determinadas por fatores genéticos ou ambientais, tendo assim papel fundamental na predição dos valores genéticos dos animais (Bourdon, 2000). Os valores estimados dos parâmetros genéticos são característicos da amostra utilizada e podem mudar no tempo devido à seleção e a decisões de manejo. Deste modo, as estimativas de herdabilidade $\left(\hat{h}^{2}\right)$ podem ser afetadas por fatores como a raça do animal e o país de origem, tipo de manejo alimentar e sexo, mas também o método de estimação, que é independente da população (Koots et al., 1994a). Há, atualmente, um grande número de trabalhos publicados contendo $\hat{h}^{2}$ para diferentes características observadas nos animais dado a importância desse parâmetro e sua ampla utilização em programas de melhoramento animal. Especificamente em melhoramento de bovinos de corte, características relativas ao peso do animal, são bastante utilizadas devido à facilidade de obtenção, à média herdabilidade e à relação, quase sempre alta, com o peso ao abate.

Muitas vezes $\hat{h}^{2}$, para determinada característica, obtidas de um grupo de animais, podem não representar bem o valor verdadeiro da herdabilidade, em virtude, principalmente, do tamanho reduzido do banco de dados. Assim, combinar $\hat{h}^{2}$ de trabalhos publicados, conseguindo valores médios, pode ser recomendável (Koots et al., 1994a).

A obtenção de estimativas combinadas através da meta-análise, definida por Glass (1976) como um procedimento estatístico para obtenção de uma medida comum 
entre várias pesquisas distintas mas relacionadas, pode ser uma opção mais segura do que simplesmente obter uma média de resultados publicados. Tal fato se deve em virtude dos propósitos atribuídos à meta-análise serem: aumento o tamanho amostral; generalizações das conclusões para um conjunto de estudo; teste da variabilidade entre os estudos; realização análise de subgrupo (Fagard et al., 1996).

A natureza diversa existente entre os estudos é um ponto fundamental na metaanálise, pois quanto mais homogêneos forem os resultados a serem combinados, mais confiável será a estimativa combinada. Na implementação da meta-análise testes de homogeneidade são formulados e, baseando-se nos seus resultados, opta-se por modelar a variância existente entre os estudos, quando há ausência de homogeneidade, ou por combiná-los sem considerar a variância entre eles (Wang \& Bushman, 1999). Os métodos utilizados para estimar a variância entre os estudos são o da máxima verossimilhança restrita $(M V R)$, o proposto por DerSimonian \& Laird $(D L)$ e o Bayesiano (Normand, 1999). Algumas discussões quanto ao método usado para estimar a variância entre os estudos, podem ser encontradas em artigos como os de DerSimonian \& Laird (1986), Normand (1999) e Brockwell \& Gordon (2001).

A técnica multivariada de análise de agrupamento é uma maneira de se obter grupos homogêneos, pois propõe conseguir um esquema que possibilite reunir os dados em questão em um determinado número de grupos, de tal modo que exista grande homogeneidade dentro de cada grupo e heterogeneidade entre eles (Jonhson \& Wichern, 1998).

Tendo como conjunto de dados as estimativas publicadas de herdabilidade das características peso ao nascimento (PN), peso à desmama (PD), peso aos 365 dias (P365) e peso aos 550 (P550) de bovinos de corte de origem indiana, o objetivo deste trabalho foi realizar a meta-análise das $\hat{h}^{2}$ para essas quatro características, fazendo previamente uma análise de agrupamento, para cada uma das quatro características, considerando como variáveis os fatores raça, país, método de estimação, número de animais e o próprio valor da estimativa de herdabilidade. 


\subsection{Material e Métodos}

Os dados utilizados neste trabalho referem-se a $869 \hat{h}^{2}$ das características de crescimento PN, PD, P365 e P550, obtidas em populações de bovinos de corte de origem indiana, sendo 182 de PN, 331 de PD, 153 de P365 e 203 de P550. Estas estimativas são procedentes de 186 artigos publicados, dos quais 102 estão presentes no trabalho de revisão realizado por Mercadante et al. (1995) e 84 são provenientes de pesquisa bibliográfica realizada para a atualização destes dados, entre os anos de 1995 a 2003. Tal pesquisa englobou anais de congressos, teses, dissertações e base de dados como CAB e AGRIS, onde as palavras chaves utilizadas foram: "nelore”; "nellore”; "zebu”; "bos indicus"; e "heritabili*” (Giannotti et al., 2002). Sempre que a variância $\left(s_{i}^{2}\right)$ de uma $\hat{h}^{2}$ não estava presente no trabalho, esta foi estimada através da metodologia descrita por Koots et al. (1994a) e Falconer \& Mackay (1996).

As $\hat{h}^{2}$ foram divididas em grupos, dentro de cada uma das quatro características, utilizando a análise de agrupamento. Tal análise procurou reunir dentro de cada grupo as $\hat{h}^{2}$ mais similares baseando-se nas informações do método utilizado para sua estimação, do seu tamanho amostral, da raça, do país de origem dos dados e do próprio valor de cada $\hat{h}^{2}$. Para tanto, criaram-se variáveis fictícias ("dummy") para as variáveis categorizadas (método de estimação, país e raça) e fez-se uma padronização das variáveis quantitativas (tamanho amostral e $\hat{h}^{2}$ ), resultando nas variáveis: $x_{1}$, cujos valores foram 1 se raça Nelore e 0 se raça não Nelore; $x_{2}$, cujos valores foram 1 se país Brasil e 0 se país não Brasil; $x_{3}$, cujos valores foram 1 se modelo animal e 0 se não modelo animal; $x_{4}$, cujos valores foram 1 se modelo touro (famílias de meios-irmãos) e 0 se não modelo touro; $x_{5}$ e $x_{6}$, cujos valores tanto do i-ésimo tamanho amostral quanto da i-ésima $\hat{h}^{2}$ foram padronizados utilizando a expressão $z=X_{i}$-mín $(x) /(\operatorname{máx}(x)-m i ́ n(x))$, sendo $X_{i}$ o i-ésimo tamanho amostral ou a i-ésima $\hat{h}^{2}, \operatorname{mín}(x)$ o menor tamanho amostral ou a menor $\hat{h}^{2}$ e máx(x), o maior tamanho amostral ou a maior $\hat{h}^{2}$. Para formar os 
grupos utilizou-se o método hierárquico de Ward, cuja principal característica é compor grupos os mais homogêneos possíveis (Sharma, 1996). O critério do pseudo F, em que um valor elevado desta estatística, quando comparado ao precedente, indica o ponto de parada, foi empregado para obter o número de grupos. Esta análise foi feita utilizando os PROC CLUSTER e TREE do SAS (SAS, 1999a; SAS, 1999b; SAS, 1999c).

De posse das $\hat{h}^{2}$ divididas em grupos, a meta-análise envolveu a análise exploratória dos dados, teste de homogeneidade tanto dentro quanto entre os grupos, modelagem da variação e obtenção da estimativa combinada para os diferentes grupos (Hedges \& Olkin, 1985).

Para a análise exploratória, construíram-se gráficos de "box-plot”, para os diferentes grupos nas quatro características. Em tal dispositivo pode-se observar tanto a distribuição quanto o resumo das principais estatísticas do conjunto de dados (mediana, quartis e prováveis dados discrepantes), sendo sua principal finalidade verificar se os conjuntos de dados são comparáveis entre si (no caso, os diferentes grupos dentro de cada característica) (Bussab \& Morettin, 2003).

O teste de homogeneidade entre grupos foi realizado formulando-se a hipótese de nulidade $H_{0}: \hat{h}_{1+}^{2}=\hat{h}_{2+}^{2}=\ldots=\hat{h}_{g+}^{2}$, sendo $g$ o número de grupos e $\hat{h}_{i+}^{2}$ a estimativa combinada das herdabilidades do i-ésimo grupo, versus a hipótese alternativa $H_{A}$ : ao menos uma $\hat{h}_{i+}^{2}$ difere das demais, através da estatística $Q_{\text {entre }}=\sum_{i=1}^{g} w_{i+}\left(\hat{h}_{i+}^{2}-\hat{h}_{++}^{2}\right)^{2}$, em que: $w_{i+}=\sum_{j=1}^{m_{i}} w_{i j}$, sendo $j$ o número de $\hat{h}^{2}$ de cada grupo, e $w_{i j}=1 / s_{i j}^{2}$ é a ponderação; $\hat{h}_{i+}^{2}=\sum_{j=1}^{m_{i}} w_{i j} \hat{h}_{i j}^{2} / \sum_{j=1}^{m_{i}} w_{i j}$; e $\hat{h}_{++}^{2}=\sum_{i=1}^{g} w_{i+} \hat{h}_{i+}^{2} / \sum_{i=1}^{g} w_{i+}$. Rejeita-se a hipótese de nulidade, ao nível de significância $p$, se $Q_{e n t r e}$ exceder o valor crítico de $100(1-p) \%$ da distribuição de qui-quadrado com $g$-1 graus de liberdade. Para o teste de homogeneidade dentro de grupos a hipótese de nulidade foi $H_{0}: \hat{h}_{i 1}^{2}=\hat{h}_{i 2}^{2}=\ldots=\hat{h}_{i m_{i}}^{2}=\hat{h}_{i+}^{2}$, em que $i=1,2, \ldots, g$, 
utilizou-se a estatística, $Q_{\text {dentro }}=\sum_{i=1}^{k} \sum_{j=1}^{m_{i}} w_{i j}\left(\hat{h}_{i j}^{2}-\hat{h}_{i+}^{2}\right)^{2}$, em que $k=m_{1}+m_{2}+\ldots+m_{g}$, com distribuição de qui-quadrado com k-g graus de liberdade (Wang \& Bushman, 1999). Estes testes foram realizados através das macros WITHIN e WAVGZ (Wang \& Bushman, 1999), e do procedimento FORMAT (SAS, 1990a). A Tabela 4 resume as várias causas de heterogeneidade numa meta-análise com $g$ grupos, assim como o teste estatístico e os correspondentes graus de liberdade.

Tabela 4. Causas de heterogeneidade para um modelo de meta-análise com $g$ grupos

\begin{tabular}{lcc}
\hline \multicolumn{1}{c}{ Causa de Heterogeneidade } & Estatística $Q$ & Graus de liberdade \\
\hline Entre grupos & $Q_{\text {entre }}$ & $g-1$ \\
Dentro de grupos & $Q_{\text {dentro }}$ & $k-g$ \\
Dentro do grupo 1 & $Q_{\text {dentro }}$ & $m_{1}-1$ \\
$\ldots$ & $\ldots$ & $\ldots$ \\
Dentro do grupo $g$ & $Q_{\text {dentro } g}$ & $m_{g}-1$ \\
Total & $Q_{\text {total }}$ & $\mathrm{k}-1$ \\
\hline
\end{tabular}

Na ausência de homogeneidade entre os estudos, o modelo de efeito aleatório, adotado para a realização da meta-análise, e posterior obtenção da estimativa combinada para as estimativas de herdabilidade, teve como estrutura $h_{i}^{2}=h_{+}^{2}+\varepsilon_{i}+e_{i}$ com $h_{i}^{2} \stackrel{\text { indep. }}{\sim} \operatorname{Normal}\left(h_{+}^{2}, s_{i}^{2}+\tau^{2}\right)$, em que $\tau^{2}$ é a variância entre estudos, estimada neste trabalho, por dois métodos distintos: o $M V R\left(\hat{\tau}_{M V R}^{2}\right)$, através do procedimento MIXED (SAS, 1996); e o $D L$, o qual é um método não iterativo tendo como estimador $\hat{\tau}_{D L}^{2}=\operatorname{máx}\left\{0,\left(Q_{\text {total }}-(k-1)\right) /\left(\sum_{i=1}^{k} w_{i}-\left(\sum_{i=1}^{k} w_{i}^{2} / \sum_{i=1}^{k} w_{i}\right)\right)\right\}$ (DerSimonian \& Laird, 1986). 
Para a obtenção das estimativas combinadas das $\hat{h}^{2}\left(\hat{h}_{+}^{2 *}\right)$ dentro de cada grupo, para cada uma das quatro características de crescimento, utilizou-se a seguinte equação, $\hat{h}_{+}^{2^{*}}=\sum_{i=1}^{k} \sum_{j=1}^{m_{i}} w_{i j}^{*} \hat{h}_{i j}^{2} / \sum_{i=1}^{k} \sum_{j=1}^{m_{i}} w_{i j}^{*}$, em que a ponderação foi $w_{i j}^{*}=1 /\left(s_{i j}^{2}+\hat{\tau}^{2}\right)$ (Wang \& Bushman, 1999), e o desvio padrão combinado, associado a cada uma das $\hat{h}_{+}^{2 *}$ foi estimado através de $s_{+}=\sqrt{1 / \sum_{i=1}^{k} \sum_{j=1}^{m_{i}}\left(1 / w_{i j}^{*}\right)}$ (Koots et al., 1994a).

\subsection{Resultados e Discussão}

Na análise de agrupamento, usando raça, país, método de estimação, tamanho da amostra $(N)$ e $\hat{h}^{2}$, foram identificados, de acordo com o critério de pseudo $\mathrm{F}$, quatro grupos para as características PN (pseudo F=201), P365 (pseudo F=213) e P550 (pseudo $\mathrm{F}=247$ ), e cinco grupos para a PD (pseudo $\mathrm{F}=405$ ) (Tabela 5).

Nos grupos formados, dentro das quatro características, verifica-se que quando a porcentagem de animais da raça Nelore é alta o país associado é o Brasil, sendo reflexo de que o rebanho brasileiro, aqui analisado, de bovinos de corte zebuínos é constituído, na sua maioria, por animais da raça Nelore. Tal observação concorda com a informação encontrada em Associação Brasileira de Criadores de Zebu (ABCZ, 2004), onde se afirma que a raça Nelore representa cerca de $80 \%$ da força produtiva da indústria de carne no Brasil.

Ainda com relação aos grupos, observa-se, em todas as características, que o modelo animal está sempre associado aos maiores valores de tamanhos amostrais médios ( $\bar{N}>4200$ ), enquanto as menores amostras estão associadas ao modelo touro $(\bar{N}<3600)$. Tal fato se explica tanto em virtude do aumento, no decorrer do tempo, das bases de dados de pesos dos animais, quanto devido à melhoria tecnológica ocorrida no final do século XX, o que possibilitou uma maior capacidade de armazenagem e análise 
de grandes conjuntos de dados, com aplicação de modelos matemáticos mais sofisticados e biologicamente mais abrangentes.

Tabela 5. Número de estimativas de herdabilidade $\left(\hat{h}^{2}\right)$, porcentagens das variáveis, e tamanhos amostrais (mínimo, médio e máximo) presentes nos grupos dentro das características peso ao nascimento (PN), peso à desmama (PD), peso aos 365 dias (P365) e peso aos 550 dias (P550)

\begin{tabular}{|c|c|c|c|c|c|c|c|c|c|}
\hline \multirow[b]{2}{*}{ Característica } & \multirow[b]{2}{*}{ Grupo } & \multirow[b]{2}{*}{ № de $\hat{h}^{2}$} & \multirow{2}{*}{$\begin{array}{l}\text { Raça } \\
\text { Nelore }\end{array}$} & \multirow{2}{*}{$\begin{array}{c}\text { País } \\
\text { Brasil }\end{array}$} & \multicolumn{2}{|c|}{ Modelo } & \multicolumn{3}{|c|}{ Tamanho amostral } \\
\hline & & & & & MA & TOURO & Mín. & Médio & Máx. \\
\hline \multirow{4}{*}{$\mathrm{PN}$} & 1 & 62 & 100 & 100 & 100 & 0 & 1019 & 20675 & 53429 \\
\hline & 2 & 27 & 0 & 33 & 100 & 0 & 967 & 7473 & 41368 \\
\hline & 3 & 43 & 100 & 95 & 0 & 88 & 259 & 3212 & 28959 \\
\hline & 4 & 50 & 0 & 54 & 0 & 90 & 63 & 1572 & 31488 \\
\hline \multirow{5}{*}{ PD } & 1 & 43 & 46 & 4 & 2 & 70 & 63 & 1956 & 31488 \\
\hline & 2 & 434 & 100 & 100 & 100 & 0 & 737 & 21517 & 88412 \\
\hline & 3 & 61 & 0 & 41 & 100 & 0 & 712 & 7650 & 38845 \\
\hline & 4 & 47 & 100 & 100 & 0 & 100 & 171 & 2100 & 29032 \\
\hline & 5 & 46 & 0 & 100 & 0 & 100 & 222 & 2021 & 18751 \\
\hline \multirow{4}{*}{ P365 } & 1 & 25 & 0 & 72 & 92 & 0 & 153 & 10294 & 28239 \\
\hline & 2 & 78 & 100 & 100 & 100 & 0 & 848 & 13296 & 37004 \\
\hline & 3 & 29 & 100 & 100 & 0 & 100 & 87 & 3567 & 29032 \\
\hline & 4 & 21 & 0 & 62 & 0 & 100 & 63 & 2443 & 31488 \\
\hline \multirow{4}{*}{ P550 } & 1 & 26 & 8 & 42 & 0 & 77 & 98 & 2141 & 31488 \\
\hline & 2 & 85 & 100 & 100 & 100 & 0 & 871 & 14422 & 44075 \\
\hline & 3 & 50 & 0 & 36 & 100 & 0 & 264 & 4292 & 18493 \\
\hline & 4 & 42 & 100 & 100 & 0 & 100 & 87 & 1494 & 7102 \\
\hline
\end{tabular}

Os box-plots (Figura 4) indicam a presença de $\hat{h}^{2}$ discrepantes nos grupos: 1 e 4 da característica PN; 2, 4 e 5 da característica PD; 2 e 4 da característica P365; 1,2,e 3 da característica P550. 


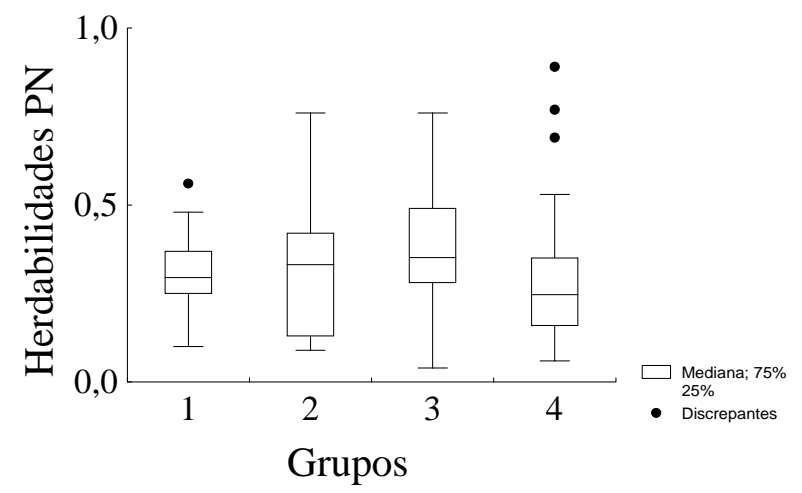

(a)

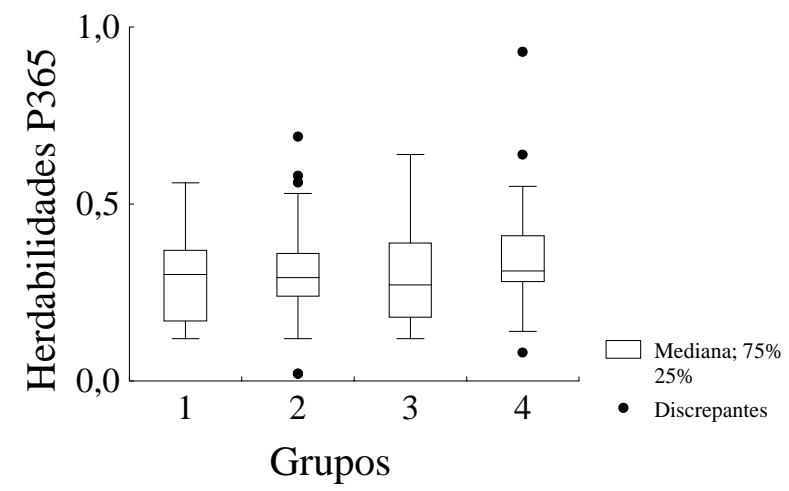

(c)

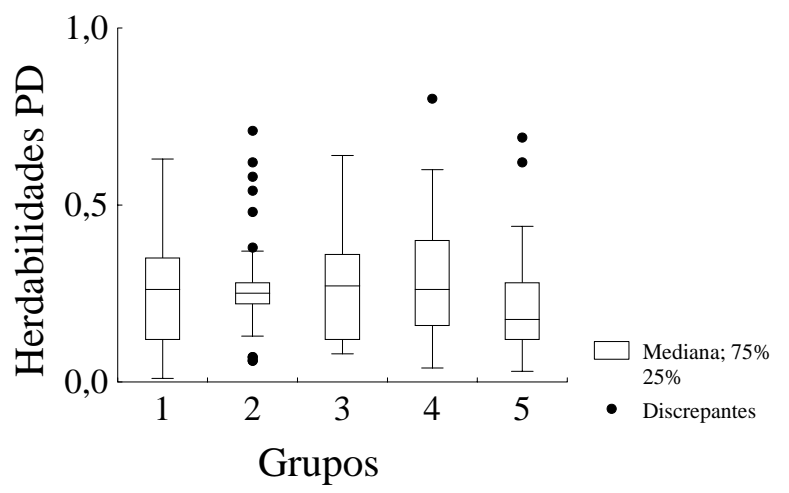

(b)

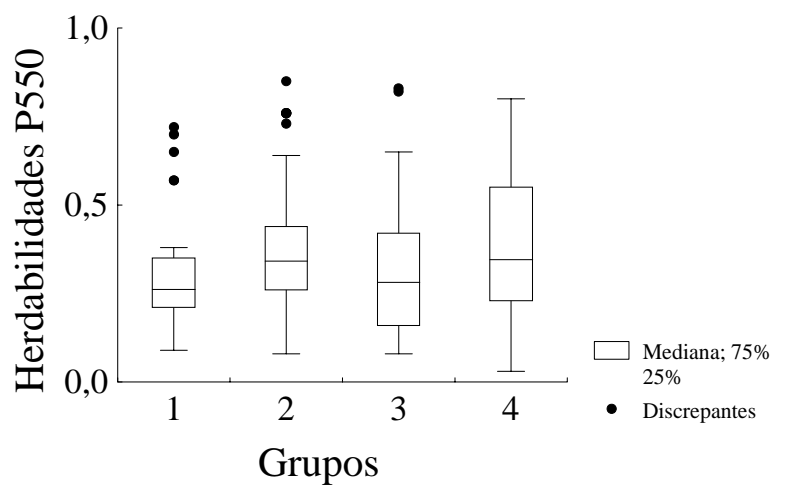

(d)

Figura 4- Box-plots das estimativas de herdabilidade para os grupos dentro das características: (a) peso ao nascimento (PN); (b) peso à desmama (PD); (c) peso aos 365 dias (P365); e (d) peso aos 550 dias (P550)

Tais valores discrepantes podem influenciar na distribuição das $\hat{h}^{2}$, porém, apesar de terem sido detectados, no presente conjunto de dados, eles foram mantidos na análise pois nos trabalhos originais os autores fazem considerações sobre as causas de terem obtidos valores elevados ou baixos para as $\hat{h}^{2}$, o que está de acordo com o procedimento adotado por Lôbo et al. (2000). Observa-se, graficamente, um relativo alinhamento das caixas dos grupos, dentro das quatro características, o que possibilita a comparação entre eles.

No teste de homogeneidade (Tabela 6), entre e dentro dos grupos para as quatro características, os valores da estatística $Q$ sugerem a rejeição das hipóteses de nulidade 
em todos os níveis testados $(p \leq 0,05)$, indicando a heterogeneidade tanto entre como dentro dos grupos.

Tabela 6. Estatística $Q$ para homogeneidade, com respectivo nível de significância e grau de liberdade (G.L.), para as estimativas de herdabilidade, das características peso ao nascimento (PN), peso à desmama (PD), peso aos 365 dias (P365) e peso aos 550 dias (P550) entre e dentro dos grupos em estudo

\begin{tabular}{|c|c|c|c|c|c|c|c|c|}
\hline \multirow{3}{*}{$\begin{array}{c}\text { Causa de } \\
\text { Heterogeneidade }\end{array}$} & \multicolumn{8}{|c|}{ Característica } \\
\hline & \multicolumn{2}{|r|}{ PN } & \multicolumn{2}{|r|}{ PD } & \multicolumn{2}{|c|}{ P365 } & \multicolumn{2}{|c|}{ P550 } \\
\hline & G.L. & $Q$ & G.L. & $Q$ & G.L. & $Q$ & G.L. & $Q$ \\
\hline Entre grupos & 3 & $28,00^{* *}$ & 4 & $44,22 * *$ & 3 & $22,29 * *$ & 3 & $79,31^{* *}$ \\
\hline Dentro de grupos & 178 & $591,67 * *$ & 326 & $1160,96 * *$ & 149 & $646,83 * *$ & 199 & $664,71^{* *}$ \\
\hline Dentro do grupo 1 & 61 & $276,88^{* *}$ & 42 & $73,12 * *$ & 24 & $138,15^{* *}$ & 25 & $22,97^{\text {ns }}$ \\
\hline Dentro do grupo 2 & 26 & $148,28 * *$ & 133 & $564,12^{* *}$ & 77 & $434,68 * *$ & 84 & $320,10 * *$ \\
\hline Dentro do grupo 3 & 42 & $100,18 * *$ & 60 & $401,28 * *$ & 28 & $59,75^{* *}$ & 49 & $259,16^{* *}$ \\
\hline Dentro do grupo 4 & 49 & $66,34^{\text {ns }}$ & 46 & $73,46^{* *}$ & 20 & $14,26^{\text {ns }}$ & 41 & $62,47^{*}$ \\
\hline Dentro do grupo 5 & & & 45 & $48,98^{\mathrm{ns}}$ & & & & \\
\hline Total & 181 & $619,65^{* *}$ & 330 & $1205,18 * *$ & 152 & $669,12^{* *}$ & 202 & $744,01^{* *}$ \\
\hline
\end{tabular}

${ }^{\text {ns }}$ Não significativo considerando nível mínimo de significância de 5\%

* Significativo pelo teste de homogeneidade, ao nível de $5 \%(p \leq 0,05)$.

** Significativo pelo teste de homogeneidade, ao nível de $1 \%(p \leq 0,01)$.

A heterogeneidade entre os grupos era um resultado esperado em virtude do método utilizado para o agrupamento; porém, almejava-se conseguir homogeneidade dentro de todos os grupos de estudo, pois, uma das características principais do método de Ward é a composição de grupos bastante homogêneos, de acordo com os fatores utilizados para formação deles, mas, a homogeneidade foi confirmada apenas para os grupos: 4 das características PN e P365; 5 da característica PD; e 1 da característica P550. 
Sempre que a hipótese de homogeneidade foi satisfeita, adotou-se um modelo de efeito fixo para reunir as $\hat{h}^{2}$. Já, a solução proposta para reunir as $\hat{h}^{2}$, quando não satisfeita a hipótese de homogeneidade, foi modelar a variância existente entre as estimativas e incorporá-la ao modelo, adotando um modelo de efeito aleatório (Wang \& Bushman, 1999). As variâncias entre os estudos, para as quatro características, estimadas pelos métodos $M V R\left(\hat{\tau}_{M V R}^{2}\right)$ e $D L\left(\hat{\tau}_{D L}^{2}\right)$ resultaram em: $\hat{\tau}_{M V R}^{2}=0,0069$ e $\hat{\tau}_{D L}^{2}=0,0057$ para PN; $\hat{\tau}_{M V R}^{2}=0,0059$ e $\hat{\tau}_{D L}^{2}=0,0049$ para PD; $\hat{\tau}_{M V R}^{2}=0,0070$ e $\hat{\tau}_{D L}^{2}=0,0070$ para P365; e $\hat{\tau}_{M V R}^{2}=0,0084$ e $\hat{\tau}_{D L}^{2}=0,0077$ para P550. Observa-se que as $\hat{\tau}^{2}$ apresentaram as menores estimativas quando calculadas pelo método $D L$.

DerSimonian \& Laird (1986) formulando uma meta-análise com diferentes artigos sobre a avaliação da eficácia de um certo tratamento para uma condição médica específica, estudaram quatro métodos (máxima verossimilhança, $M V R$, método dos momentos com ponderações iguais e desiguais) para estimar a variância entre os estudos. Estes autores concluíram que os métodos da máxima verossimilhança e o dos momentos com ponderações desiguais produziram maiores valores da variância entre os estudos quando comparados aos métodos $M V R$ e dos momentos com ponderações iguais, e terminam por recomendar a utilização do método dos momentos com ponderações desiguais (o qual foi batizado posteriormente como estimador de DerSimonian \& Laird - DL) em virtude da relativa facilidade dos cálculos envolvidos.

Normand (1999), realizando duas meta-análises, com artigos da área médica, estudou três métodos de estimar a variância entre os estudos, o $M V R$, o $D L$ e o Bayesiano. A conclusão obtida para a primeira meta-análise foi a existência de homogeneidade entre os estudos, não necessitando modelar a variância existente entre eles. Para a segunda meta-análise os valores obtidos para a variância entre os estudos foram distintos nos três métodos, sendo maiores aqueles provenientes de $M V R$ e Bayesiano, entretanto a autora não faz nenhum tipo de recomendação sobre qual método utilizar para estimar a variância entre os estudos. Brockwell \& Gordon (2001), trabalhando tanto com dados simulados quanto com um exemplo na área médica, 
estudaram três métodos de estimar a variância entre os estudos, dois baseados na teoria da máxima verossimilhança e o $D L$, chegaram à conclusão que o estimador $D L$ subestima esta variância, e não recomendam seu uso, especialmente quando se trabalha com menos de vinte resultados de estudos. Tais resultados, apesar de serem da área médica, concordam com os encontrados no presente trabalho, uma vez que os valores da variância entre os estudos obtidos por $M V R$ foram sempre superiores aos obtidos por $D L$.

Para obtenção das estimativas combinadas das herdabilidades $\left(\hat{h}_{+}^{2^{*}}\right)$, e seus respectivos desvios padrões, incorporou-se às ponderações as $\hat{\tau}^{2}$ obtidas anteriormente, apenas nos grupos em que a homogeneidade entre os estudos não foi confirmada. Para os grupos: 4 das características PN e P365; 5 da característica PD; e 1 da característica P550, utilizou-se como ponderação o inverso da variância da própria $\hat{h}^{2}$ (Tabela 7 e Figura 5).

Nos grupos em que foram incluídas as $\hat{\tau}^{2}$ na ponderação, pôde-se observar que os valores das $\hat{h}_{+}^{2 *}$, provenientes dos dois métodos de estimação, foram próximos, mesmo observando-se que os valores das estimativas das $\tau^{2}$ obtidas pelo método de $D L$ foram mais baixos, tanto dentro quanto entre os grupos, quando se considera cada uma das quatro características em estudo.

Quanto a magnitude obtida para as $\hat{h}_{+}^{2^{*}}$, considerando os grupos formados nas quatro características, os valores apresentaram-se mais baixos do que os considerados referências por Bourdon (2000): 0,40 para PN; 0,30 para PD; 0,40 para P365; e 0,65 para P550. São consideradas pouco herdáveis estimativas com valores abaixo de 0,20, moderadamente herdáveis estimativas com valores entre 0,20 e 0,40, e altamente herdáveis estimativas com valores superiores a 0,40 (Bourdon, 2000). Assim, as estimativas combinadas obtidas neste trabalho podem ser consideradas moderadamente herdáveis para todos os grupos exceto para o grupo 4 da característica PD em que observa-se um valor mais baixo. 
Tabela 7. Estimativas de herdabilidades combinadas obtidas a partir das ponderações utilizando os métodos da Máxima Verossimilhança Restrita $\left(\hat{h}_{+M V R}^{2^{*}}\right)$ e 0 proposto por DerSimonian e Laird $\left(\hat{h}_{+D L}^{2 *}\right)$, com respectivos desvios-padrões, para as características peso ao nascimento (PN), peso à desmama (PD), peso aos 365 dias (P365) e peso aos 550 dias (P550), nos diferentes grupos

\begin{tabular}{|c|c|c|c|c|c|c|c|c|}
\hline \multirow[b]{3}{*}{ Grupo } & \multicolumn{8}{|c|}{ Característica } \\
\hline & \multicolumn{2}{|c|}{ PN } & \multicolumn{2}{|c|}{ PD } & \multicolumn{2}{|c|}{ P365 } & \multicolumn{2}{|c|}{ P550 } \\
\hline & $\hat{h}_{+M V R}^{2^{*}}$ & $\hat{h}_{+D L}^{2^{*}}$ & $\hat{h}_{+M V R}^{2^{*}}$ & $\hat{h}_{+D L}^{2 *}$ & $\hat{h}_{+M V R}^{2^{*}}$ & $\hat{h}_{+D L}^{2^{*}}$ & $\hat{h}_{+M V R}^{2^{*}}$ & $\hat{h}_{+D L}^{2^{*}}$ \\
\hline 1 & $0,31 \pm 0,01$ & $0,31 \pm 0,01$ & $0,21 \pm 0,02$ & $0,20 \pm 0,02$ & $0,24 \pm 0,02$ & $0,24 \pm 0,02$ & \multicolumn{2}{|c|}{$0,32 \pm 0,04$} \\
\hline 2 & $0,30 \pm 0,02$ & $0,30 \pm 0,02$ & $0,24 \pm 0,01$ & $0,24 \pm 0,01$ & $0,28 \pm 0,01$ & $0,28 \pm 0,01$ & $0,33 \pm 0,01$ & $0,33 \pm 0,01$ \\
\hline 3 & $0,33 \pm 0,02$ & $0,33 \pm 0,02$ & $0,23 \pm 0,01$ & $0,23 \pm 0,01$ & $0,25 \pm 0,02$ & $0,25 \pm 0,02$ & $0,25 \pm 0,02$ & $0,25 \pm 0,02$ \\
\hline 4 & \multicolumn{2}{|c|}{$0,22 \pm 0,02$} & $0,26 \pm 0,02$ & $0,26 \pm 0,02$ & \multicolumn{2}{|c|}{$0,33 \pm 0,04$} & $0,28 \pm 0,03$ & $0,28 \pm 0,03$ \\
\hline 5 & \multicolumn{6}{|c|}{$0,18 \pm 0,02$} & & \\
\hline Total & $0,30 \pm 0,01$ & $0,30 \pm 0,01$ & $0,23 \pm 0,01$ & $0,23 \pm 0,01$ & $0,27 \pm 0,01$ & $0,27 \pm 0,01$ & $0,31 \pm 0,01$ & $0,31 \pm 0,01$ \\
\hline
\end{tabular}

As maiores $\hat{h}_{+}^{2 *}$ foram encontradas em grupos cuja característica é serem compostos, na sua maioria, por tanto animais da raça Nelore quanto o Brasil ser o país de origem dos dados. Tal fato reflete a grande variabilidade genética do Nelore para as características de crescimento, o que permite que ganhos genéticos satisfatórios possam ser atingidos em programas de melhoramento que incluam estas características em seu critério de seleção. 


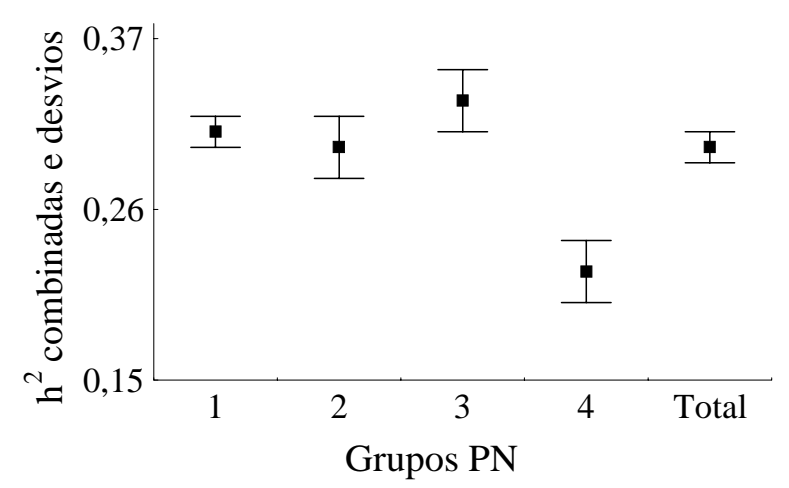

(a)

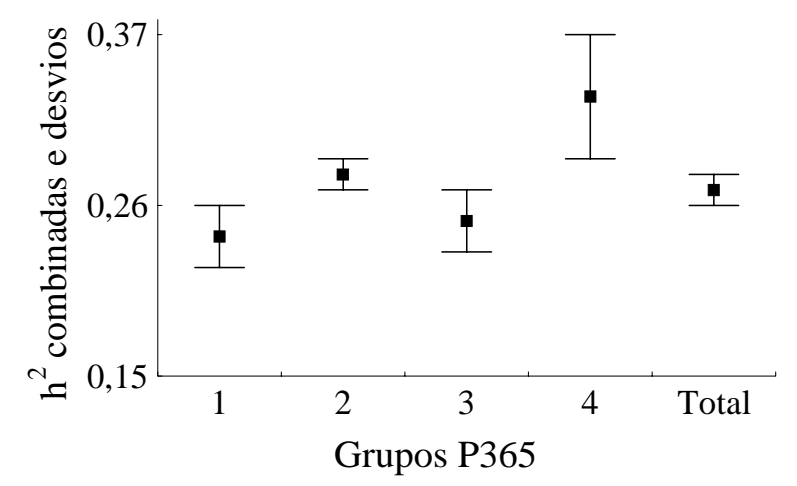

(c)

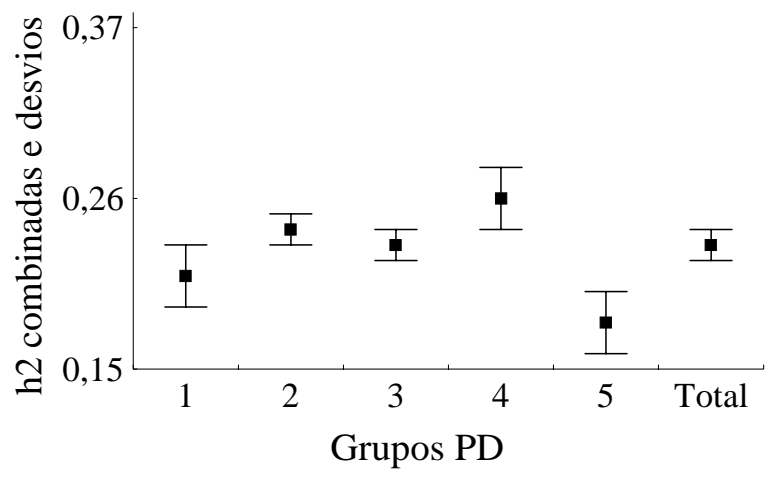

(b)

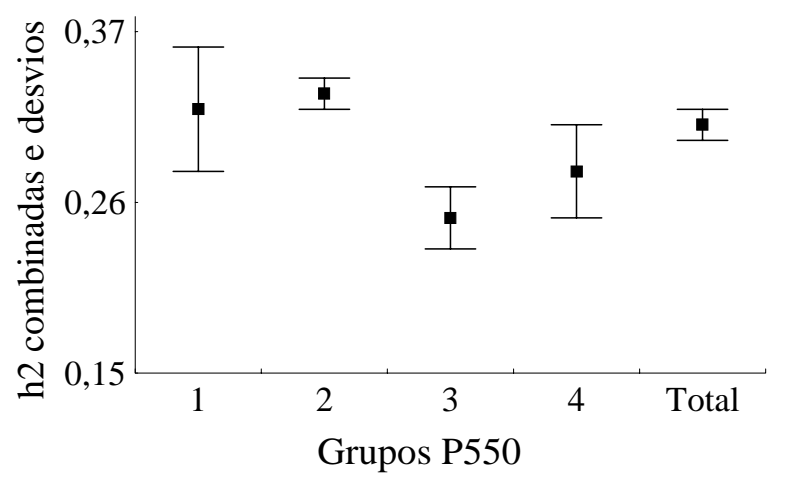

(d)

Figura 5- Estimativas de herdabilidades combinadas obtidas por Máxima Verossimilhança Restrita e desvio-padrão correspondente, para as características: (a) peso ao nascimento (PN); (b) peso à desmama (PD); (c) peso aos 365 dias (P365); (d) e peso aos 550 dias (P550)

A formação de grupos de resultados com mesmas características, como realizado no presente trabalho, utilizando a técnica de agrupamento, pode ser interessante para o usuário das estimativas de herdabilidade combinada, uma vez que esta técnica permite fornecer valores específicos com características específicas, mais próximas da realidade, do que uma só estimativa combinada geral, como mostrado nas revisões de Mercadante et al. (1995), Koots et al. (1994a) e Lôbo et al. (2000). Assim, se a necessidade é ter, por exemplo, uma estimativa combinada de peso ao nascer proveniente de animais somente da raça Nelore e usando exclusivamente o modelo animal, a partir das informações contidas na Tabela 5 e na Figura 5, opta-se por usar o valor estimado no grupo 1. 


\subsection{Conclusões}

Apesar dos valores das estimativas da variância entre os estudos terem sido distintos nos dois métodos de estimação, os valores da estimativa combinada das herdabilidades, nas quatro características, foram próximos, independente do método utilizado.

A análise de agrupamento permitiu a formação de grupos de resultados de estudos semelhantes, fornecendo, assim, estimativas combinadas de herdabilidades para grupos específicos. 


\section{META-ANÁLISE SOB ENFOQUE BAYESIANO DE ESTIMATIVAS DE HERDABILIDADE E COEFICIENTES DE CORRELAÇÃO PARA CARACTERÍSTICAS DE CRESCIMENTO EM BOVINOS DE CORTE}

\section{Resumo}

Com um conjunto de estimativas de herdabilidade, para características de crescimento em bovinos de corte de raças indianas, contendo 869 estimativas de herdabilidade de efeito direto, 186 estimativas de herdabilidade de efeito materno e 123 estimativas do coeficiente de correlação genético entre os efeitos direto e maternos, conduziu-se uma meta-análise sob enfoque Bayesiano. A construção e desenvolvimento de um modelo hierárquico possibilitou a obtenção de estimativas combinadas de herdabilidade para as características peso ao nascimento, peso à desmama, peso aos 365 dias e peso aos 550 dias, cujos valores foram, respectivamente: 0,31, 0,24, 0,28 e 0,33 para efeitos diretos; 0,09, 0,13, 0,12 e 0,05 para efeitos maternos; e -0,16, -0,16, -0,20 e -0,16 para as correlações entre estes efeitos. A meta-análise conduzida sob enfoque Bayesiano mostrou-se bastante adequada, uma vez que um modelo hierárquico considera as variâncias dentro e entre os estudos, e sua implementação e condução são facilitadas em virtude, principalmente, do avanço conseguido na área computacional.

\section{Summary}

Bayesian meta-analysis were performed in a data set of heritability estimates for growth traits of zebu beef cattle with 869 direct heritabilities, 186 maternal heritabilities and 123 direct-maternal genetic correlation. With the fitting and development of a hierarchical model it was possible to obtain pooled heritability estimates for birth 
weight, weaning weight, weight at 365 days of age and weight at 550 days of age whose values were, respectively: $0.31,0.24,0.28$ e 0.33 for direct effects; $0.09,0.13,0.12$ e 0.05 for maternal effects; and $-0.16,-0.16,-0.20$ e -0.16 for direct-maternal genetic correlation. The meta-analysis conducted under Bayesian framework was adequate since the hierarchical model considers the between-study and within-study variances, and its implementation and conduction are facilitated, mainly, due to of the advance in computational area.

\subsection{Introdução}

Artigos científicos versando sobre o mesmo assunto, utilizando a mesma metodologia de análise e, algumas vezes, até o mesmo conjunto de dados, porém com atualizações, é uma prática comum na pesquisa aplicada em geral e no melhoramento genético animal em particular. Neste contexto, é grande o número de artigos publicados sobre estimativas de herdabilidade de efeito direto e materno, e a correlação entre estes efeitos, para as características de crescimento. Conscientes do grande número de estimativas de herdabilidade de efeitos direto e materno, e suas correlações, presente em artigos publicados, Mohiuddin (1993), Koots et al. (1994a, 1994b), Mercadante et al. (1995) e Lôbo et al. (2000) realizaram, independentemente, revisões sobre esses parâmetros genéticos, para características de crescimento, em bovinos de corte de diferentes raças. O principal objetivo destes autores foi encontrar valores médios para um conjunto destas estimativas contidas em diferentes trabalhos publicados.

A amplitude de variação dos resultados presente na literatura e o grande número de artigos publicados sobre um mesmo assunto, são os principais argumentos para pesquisadores obterem valores médios. Como um exemplo, tem-se a abrangência dos resultados obtidos de estimativas de herdabilidade de efeito direto para a característica peso ao nascimento, podendo-se citar os trabalhos de Cárdenas et al. (2001) e Tawah et al. (1993), em que os valores estimados, para este parâmetro, foram 0,09 e 0,65, respectivamente. Apesar da herdabilidade ser um parâmetro referente à uma população, são esperadas estimativas com valores diferentes, mas não tão discrepantes. 
Características com estimativas de herdabilidade abaixo de 0,20 são consideradas pouco herdáveis, já aquelas com valores acima de 0,40, são consideradas altamente herdáveis (Bourdon, 2000). Deste modo, prevalece a dúvida da característica peso ao nascimento ser pouco ou muito herdável. Ainda mais discutíveis são as estimativas de correlação entre os efeitos direto e materno publicadas para as características de crescimento, principalmente até um ano de idade, como pode ser visto nos trabalhos de Tawah et al. (1993) e Salles (1995) que encontraram, respectivamente, os valores de -0,93 e 0,12, para a característica peso ao nascimento. Assim, para nortear uma conclusão, uma média obtida para resultados já existentes pode ser uma solução interessante.

Porém, para alcançar uma média confiável de resultados publicados, existe o desafio de desenvolver metodologias efetivas para comparar, e possivelmente combinar, informações de trabalhos relacionados, a fim de realizar alguma inferência sobre determinado tema. Assim, é crescente o número de estudos sobre a implementação e melhoria de procedimentos estatísticos para a aplicação da meta-análise. Trabalho pioneiro na área de meta-análise no Brasil foi efetuado por Giannotti et al. (2002).

O principal foco de crítica para a aplicação da meta-análise é quanto à variabilidade existente entre os estudos a serem combinados. Assim, modelos de metaanálise que incorporam na análise o componente da variância entre os estudos, são amplamente discutidos tanto na teoria clássica quanto na Bayesiana. Porém, autores como Larose \& Dey (1997), DuMouchel (1996), Mallick e Walker (1997) e Gelman et al. (2004), consideram que a formulação de um modelo Bayesiano hierárquico oferece um mecanismo natural para descrever e explicar a heterogeneidade existente entre os estudos individuais, enquanto que a teoria clássica para condução da meta-análise envolve a combinação da magnitude de efeitos.

Outras duas vantagens apresentadas pelos métodos Bayesianos, sobre os clássicos, na aplicação da meta-análise, são que os primeiros oferecem uma estrutura conveniente para a incorporação de informações disponíveis a priori, e são aplicáveis a problemas de combinar estudos com tamanhos amostrais pequenos, o que não ocorre 
quando se utiliza métodos assintóticos dos estimadores de máxima verossimilhança (Larose \& Dey, 1997). Assim, as inferências a serem conduzidas, observando-se os resultados da análise, serão, possivelmente, mais precisas do que aquelas obtidas pelo método clássico.

Em face do que foi apresentado anteriormente, ou seja, o número elevado de artigos publicados contendo estimativas de herdabilidade de efeito direto, materno e sua correlação, os resultados muitas vezes destoantes presentes na literatura para estes parâmetros genéticos, e a meta-análise Bayesiana apresentada como uma possível solução para obtenção de estimativas combinadas mais confiáveis, o presente trabalho teve como objetivo combinar estimativas publicadas destes parâmetros genéticos, através da meta-análise, utilizando um modelo Bayesiano hierárquico, para as características de crescimento peso ao nascimento (PN), peso à desmama (PD), peso aos 365 dias (P365) e peso aos 550 dias (P550), em bovinos de corte de origem indiana.

\subsection{Material e Métodos}

Os dados utilizados neste trabalho referem-se a 869 estimativas de herdabilidade de efeito direto $\left(\hat{h}_{d}^{2}\right)$, 186 estimativas de herdabilidade de efeito materno $\left(\hat{h}_{m}^{2}\right)$ e 123 estimativas do coeficiente de correlação genética entre os efeitos direto e materno $\left(r_{d m}\right)$ das características de crescimento PN, PD, P365 e P550, obtidas em populações de bovinos de corte de origem indiana, sendo: 182 de $\hat{h}_{d}^{2}$, 33 de $\hat{h}_{m}^{2}$ e 27 de $r_{d m}$ para PN; 331 de $\hat{h}_{d}^{2}$, 81 de $\hat{h}_{m}^{2}$ e 57 de $r_{d m}$ para PD; 153 de $\hat{h}_{d}^{2}$, 34 de $\hat{h}_{m}^{2}$ e 22 de $r_{d m}$ para P365 e;

203 de $\hat{h}_{d}^{2}$, 38 de $\hat{h}_{m}^{2}$ e 17 de $r_{d m}$ para P550. Estas estimativas são procedentes de 186 artigos publicados, dos quais 102 estão presentes no trabalho de revisão realizado por Mercadante et al. (1995) e 84 são provenientes de pesquisa bibliográfica realizada para a atualização destes dados, do ano de 1995 até 2003. Tal pesquisa englobou anais de congressos, teses e dissertações e base de dados como CAB e AGRIS, onde as palavras chaves utilizadas foram: "nelore”; “nellore”; “zebu”; "bos indicus”; e "heritabili*”. 
A informação da variância associada a cada valor de estimativa de herdabilidade é essencial em uma meta-análise. As variâncias das estimativas de herdabilidade foram calculadas através da metodologia descrita por Koots et al. (1994a) e Falconer \& Mackay (1996). Os valores de $\hat{r}_{d m}$ foram transformados para a quantidade $z$, conforme descrito por Giannotti et al. (2002), que é recomendado pelo fato do valor $z_{i}$ apresentar distribuição normal com variância igual a $\operatorname{var}\left(z_{i}\right)=1 /\left(n_{i}-3\right)$, em que $n_{i}$ é o número de observações do i-ésimo estudo. Assim, para combinar os $\hat{r}_{d m}$, utilizou-se as variâncias de $Z$.

Uma forma natural para descrever o problema e analisar os dados em questão é utilizar um modelo Bayesiano hierárquico. Na análise Bayesiana hierárquica, os parâmetros das distribuições dos parâmetros, chamados hiperparâmetros, são desconhecidos, mas com uma distribuição conhecida (Gelman et al., 2004). Assim, o modelo hierárquico para a realização da meta-análise teve a seguinte estrutura, assumindo $s_{i}^{2}$ conhecido:

$$
\begin{aligned}
& y_{i} \mid \alpha_{i}, s_{i}^{2} \stackrel{\text { ind }}{\sim} \operatorname{Normal}\left(\alpha_{i}, s_{i}^{2}\right) \\
& \alpha_{i} \mid \mu, \tau^{2} \stackrel{\text { ind }}{\sim} \operatorname{Normal}\left(\mu, \tau^{2}\right)
\end{aligned}
$$

em que:

$y_{i}$ é a estimativa a ser combinada correspondente ao i-ésimo estudo $(i=1, \ldots, I)$ (representada por $\hat{h}_{d i}^{2}$ para a i-ésima herdabilidade de efeito direto, ou $\hat{h}_{m i}^{2}$ para a $i$ ésima herdabilidade de efeito materno, ou $z_{i}$ para o i-ésimo coeficiente de correlação transformado entre as herdabilidades de efeito direto e materno, nas quatro características);

$\alpha_{i}$ é o valor verdadeiro da estimativa a ser combinada $\left(h_{d i}^{2}\right.$, ou $h_{m i}^{2}$, ou $\left.z_{i}\right)$ correspondente ao i-ésimo estudo; 
$s_{i}^{2}$ é a variância da estimativa a ser combinada, ou seja, a variância presente dentro do $i$ ésimo estudo (representada por $\operatorname{var}\left(\hat{h}_{d i}^{2}\right)$ para a variância de $\hat{h}_{d i}^{2}$, ou $\operatorname{var}\left(\hat{h}_{m i}^{2}\right)$ para a variância de $\hat{h}_{m i}^{2}$, ou $\operatorname{var}\left(z_{i}\right)$ para a variância de $z_{i}$, nas quatro características);

$\mu$ é a estimativa combinada (representada por $\hat{h}_{d+}^{2}$ para herdabilidades de efeito direto, ou $\hat{h}_{m+}^{2}$ para herdabilidades de efeito materno, ou $\hat{r}_{d m_{+}}$para coeficiente de correlação entre as herdabilidades de efeito direto e materno, nas quatro características);

$\tau^{2}$ é a variância existente entre os estudos, $\tau^{2}>0$ (representada por $\hat{\tau}_{d}^{2}$ para os estudos contendo herdabilidades de efeito direto, $\hat{\tau}_{m}^{2}$ para os estudos contendo herdabilidades de efeito materno, ou $\hat{\tau}_{d m}^{2}$ para estudos contendo os coeficientes de correlação entre os efeitos direto e materno, nas quatro características).

A partir do modelo especificado anteriormente, a função de verossimilhança para $\alpha_{1}, \alpha_{2}, \ldots, \alpha_{\mathrm{I}}$, é dada por:

$$
\begin{aligned}
L\left(\alpha_{1}, \ldots, \alpha_{I}\right)= & \prod_{i=1}^{I} \frac{1}{\sqrt{2 \pi s_{i}}} \exp \left\{\frac{-1}{2 s_{i}^{2}}\left(y_{i}-\alpha_{i}\right)^{2}\right\} \times \prod_{i=1}^{I} \frac{1}{\sqrt{2 \pi \tau}} \exp \left\{\frac{-1}{2 \tau^{2}}\left(\alpha_{i}-\mu\right)^{2}\right\} \propto \\
& \propto \exp \left\{\frac{-1}{2 s_{i}^{2}} \sum_{i=1}^{I}\left(y_{i}-\alpha_{i}\right)^{2}\right\} \times \tau^{-I} \exp \left\{\frac{-1}{2 \tau^{2}} \sum_{i=1}^{I}\left(\alpha_{i}-\mu\right)^{2}\right\} .
\end{aligned}
$$

Para o modelo sugerido anteriormente, as distribuições a priori são especificadas da seguinte maneira:

$\mu \sim \operatorname{Normal}(a, b)$

$\tau^{2} \sim$ Gama Inversa $(c, d)$,

em que, para os dados em questão os valores foram $a=0 ; b=10^{-6} ; c=0,001$ e $d=0,001$. Tais valores foram empregados pois optou-se pela utilização de prioris não-informativas, a razão principal para utilizá-las baseia-se no fato das inferências não serem afetadas por informações externas aos dados (Gelman et al., 2004). 
Assim, as distribuições a priori para os hiperparâmetros $\mu$ e $\tau^{2}$ são, respectivamente, dadas por:

$$
\begin{aligned}
& p(\mu)=\frac{1}{\sqrt{2 \pi b^{1 / 2}}} \exp \left\{\frac{-1}{2 b}(\mu-a)^{2}\right\} \propto \exp \left\{\frac{-1}{2 b}(\mu-a)^{2}\right\} \\
& p\left(\tau^{2}\right)=\frac{d^{c}}{\Gamma(c)}\left(\tau^{2}\right)^{-(c+1)} \exp \left\{\frac{-d}{\tau^{2}}\right\} \propto\left(\tau^{2}\right)^{-(c+1)} \exp \left\{\frac{-d}{\tau^{2}}\right\} .
\end{aligned}
$$

Portanto, assumindo independência, a distribuição a priori conjunta para $\alpha_{1}$, $\alpha_{2}, \ldots, \alpha_{I}, \mu$ e $\tau^{2}$, é dada por:

$p\left(\alpha_{1}, \ldots, \alpha_{I}, \mu, \tau^{2}\right) \propto \tau^{-I} \exp \left\{\frac{-1}{2 \tau^{2}} \sum_{i=1}^{I}\left(\alpha_{i}-\mu\right)^{2}\right\} \times \exp \left\{\frac{-1}{2 b}(\mu-a)^{2}\right\} \times\left(\tau^{2}\right)^{-(c+1)} \exp \left\{\frac{-d}{\tau^{2}}\right\}$

Combinando a distribuição a priori conjunta com a função de verossimilhança, a distribuição a posteriori conjunta é dada por:

$$
\begin{aligned}
p\left(\alpha_{1}, \ldots, \alpha_{I}, \mu, \tau^{2} \mid \text { Dados }\right) & \propto \exp \left\{\frac{-1}{2 s_{i}^{2}} \sum_{i=1}^{I}\left(y_{i}-\alpha_{i}\right)^{2}\right\} \tau^{-I} \times \exp \left\{\frac{-1}{2 \tau^{2}} \sum_{i=1}^{I}\left(\alpha_{i}-\mu\right)^{2}\right\} \\
& \times \exp \left\{\frac{-1}{2 b}(\mu-a)^{2}\right\} \times\left(\tau^{2}\right)^{-(c+1)} \exp \left\{\frac{-d}{\tau^{2}}\right\} .
\end{aligned}
$$

A partir da distribuição a posteriori conjunta, as distribuições marginais dos parâmetros $\alpha_{i}$, $\mu$ e $\tau^{2}$ são:

$$
\begin{aligned}
& p\left(\tau^{2}\right)=\int \ldots \int p\left(\alpha_{1}, \ldots, \alpha_{I}, \mu, \tau^{2} \mid \text { Dados }\right) d \alpha_{1} \ldots d \alpha_{I} d \mu \\
& p(\mu)=\int \ldots \int p\left(\alpha_{1}, \ldots, \alpha_{I}, \mu, \tau^{2} \mid \text { Dados }\right) d \alpha_{1} \ldots d \alpha_{I} d \tau^{2} ; \\
& p\left(\alpha_{i}\right)=\int \ldots \int p\left(\alpha_{(-i)}, \mu, \tau^{2} \mid \text { Dados }\right) d \alpha_{-i} d \mu d \tau^{2}, \quad \alpha_{-i}=\left(\alpha_{1}, \ldots, \alpha_{i-1}, \alpha_{i+1}, \ldots, \alpha_{I}\right) .
\end{aligned}
$$

A parte computacional deste trabalho foi desenvolvida utilizando-se o programa WinBUGS (Spiegelhalter et al., 2004) cujas principais características são acomodar uma ampla classe de modelos, possibilitar que os modelos sejam especificados de maneira concisa, e construir e amostrar a distribuição a posterior conjunta (Gilks et al., 1994). 
Para a condução da análise, foi gerada uma cadeia com 55000 valores para cada estimativa a ser combinada $\left(\hat{h}_{d}^{2}\right.$, ou $\hat{h}_{m}^{2}$, ou $z$ ) dentro de cada uma das quatro características em estudo, PN, PD, P365 e P550. Os primeiros 5000 valores foram descartados ("burn-in" de 5000) e os demais 50000 valores foram selecionados de 10 em 10 (“thin” de 10).

A indicação de convergência para os hiperparâmetros de interesse $\mu$ (representado por $\hat{h}_{d}^{2}, \hat{h}_{m}^{2}$ e $z$ ) e $\tau^{2}$ (representado por $\hat{\tau}_{d}^{2}, \hat{\tau}_{m}^{2}$ e $\hat{\tau}_{d m}^{2}$ ), foi verificada tanto graficamente através da análise de comportamento das trajetórias das cadeias, quanto a partir dos diagnósticos de convergência Geweke e Raftery \& Lewis, disponíveis no pacote computacional R (R Development Core Team, 2003) na "library” CODA (Best et al., 2004).

\subsection{Resultados e Discussão}

O algoritmo de amostragem utilizado na condução da inferência Bayesiana foi o de Gibbs, de acordo com informação fornecida pelo programa WinBUGS (Spiegelhalter et al., 2004).

Nas Figuras 6 e 7 observam-se as formas das distribuições a posteriori para os hiperparâmetros $\tau^{2}$ e $\mu$, nas quatro características em estudo. As distribuições a posteriori, estimadas nos métodos Bayesianos, podem ser interpretadas considerando-se que estas representam uma aproximação com relação à verdadeira distribuição de probabilidade dos valores dos parâmetros, tendo sido observados os dados. Assim, aumentando-se a precisão com que os dados são observados (ou estimados) isso conduziria a distribuições de probabilidade que descreveriam verdadeiramente o comportamento do parâmetro. A convergência dos hiperparâmetros foi confirmada tanto graficamente (Figuras 6 e 7), quanto numericamente através do diagnóstico proposto por Geweke e Raftery \& Lewis (Best et al., 2004). 


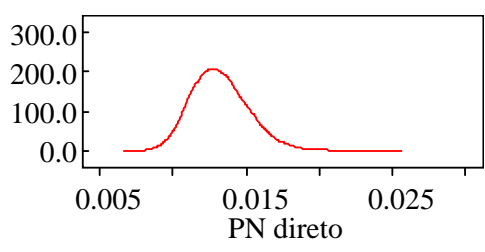

(a)

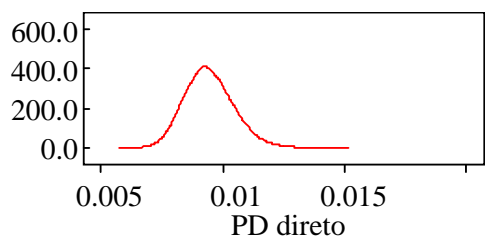

(d)

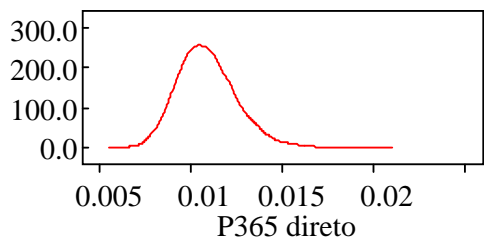

(g)

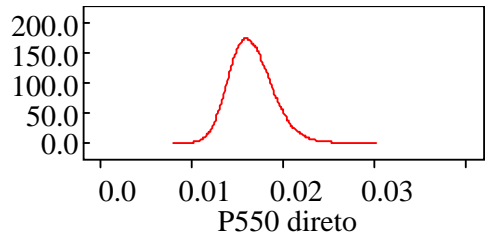

(j)

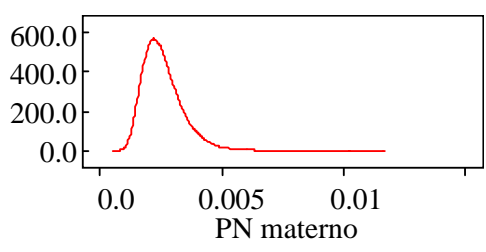

(b)

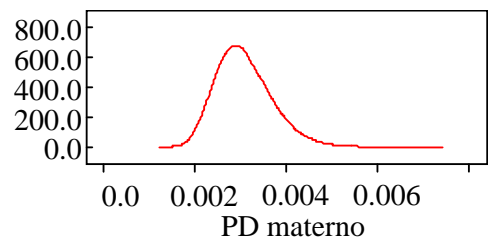

(e)

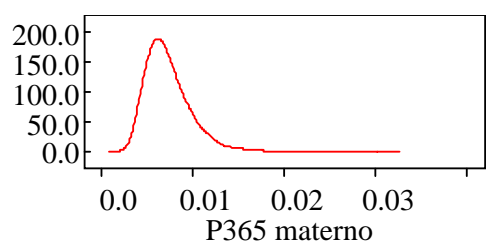

(h)

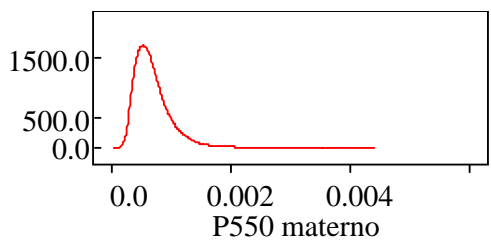

(k)

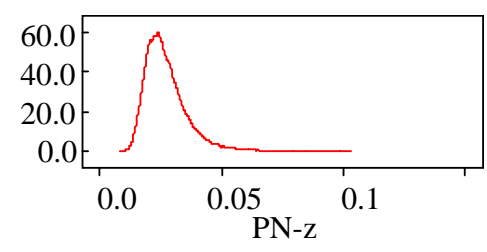

(c)

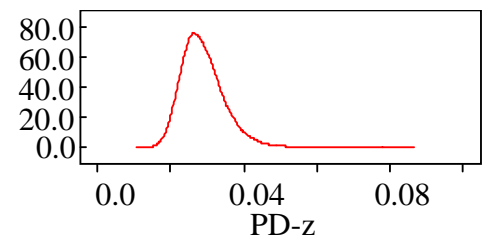

(f)

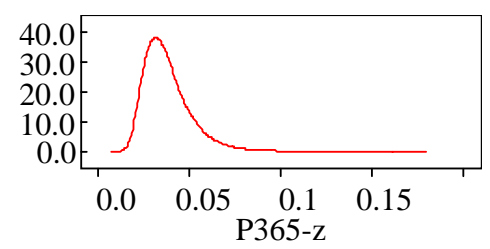

(i)

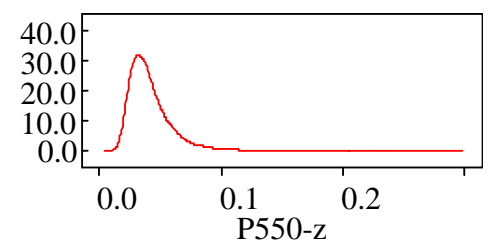

(l)

Figura 6- Gráficos com as distribuições a posteriori para o hiperparâmetro $\tau^{2}$ representado por: (a) $\hat{\tau}_{d}^{2}$ para PN; (b) $\hat{\tau}_{m}^{2}$ para PN; (c) $\hat{\tau}_{d m}^{2}$ para PN; (d) $\hat{\tau}_{d}^{2}$ para PD; (e) $\hat{\tau}_{m}^{2}$ para PD; (f) $\hat{\tau}_{d m}^{2}$ para PD; (g) $\hat{\tau}_{d}^{2}$ para P365; (h) $\hat{\tau}_{m}^{2}$ para P365; (i) $\hat{\tau}_{d m}^{2}$ para P365; (j) $\hat{\tau}_{d}^{2}$ para P550; (k) $\hat{\tau}_{m}^{2}$ para P550; (l) $\hat{\tau}_{d m}^{2}$ para P550 


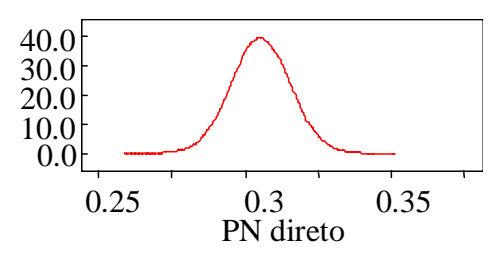

(a)

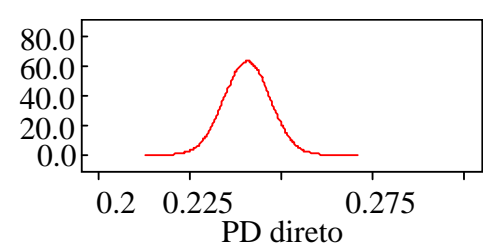

(d)

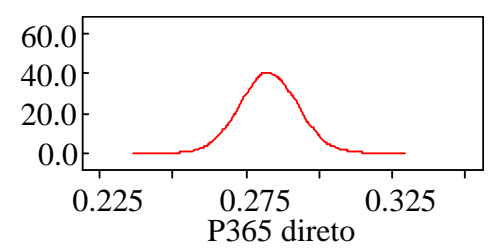

(g)

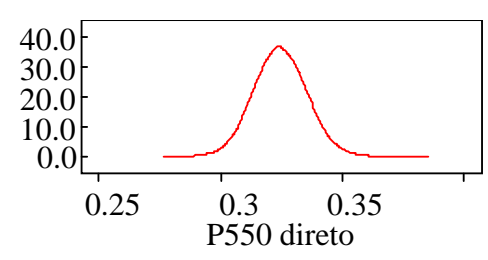

(j)

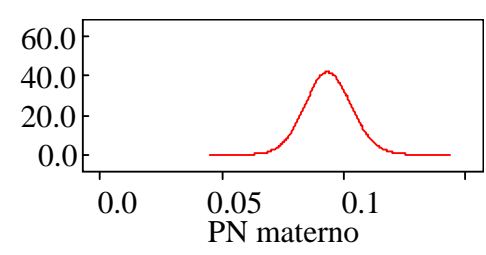

(b)

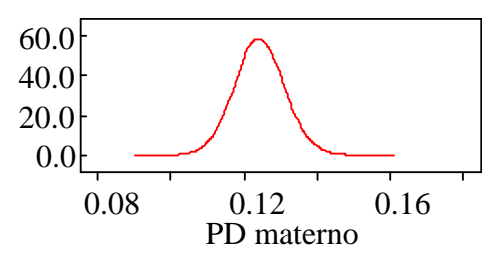

(e)

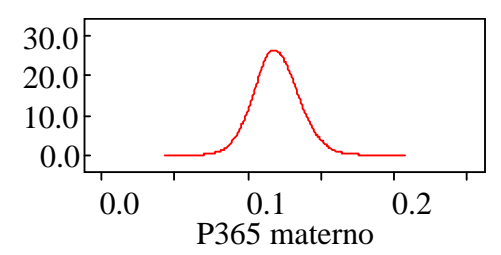

(h)

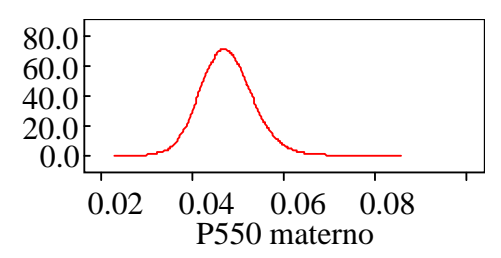

(k)

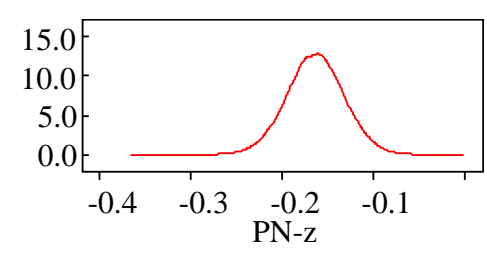

(c)

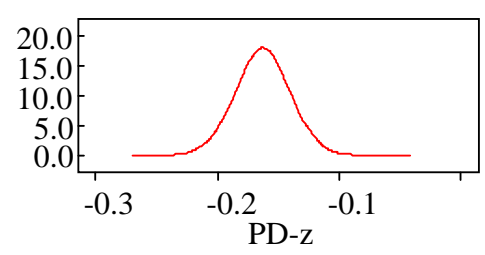

(f)

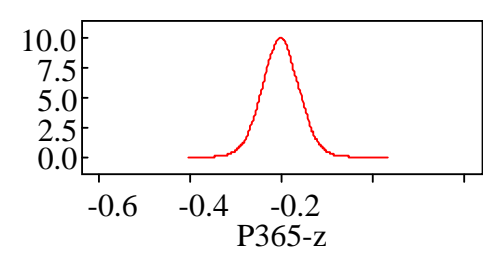

(i)

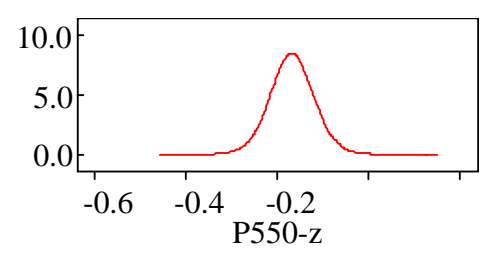

(l)

Figura 7- Gráficos com as distribuições a posteriori para o hiperparâmetro $\mu$ representado por: (a) $\hat{h}_{d}^{2}$ para PN; (b) $\hat{h}_{m}^{2}$ para PN; (c) z para PN; (d) $\hat{h}_{d}^{2}$ para PD; (e) $\hat{h}_{m}^{2}$ para PD; (f) z para PD; (g) $\hat{h}_{d}^{2}$ para P365; (h) $\hat{h}_{m}^{2}$ para P365; (i) z para P365; (j) $\hat{h}_{d}^{2}$ para P550; (k) $\hat{h}_{m}^{2}$ para P550; (l) z para P550

Na Tabela 8 estão expostas: a variância entre os estudos contendo herdabilidades de efeito direto $\left(\hat{\tau}_{d}^{2}\right)$; a variância entre os estudos contendo herdabilidades de efeito materno $\left(\hat{\tau}_{m}^{2}\right)$; a variância entre os estudos contendo coeficiente de correlação entre 
efeitos direto e materno $\left(\hat{\tau}_{d m}^{2}\right)$, com respectivos intervalos de credibilidade, para as características PN, PD, P365 e P550.

Tabela 8. Variâncias a posteriori e intervalo de credibilidade 95\% (IC 95\%) para o parâmetro $\tau^{2}$, representado por $\hat{\tau}_{d}^{2}$ (variância entre os estudos de herdabilidades de efeito direto), $\hat{\tau}_{m}^{2}$ (variância entre os estudos de herdabilidades de efeito materno) e $\hat{\tau}_{d m}^{2}$ (variância entre os estudos de coeficiente de correlação entre efeitos direto e materno), nas características peso ao nascimento (PN), peso a desmama (PD), peso aos 365 dias (P365) e peso aos 550 dias (P550)

\begin{tabular}{lccc}
\hline Característica & Parâmetro & Variância a posteriori & IC 95\% \\
\hline PN & $\hat{\tau}_{d}^{2}$ & 0,013 & $(0,009 ; 0,017)$ \\
& $\hat{\tau}_{m}^{2}$ & 0,003 & $(0,001 ; 0,005)$ \\
& $\hat{\tau}_{d m}^{2}$ & 0,027 & $(0,015 ; 0,047)$ \\
PD & $\hat{\tau}_{d}^{2}$ & 0,009 & $(0,008 ; 0,012)$ \\
& $\hat{\tau}_{m}^{2}$ & 0,003 & $(0,002 ; 0,005)$ \\
& $\hat{\tau}_{d m}^{2}$ & 0,029 & $(0,019 ; 0,042)$ \\
P365 & $\hat{\tau}_{d}^{2}$ & 0,010 & $(0,008 ; 0,014)$ \\
& $\hat{\tau}_{m}^{2}$ & 0,007 & $(0,004 ; 0,013)$ \\
& $\hat{\tau}_{d m}^{2}$ & 0,038 & $(0,020 ; 0,070)$ \\
& & & $(0,013 ; 0,022)$ \\
& $\hat{\tau}_{d}^{2}$ & 0,017 & $(0,0002 ; 0,001)$ \\
& $\hat{\tau}_{m}^{2}$ & 0,0006 & $(0,020 ; 0,084)$ \\
\hline
\end{tabular}

Na Tabela 9 estão expostas as estimativas combinadas de herdabilidades para efeitos diretos $\left(\hat{h}_{d+}^{2}\right)$ e maternos $\left(\hat{h}_{m+}^{2}\right)$ e coeficientes de correlação combinados entre os 
efeitos diretos e maternos $\left(\hat{r}_{d m+}\right)$, com respectivos intervalos de credibilidade, para as características PN, PD, P365 e P550.

As médias e variâncias a posteriori, assim como os intervalos de credibilidade, presentes nas Tabelas 8 e 9, foram obtidos via simulação utilizando o modelo Bayesiano hierárquico proposto e definido anteriormente.

Tabela 9. Médias a posteriori e intervalo de credibilidade 95\% (IC 95\%) para o parâmetro $\mu$, representado por $\hat{h}_{d+}^{2}$ (estimativa combinada para efeito direto), $\hat{h}_{m+}^{2}$ (estimativa combinada para efeito materno) e $\hat{r}_{d m+}$ (estimativa combinada para correlação entre os efeitos direto e materno), nas características peso ao nascimento (PN), peso a desmama (PD), peso aos 365 dias (P365) e peso aos 550 dias (P550)

\begin{tabular}{lccc}
\hline Característica & Parâmetro & Média a posteriori & IC 95\% \\
\hline \multirow{4}{*}{ PN } & $\hat{h}_{d+}^{2}$ & 0,31 & $(0,29 ; 0,33)$ \\
& $\hat{h}_{m+}^{2}$ & 0,09 & $(0,08 ; 0,11)$ \\
& $\hat{r}_{d m+}$ & $-0,16$ & $(-0,22 ;-0,10)$ \\
& $\hat{h}_{d+}^{2}$ & 0,24 & $(0,23 ; 0,25)$ \\
PD & $\hat{h}_{m+}^{2}$ & 0,13 & $(0,11 ; 0,14)$ \\
& $\hat{r}_{d m+}$ & $-0,16$ & $(-0,20 ;-0,12)$ \\
& $\hat{h}_{d+}^{2}$ & 0,28 & $(0,26 ; 0,30)$ \\
& $\hat{h}_{m+}^{2}$ & 0,12 & $(0,09 ; 0,15)$ \\
& $\hat{r}_{d m+}$ & $-0,20$ & $(-0,28 ;-0,12)$ \\
& $\hat{h}_{d+}^{2}$ & 0,33 & $(0,30 ; 0,35)$ \\
& $\hat{h}_{m+}^{2}$ & 0,05 & $(0,04 ; 0,06)$ \\
& $\hat{r}_{d m+}$ & $-0,16$ & $(-0,26 ;-0,07)$ \\
\hline
\end{tabular}


Foram revisados trabalhos publicados sobre estimativas de herdabilidade de características de crescimento, os quais apresentaram os componentes genéticos direto e materno. O componente genético direto dessas características é relativo aos efeitos dos genes para crescimento do próprio indivíduo sobre o seu desempenho, enquanto que o componente materno é relativo aos efeitos dos genes da mãe para habilidade materna, principalmente para a produção de leite, que influenciam o desempenho dos bezerros através do ambiente oferecido por ela. Das quatro características de crescimento consideradas neste trabalho, aquelas mais influenciadas pela habilidade materna são o PN e o PD, assim, era esperado que as $\hat{h}_{m+}^{2}$ fossem maiores para estas características do que para P365 e P550.

Os valores obtidos (Tabela 9) para as $\hat{h}_{d+}^{2}$, indicam que 31\% para PN, 24\% para PD, 28\% para P365 e 33\% para P550, da variação entre os indivíduos é devida a genes de efeito aditivo que agem no crescimento. Os valores de $\hat{h}_{m+}^{2}$ indicam que 9\% para PN, 13\% para PD, 12\% para P365 e 5\% para P550, do desempenho dos indivíduos é devido a genes de efeito aditivo que determinam a habilidade materna de suas mães. Como pôde ser observado, os valores das $\hat{h}_{m+}^{2}$ são mais baixos que os das $\hat{h}_{d_{+}}^{2}$, indicando, assim, que as características de crescimento, aqui estudadas, são mais influenciadas por efeitos genéticos que atuam no crescimento do próprio bezerro do que pelos efeitos genéticos para habilidade materna de sua mãe.

Os valores obtidos para as $\hat{r}_{d m+}$ foram semelhantes nas quatro características, ou seja, negativos e baixos, sugerindo uma associação fraca entre os componentes direto e materno. Entretanto, numerosos estudos, em particular de características de crescimento pré-desmama de bovinos de corte e ovinos, têm encontrado correlação antagônica entre os efeitos genéticos direto e materno, freqüentemente de $-0,5$ ou mais altas, e tais estimativas tem sido vistas com justificado ceticismo (Meyer, 1997). Para obter boas estimativas são necessárias várias gerações de dados, com boas ligações entre elas, e para obter boas estimativas da habilidade materna das filhas de um touro, este animal 
deve ter filhas com progênies. Frequentemente há insuficientes ligações entre as gerações e isto tem sido a causa de muitas estimativas publicadas de coeficientes de correlação entre os efeitos diretos e maternos serem viesadas (Schaeffer, 1999). Em muitos casos as $\hat{h}_{d}^{2}$ e $\hat{h}_{m}^{2}$ são subestimadas, enquanto os efeitos de ambiente permanente materno são superestimados.

Mohiuddin (1993) utilizando como ponderação o inverso do desvio padrão de dentro dos estudos para combinar as $\hat{h}^{2}$ para características de crescimento em bovinos de corte de raças européias e cruzamentos, obteve: $\hat{h}_{d+}^{2}$ de $0,30, \hat{h}_{m+}^{2}$ de 0,10 e $\hat{r}_{d m+}$ de 0,35 para PN; $\hat{h}_{d+}^{2}$ de 0,22, $\hat{h}_{m+}^{2}$ de 0,13 e $\hat{r}_{d m_{+}}$de $-0,15$ para PD; $\hat{h}_{d+}^{2}$ de $0,31, \hat{h}_{m+}^{2}$ de 0,11 e $\hat{r}_{d m+}$ de $-0,26$ para P365. Koots et al. (1994a) utilizando como ponderação o inverso da variância de dentro dos estudos para combinar as $\hat{h}^{2}$ para características de crescimento em bovinos de corte de raças zebuínas, européias e cruzamentos, obtiveram: $\hat{h}_{d+}^{2}$ de $0,31 \pm 0,003$ e $\hat{h}_{m+}^{2}$ de $0,14 \pm 0,002$ para PN; $\hat{h}_{d+}^{2}$ de $0,24 \pm 0,002$ e $\hat{h}_{m+}^{2}$ de

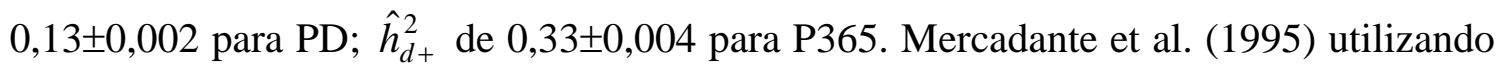
como ponderação o inverso do desvio padrão dentro dos estudos para combinar $\hat{h}^{2}$ para características de crescimento em bovinos de corte de raças zebuínas, obtiveram: $\hat{h}_{d+}^{2}$ de 0,33, $\hat{h}_{m+}^{2}$ de 0,12 e $\hat{r}_{d m+}$ de $-0,37$ para PN; $\hat{h}_{d+}^{2}$ de $0,22, \hat{h}_{m+}^{2}$ de 0,18 e $\hat{r}_{d m+}$ de $-0,23$ para PD; $\hat{h}_{d+}^{2}$ de $0,20, \hat{h}_{m+}^{2}$ de 0,16 e $\hat{r}_{d m+}$ de $-0,30$ para P365; $\hat{h}_{d+}^{2}$ de $0,38, \hat{h}_{m+}^{2}$ de 0,05 para P550. Comparando-se os valores encontrados neste trabalho com aqueles presentes nos artigos de Mohiuddin (1993), Koots et al. (1994a) e Mercadante et al. (1995), verifica-se que os valores obtidos nestas revisões foram próximos aos encontrados no presente trabalho, mesmo sendo utilizados naquelas tanto metodologia para combinar as estimativas em questão quanto raças distintas (exceto em Mercadante et al. (1995)) das aqui utilizadas. 
Com relação aos aspectos computacionais da condução da meta-análise sob o enfoque Bayesiano, presente neste trabalho, o programa WinBUGS (Spiegelhalter et al., 2004) mostrou-se satisfatório, em virtude dos resultados aqui obtidos serem consistentes e da programação utilizada ser relativamente simples e estar bastante documentada, tanto no próprio módulo de ajuda do programa quanto em artigos e livros (Gilks, et al., 1994; Smith \& Spiegelhalter, 1996; Normand, 1999; Gelman et al., 2004).

\subsection{Conclusões}

A utilização do modelo Bayesiano hierárquico é bastante conveniente em metaanálise pois leva em consideração as variâncias dentro e entre os estudos. A implementação desses métodos é facilitada tanto pelo avanço conseguido na área de processamento de dados, quanto pelo desenvolvimento de programas computacionais, possibilitando a pesquisadores de áreas aplicadas conduzir análises sem a necessidade de programações mais complexas.

As estimativas combinadas de herdabilidade e correlação, de características de crescimento, foram coerentes e apresentaram intervalos de credibilidade bastante adequados. 


\section{CONCLUSÕES GERAIS}

A metodologia da meta-análise é recomendável para a obtenção de valores combinados de estimativas de herdabilidade de efeito direto, materno e suas correlações, para as características de crescimento em bovinos de corte de origem indiana, em virtude de permitir a comparação e reunião de resultados distintos, possibilitando uma conclusão geral sobre o corpo da pesquisa. Há que se considerar, porém, tanto as pressuposições para a implementação da meta-análise, pois estas validarão os resultados obtidos, quanto à variância existente entre os estudos, a qual deve ser estimada por algum dos métodos disponíveis, e incluída na obtenção da estimativa combinada.

Os três métodos utilizados para estimar a variância entre os estudos, o da máxima verossimilhança restrita, o proposto por DerSimonian \& Laird e o Bayesiano, conduziram a valores distintos para esta variância, sendo sempre maiores aqueles estimados pelo método Bayesiano e sempre menores os obtidos por DerSimonian \& Laird. Mas, apesar dos valores da variância entre os estudos diferirem em função do método utilizado para sua estimação, os valores das estimativas combinadas das herdabilidades de efeito direto foram bastante próximos, e até mesmo iguais, para os três métodos.

Comparando os valores das estimativas combinadas da herdabilidade para efeitos diretos, obtidos para as quatro características consideradas neste trabalho, observou-se que independente do método utilizado para estimar a variância entre os estudos e a estimativa combinada, estes foram sempre menores para a característica peso à desmama e sempre maiores para a característica peso aos 550 dias. Para os valores das estimativas combinadas da herdabilidade para efeitos maternos obtidos para as quatro 
características, observou-se que estes foram menores para a característica peso aos 550 dias e maiores para a característica peso à desmama. Os valores dos coeficientes de correlação genética combinados entre os efeitos diretos e maternos foram negativos e baixos nas quatro características.

A meta-análise oferece a oportunidade de revisar sistematicamente a literatura, possibilitando a obtenção de uma resposta única para uma série de resultados, muitas vezes conflitantes. Ela pode não fornecer, em algumas ocasiões, a solução final do problema, mas indica novas hipóteses a serem testadas em estudos futuros. 


\section{REFERÊNCIAS BIBLIOGRÁFICAS}

ALBUQUERQUE, L.G. de; MEYER, K. Estimates of direct and maternal genetic effects for weights from birth to 600 days of age in Nelore cattle. Journal of Animal Breeding and Genetic, v.118, 83-92, 2001.

ARTHUR, W. JUNIOR.; BENNETT, W. JUNIOR.; HUFFCUTT, A.I. Conducting meta-analysis using SAS. London: Lawrence Erlbaum, 2001. 188p.

ASSOCIAÇÃO BRASILEIRA DE CRIADORES DE ZEBU (ABCZ). Raças zebuínas. http://www.braziliancattle.com.br/racaszebuinas.php. (10 fev. 2004).

BECKETT, S.D.; LEAN, I.J. Gonadotrophin-releasing hormone in postpartum dairycattle: a meta-analysis of effects on reproductive efficiency. Animal Reproduction Science, v.48, p.93-112, 1997.

BEGG, C.B.; MAZUMDAR, M. Operating characteristics of a rank correlation test for publication bias. Biometrics, v.50, p.1088-1101, 1994.

BERKEY, C.S.; HOAGLIN, D.C.; MOSTELLER, F. et al. A random-effects regression model for meta-analysis. Statistics in Medicine, v.14, p.395-411, 1995.

BEST, N.G.; COWLES, M.K.; VINES, S.K. CODA manual version 0.30 . http://www.mrc-bsu.cam.ac.uk/bugs/documentation/coda03/node9.html (02 jun. 2004)

BINI, L.M.; COELHO, A.S.G.; DINIZ-FILHO, J.A.F. Is the relationship between population density and body size consistent across independent studies? A metaanalytical approach. Revista Brasileira de Biologia, v.61, n.1, p.1-6, 2001. 
BORENSTEIN, M.; COHEN, J.; ROTHSTEIN, H. et al. Comprehensive metaanalysis. http://www.meta-analysis.com (29 Out. 2002a).

BOREnStein, M.; COHEN, J.; ROThSTEIN, H. et al. Power and precision. http://www.poweranalysis.com/about_biostat.htm (29 Out. 2002b).

BOURDON, G.E.P. Understanding animal breeding. Upper Saddle River: PrenticeHall, 2000. 538p.

BOX, G.E.P.; COX, D.R. An analysis of transformations. Journal of the Royal Statistical Society, v.26, p.211-252, 1964.

BROCKWELL, S.E.; GORDON, I.R. A comparation of statistical methods for metaanalysis. Statistics in Medicine, v.20, p.825-840, 2001.

BUSSAB, W.O.; MORETTIN, P.A. Estatística básica. 5.ed. São Paulo: Saraiva, 2003. $526 \mathrm{p}$.

CAMERON, E.Z. Is suckling behaviour a useful predictor of milk intake? A review. Animal Behaviour, v.56, p.521-532, 1998.

CANNER, P.L. An overview of six clinical trials of aspirin in coronary heart disease. Statistics in Medicine, v.6, p.255-263, 1987.

CÁRDENAS, I.; MONTONI, D.; VITTO, R. et al. Estimacion de parametros geneticos directos e maternos para el peso al nacer, peso al destete y peso a los 18 meses en un rebaño Brahman registrado. I. Indices de herencia (compact disc). In: REUNIÓN DE LA ASOCIACIÓN LATINOAMERICANA DE PRODUCCIÓN ANIMAL, 17. La Habana: ALPA, 2001.

COCHRAN, W.G. Problems arising in the analysis of a series of similar experiments. Journal of the Royal Statistical Society, v.4, suppl.1, p.102-118, 1937.

COOPER, H.M. Integrating research: a guide for literature reviews. 2.ed. Newbury Park: Sage, 1990. 157 p. 
COSTA, P.A.B. Um enfoque segundo a teoria de conjuntos difusos para a meta-análise. Florianópolis, 1999. 153p. Tese (Doutorado) - Universidade Federal de Santa Catarina.

CURTIS, P.S.; WANG, X. A meta-analysis of elevated $\mathrm{CO}_{2}$ effects on woody plant mass, form, and physiology. Oecologia, v.113, p.299-313, 1998.

DEAR, K.B.G. Iterative generalized squares for meta-analysis of survival data at multiple times. Biometrics, v.50, p.989-1002, 1994.

DEMPSTER, A. P.; LAIRD, N. M.; RUBIN, D. B. Maximum likelihood from incomplete data via the EM algorithm. Journal of the Royal Statistical Society, v.39, p.1-38, 1977

DerSIMONIAN, R.; LAIRD, N. Meta-analysis in clinical trials. Controlled Clinical Trials, v.7, p.177-188, 1986.

DEVIN, B.; DANIELS, M.; ROEDER, K. The heritability of IQ. Nature, v.388, n.31, p.468-471, 1997.

DICKERSIN, K.; BERLIN, J.A. Meta-analysis: state-of-the-Science. Epidemiology Reviews, v.14, p.154-176, 1992.

DuMOUCHEL, W. Precictive cross-validation of bayesian meta-analyses. Bayesian Statistics, v.5, p.107-127, 1996.

EDDY, D.M.; HASSELBLAD, V. Fast*Pro: software for meta-analysis by the confidence profile method. http://www.harcourtinternational.com/catalogue/title.cfm?ISBN=012230621X (29 Out. 2002).

EGGER, M.; SMITH, G.D. Meta-analysis: potentials and promise. British Journal of Medicine, v.315, 1371-1374, 1997.

EGGER, M.; SMITH, G.D. Meta-analysis: bias in location and selection of studies. British Journal of Medicine, v.316, p.61-66, 1998. 
EGGER, M.; SMITH, G.D.; PHILLIPS, A.N. Meta-analysis: principles and procedures. British Journal of Medicine, v.315, p.1533-1537, 1997.

EPISTAT SERVICES. True epistat. http://www.insp.mx/dinf/stat_list.html\#True (29 Out. 2002).

FAGARD, R.H.; STAESSEN, J.A.; THIJS, L. Advantages and disadvantages of the meta-analysis approach. Journal of Hypertension, v.14, suppl.2, p.9-13, 1996.

FALCONER, D.S.; MACKAY, T.F.C. Introduction to quantitative genetics. Edinburgh: Addison Wesley Longman, 1996. 464p.

FERREIRA, M.C.G.; KRZYZANOWSKI, R.F. Periódicos científicos: critérios de qualidade. Pesquisa Odontológica Brasileira, v.17, suppl.1, p.43-48, 2003.

FISHER, R.A. Statistical methods for research worker. London: Oliver and Boyde, 1932. 307p.

FORTULAN, V.C. Meta-análise: um enfoque bayesiano. São Carlos, 1999. 133p. Dissertação (Mestrado) - Instituto de Ciências Matemáticas de São Carlos, Universidade de São Paulo.

FRIENDLY, M. Power transformations by box-cox method for GLMs: SAS macroprograms: box-glm. http://www.math.yorku.ca/SCS/sasmac/boxglm.html. (04 ago.2003).

GAVER, J.R.; DRAPER, D.P.; GOEL, P.K. et al. Panel on statistical issues and opportunities for research in the combination of information. Washington: National Academic Press, 1992. 217p.

GELFAND, A.E.; SMITH, A.F.M. Sampling-based approaches to calculing marginal densities. Journal of the American Statistical Association, v.85, p.398-409, 1990.

GELMAN, A.; CARLIN, J.B.; STERN, H.S. et al. Bayesian data analysis. 2.ed. Boca Raton: Chapman \& Hall, 2004. 668p. 
GIANNOTTI, J.G. Meta-análise de estimativas da correlação genética entre pesos ao nascer e desmama de bovinos. Piracicaba, 2000. 85p. Dissertação (Mestrado) Escola Superior de Agricultura “Luiz de Queiroz”, Universidade de São Paulo.

GIANNOTTI, J.G.; PACKER, I.U.; MERCADANTE, M.E.Z. Meta-análise para estimativas de correlação genética entre pesos ao nascer e desmama de bovinos. Scientia Agricola, v.59, n.3, p.435-440, 2002.

GILKS, W.R.; THOMAS, A.; SPIEGELHALTER, D.J. A language and program for complex Bayesian modelling. The Statistician, v.43, n.1, p.169-177, 1994.

GLASS, G.V. Primary, secundary, and meta-analysis of research. Educational Researcher, v.6, p.3-8, 1976.

GLASS, G.V.; McGRAW, B.; SMITH, M.L. Meta-analysis in social research. Beverly Hills: Sage Publ., 1981. 280p.

GOFFINET, B.; GERBER, S. Quantitative trait loci: a meta-analyis. Genetics, v.155, p.463-473, 2000.

GOODMAN, S.N. Meta-analysis and evidence. Controlled Clinical Trials, v.10, p.188-204, 1989.

GUREVITCH, J.; HEDGES, L. V. Meta-analysis: combining the results of independent experiments. In: SCHEINER, S. M.; GUREVITCH, J. Design and analysis of ecological experiments. New York: Chapman \& Hall, 1993. cap. 17, p.378-398.

HEDGES, L.V. Meta-analysis. Journal of Educational Statistics, v.17, n.4, p.279296, 1992.

HEDGES, L.V.; OLKIN, I. Statistical methods for meta-analysis. London: Academic Press, 1985. 369p.

HOUWELINGEN, H.C.V. The future of biostatistics: expecting the unexpected. Statistics in Medicine, v.16, p.2773-2784, 1997. 
HOUWELINGEN, H.C.V.; ARENDS, L.R.; STIJNEN, T. Tutorial in biostatistics: Advanced methods in meta-analysis: multivariate approach and meta-regresion. Statistics in Medicine, v.21, p.589-624, 2002.

HUNTER, J.E.; SCHMIT, F.L. Methods of meta-analysis. Newbury Park: Sage Publ., 1990. 592p.

JOHNSON, B.T.; MULLEN B. CTI softwares review. http://www1.york.ac.uk/inst/ctipsych/web/CTI/DirTxt/reviews/dstat.html (29 Out. 2002).

JOHNSON, R.A.; WICHERN, D.W. Applied multivariate statistical analysis. 4.ed. Englewood Cliffs: Prentice Hall, 1998. 816p.

KENNY, D.A. Meta Program Information. http://users.rcn.com/dakenny/metain.htm (29 Out. 2002).

KIRBY, K.N. Advanced data analysis with SYSTAT. New York: Van Nostrand Reinhold, 1993. 475p.

KOOTS, K.R.; GIBSON, J.P.; SMITH, C. et al. Analyses of publised genetic parameter estimates for beef production traits. 1. Heritability. Animal Breeding Abstracts, v.62, n.5, p. 309-338, 1994a.

KOOTS, K.R.; GIBSON, J.P.; SMITH, C. et al. Analyses of publised genetic parameter estimates for beef production traits. 2. Phenotypic and genetic correlations. Animal Breeding Abstracts, v.62, n.11, p. 826-853, 1994b.

KUSS, O.; KOCH, A. Meta-analysis macros for SAS. The Statistical Software Newsletter, v.22, p.325-333, 1996.

LAROSE, D.T.; DEY, D.K. Grouped random effects models for bayesian metaanalysis. Statistics in Medicine, v.16, p.1817-1829, 1997. 
LI, Z. A multiplicative random effects model for meta-analysis with application to estimation of admisture component. Biometrics, v.51, p.864-873, 1995.

LI, Z.; BEGG, C.B. Random effects for combining results from controlled and uncontrolled studies in a meta-analysis. Journal of the American Statistical Association, v.89, p.1523-1527, 1994.

LÔBO, R.N.B; MADALENA, F.E.; VIEIRA, A.R. Average estimates of genetic parameters for beef and dairy cattle in Tropical regions. Animal Breeding Abstracts, v.68, p.433-462, 2000.

MALLICK, B.K.; WALKER, S.G. Combining information from several experiments with nonparametric priors. Biometrika, v.84, n.3, p.697-706, 1997.

MARTINS, R.M. Estudo do crescimento da cana-de-açúcar através da meta-análise. Botucatu, 2001. 68p. Dissertação (Mestrado) - Faculdade de Ciências Agronômicas, Universidade Estadual Paulista "Júlio de Mesquita Filho”.

MERCADANTE, M.E.Z.; LÔBO, R.B.; REYES, A. Parámetros genéticos para características de crecimiento en cebuínos de carne: una revisión. Archivo Latinoamericano Producción Animal, v. 3, n. 1, p.45-89, 1995.

MEYER, K. Estimates of genetic parameters for weaning weight of beef cattle accounting for direct-maternal environmental covariances. Livestock Production Science, v.52, p.187-199, 1997.

MINITAB. MINITAB homepage: making data analysis easier. http://www.minitab.com (29 Out. 2002).

MOHIUDDIN, G. Estimates of genetic and phenotypic parameters of some trais in beef cattle. Animal Breeding Astracts, v.61, n.8, p.495-522, 1993.

MOLLER, A.P.; JENNIONS, M.D. Testing and adjusting for publication bias. TRENDS in Ecology \& Evolution, v.16, n.10, p.580-586, 2001. 
MURPHY, K. Matlab software by Kevin Murphy. http://www.ai.mit.edu/ murphyk/Software/index.html (29 Out. 2002).

NORMAND, S.T. Meta-analysis software: a comparative review. Journal of the American Statistician Association, v.49, n.3, p.298-309, 1995.

NORMAND, S.T. Tutorial in biostatistics meta-analysis: formulating, evaluating, combining, and reporting. Statistics in Medicine, v.18, p.321-359, 1999.

OETZEL, G.R. Meta-analysis of nutritional risk factors for milk fever in dairy cattle. Journal of Dairy Science, v.74, p.3900-3912, 1991.

OLKIN, I. Meta-analysis: methods for combining independent studies. Statistical Science, v.7, n.2, p.226, 1992.

OLKIN, I. Meta-analysis: reconciling the results of independent studies. Statistics in Medicine, v.14, p.457-472, 1995.

OLKIN, I.; SHAW, D.V. Meta-analysis and its applications in horticultural science. HortScience, v.30, n.7, p.1343-1348, 1995.

PETERS, A.R.; MARTINEZ, T.A.; COOK, A.J.C. A meta-analysis of studies of the effect of GNRH 11-14 days after insemination on pregnancy rates in cattle. Theriogenology, v.54, p.1317-1326, 2000.

PETITTI, D.B. Meta-analysis, decision analysis and cost effectiveness analysis. Oxford: Oxford University Press, 1994. 246p.

R DEVELOPMENT CORE TEAM R: A language and environment for statistical computing, 2003. http://www.R-project.org. (02 jun. 2004).

REYES, A. de los; LÔBO, R.B.; OLIVEIRA, H.N. de et al. Estimation de (co)varianzas y DEP's por modelo animal bicaracter para pesos y perimetro escrotal de ganado nelore en Brasil. Revista Argentina de Producción Animal, v.15, n.3/4, p.926930, 1995. 
ROSENTHAL, R. Meta-analytic procedures for social research. Beverly Hills: Sage Publ., 1984. 150p.

ROUGHSEDGED, T.; THOMPSON, R.; VILLANUEVA, B. et al. Synthesis of direct and maternal genetic components of economically important traits from beef breedcross evaluations. Journal of Animal Science, v.79, p.2307-2319, 2001.

SALLES, P.A. Critérios de seleção para características de crescimento em machos da raça nelore. Ribeirão Preto, 1995. 69p. Dissertação (Mestrado) - Faculdade de Medicina de Ribeirão Preto, Universidade de São Paulo.

SAS INSTITUTE. SAS/IML software usage and reference, version 6. Cary, 1990a. 501p.

SAS INSTITUTE. SAS/STAT user's guide: version 6. 4.ed. Cary, 1990b. 846p.

SAS INSTITUTE. SAS/STAT software: changes and enhancements through release 6.12. Cary, 1996. 1162p.

SAS INSTITUTE. SAS OnlineDoc®: version 8. Cary, 1999a. http://www.id.unizh.ch/software/unix/statmath/sas/sasdoc/stat/chap8/sect10.htm. (21 nov. 2003).

SAS INSTITUTE. SAS OnlineDoc ${ }^{\circledR}$ : version 8. Cary, 1999b. http://www.id.unizh.ch/software/unix/statmath/sas/sasdoc/stat/chap23/sect25.htm. (21 nov. 2003).

SAS INSTITUTE. SAS OnlineDoc ${ }^{\circledR}$ : version 8. Cary, 1999c. http://www.id.unizh.ch/software/unix/statmath/sas/sasdoc/stat/chap23/sect2.htm. (21 nov. 2003).

SCHAEFFER, L.R. Animal Models-10-637-Winter 99. Guelph: University of Guelph, 1999. 
SCHEINER, S. M.; GUREVITCH, J. Design and analysis of ecological experiments. New York: Chapman \& Hall, 1993. 445p.

SHAPIRO, S.S.; WILK, M.B. An analysis of variance test for normality (complete samples). Biometrika, v.52, p.591-611, 1965.

SHARMA, S. Applied multivariate techniquies. NewYork: John Wiley, 1996. 493p.

SILLIMAN, N.P. Nonparametric classes of weights functions to model publication bias. Biometrika, v.84, n.4, p.909-918, 1997.

SMITH, T.C.; SPIEGELHALTER, D.J. Bayesian meta-analysis of randomized trials using graphical models and BUGS. In: BERRY, D.A.; STANGL, D.K. Bayesian biostatistics. New York: Marcel Dekker, 1996. cap. 15, p.411-427.

SPIEGELHALTER, D.J.; THOMAS, A., BEST, N.G., GILKS, W.R. BUGS: Bayesian inference using Gibbs sampling, version 0.50 . http://www.mrcbsu.cam.ac.uk/bugs/ (02 jun. 2004).

STATSDIRECT LTD. Direct statistical software. http://www.camcode.com/ (29 Out. 2002).

STIGLER, M.S. The history of statistics: the measurement of uncertainty before 1900 . Cambridge: Harvard University Press, 1986. 410p.

St-PIERRE, N.R. Integrating quantitative findings from multiple studies using mixed model methodology. Journal of Dairy Science, v.84, p.741-755, 2001.

TAWAH, C.L.; MBAH, D.A.; REGE, J.E.O. et al. Genetic evaluation of birth and weaning weight of Gudali and two-breed synthetic Wakwa beef cattle populations under selection in Cameroon: genetic and phenotypic parameters. Animal Production, v.57, p.73, 1993.

WANG, M. C.; BUSHMAN, B. J. Integration results: through meta-analytic review using SAS software. Cary: SAS Institute, 1999. 400p. 


\section{BIBLIOGRAFIA UTILIZADA NA META-ANÁLISE}

ALBUQUERQUE, L.G. de; FARO, L. el. Consequências da correlação genética entre características. In: CONGRESSO BRASILEIRO DAS RAÇAS ZEBUÍNAS, 5., Uberaba, 2002. Os mitos e realidade da carne bovina. Uberaba: ABCZ, 2002. p. 269-270.

ALBUQUERQUE, L.G. de; MEYER, K. Estimates of direct and maternal genetic effects for weights from birth to 600 days of age in Nelore cattle. Journal of Animal Breeding and Genetic, v.118, 83-92, 2001.

BALIEIRO, J.C.C.; LOPES, P.S.; ELER, J.P. et al. Efeito da heterogeneidade da variância na avaliação genética de bovinos da raça Nelore: análises de características múltiplas para peso à desmama (compact disc). In: REUNIÃO ANUAL DA SOCIEDADE BRASILEIRA DE ZOOTECNIA, 39., Recife, 2002. Anais. Recife: SBZ, 2002.

BARBOSA, S.B.P.; MARTINS FILHO, R.; MARTINS, G.A. et al. Aspectos genéticos e de ambiente em características de crescimento em bovinos da raça Nelore, no estado de Pernambuco (compact disc). In: REUNIÃO ANUAL DA SOCIEDADE BRASILEIRA DE ZOOTECNIA, 36., Porto Alegre, 1999. Anais. Porto Alegre: SBZ, 1999a. 
BARBOSA, S.B.P.; MARTINS FILHO, R.; MARTINS, G.A. et al. Fatores ambientais e genéticos que influenciam os pesos corporais de bovinos guzerá no estado de Pernambuco (compact disc). In: REUNIÃO ANUAL DA SOCIEDADE BRASILEIRA DE ZOOTECNIA, 36., Porto Alegre, 1999. Anais. Porto Alegre: SBZ, 1999b.

BERGMANN, J.A.G.;ZAMBORLINI, L.C.; ANDRADE, V.J. et al. Estimativas de parâmetros genéticos do perímetro escrotal e do peso corporal em animais da raça Nelore. Arquivo Brasileiro de Medicina Veterinária e Zootecnia, v.48, n.1, p.69-78, 1996. /Resumo em CAB Abstracts on CD-ROM, 1996-1998/.

BIFFANI, S.; MARTINS FILHO, R.; GIORGETTI, A. et al. Parâmetros genéticos e fenotípicos para características de crescimento em animais da raça Nelore (compact disc). In: REUNIÃO ANUAL DA SOCIEDADE BRASILEIRA DE ZOOTECNIA, 35., Botucatu, 1998. Anais. Botucatu: SBZ, 1998.

BIFFANI, S.; MARTINS FILHO, R.; GIORGETTI, A. et al. Fatores ambientais e genéticos sobre o crescimento ao ano e sobreano de bovinos Nelore, criados no Nordeste do Brasil. Revista Brasileira de Zootecnia, v.28, n.3, p.468-473, 1999a.

BIFFANI, S.; MARTINS FILHO, R.; MARTINI, A. et al. Fatores ambientais e genéticos que influenciam o desenvolvimento ponderal até o desmame de animais Nelore criados no Nordeste do Brasil. Revista Brasileira de Zootecnia, v.28, n.4, p.693-700, 1999b.

BITTENCOURT, T.C.C. de; BERLIM, C.; PIRES, A. Avaliação de parâmetros ambientais e da herdabilidade dos pesos ao nascer e a desmama de bezerros da raça Nelore no Estado da Bahia. Arquivos da Escola de Medicina Veterinária da Universidade Federal da Bahia, v.18, n.1, p.232-240, 1996. /Resumo em CAB Abstracts on CD-ROM, 1996-98/. 
BITTENCOURT, T.C.C. de; ROCHA, J.C.M.C.; LOBO, R.B. et al. Estimação de componentes de (co)variâncias e predição de DEP's para características de crescimento pós-desmama em bovinos da raça Nelore, usando diferentes modelos estatísticos. Arquivo Brasileiro de Medicina Veterinária e Zootecnia, v.54, n.3, p.303-308, 2002. /Resumo em CAB Abstracts on CD-ROM, 2002/.

CÁRDENAS, I.; MONTONI, D.; VITTO, R. et al. Estimacion de parametros geneticos directos e maternos para el peso al nacer, peso al destete y peso a los 18 meses en un rebaño Brahman registrado. I. Indices de herencia (compact disc). In: REUNIÓN DE LA ASOCIACIÓN LATINOAMERICANA DE PRODUCCIÓN ANIMAL, 17., La Habana: ALPA, 2001.

CARVALHO, J.C.M. de; BUXADERA, A.M. Análise das causas de variação do crescimento pré-desmame no gado Nelore em um rebanho no Estado de Minas Gerais. In: REUNIÃO ANUAL DA SOCIEDADE BRASILEIRA DE ZOOTECNIA, 33., Fortaleza, 1996. Anais. Viçosa: SBZ, 1996. p.167.

CUNHA, R.M.; LIMA, F.A.M.; OLIVEIRA, S.M.P. de et al. Estimativas de herdabilidades de pesos e ganhos de pesos do nascimento à desmama de bovinos da raça Nelore. In: REUNIÃO ANUAL DA SOCIEDADE BRASILEIRA DE ZOOTECNIA, 33., Fortaleza, 1996. Anais. Viçosa: SBZ, 1996. p.212.

CYRILLO, J.N.S.G.; ALENCAR, M.M.; RAZOOK, A.G. et al. Modelagem e estimação de parâmetros genéticos para características de crescimento do nascimento ao momento da seleção (378 dias) de machos Nelore. (compact disc). In: REUNIÃO ANUAL DA SOCIEDADE BRASILEIRA DE ZOOTECNIA, 40., Santa Maria, 2003. Anais. Santa Maria: SBZ, 2003.

CYRILLO, J.N.S.G; RAZOOK, A.G.; FIGUEIREDO, L.A. de et al. Estimativas de tendências e parâmetros genéticos do peso padronizado aos 378 dias de idade, medidas corporais e perímetro escrotal de machos Nelore de Sertãozinho. Revista Brasileira de Zootecnia, v.30, n.1, p.56-65, 2001. 
DIAS, D.S.O.; TONHATI, H.; MAGNABOSCO, C.U. et al. Análise genética de características de crescimento em rebanhos Nelore da região Centro-Oeste do Brasil (compact disc). In: REUNIÃO ANUAL DA SOCIEDADE BRASILEIRA DE ZOOTECNIA, 39., Recife, 2002. Anais. Recife: SBZ, 2002a.

DIAS, D.S.O.; TONHATI, H.; MAGNABOSCO, C.U. et al. Estimativas de componentes de variância e herdabilidade para o peso adulto de fêmeas nelore (compact disc). In: SIMPÓSIO NACIONAL DE MELHORAMENTO ANIMAL, Campo Grande, 2002. Anais. Campo Grande: SBMA, 2002b.

ELER, J.P.; FERRAZ, J.B.S.; DIAS, F. Estimação de parâmetros genéticos para características produtivas na raça Nelore. I. Fase pré-desmama (compact disc). In: REUNIÓN DE LA ASOCIACIÓN LATINOAMERICANA DE PRODUCCIÓN ANIMAL, 17., La Habana: ALPA, 2001.

ELER, J.P.; FERRAZ, J.B.S.; SILVA, P.R. Parâmetros genéticos de pesos de bovinos da raça Nelore. In: REUNIÃO ANUAL DA SOCIEDADE BRASILEIRA DE ZOOTECNIA, 32., Brasília, 1995. Anais. Viçosa: SBZ, 1995. p.709-710.

ELER, J.P.; FERRAZ, J.B.S.; SILVA, P.R. Estimação simultânea de parâmetros genéticos para características de importância econômica na raça nelore, com a utilização de modelos animais. In: REUNIÃO ANUAL DA SOCIEDADE BRASILEIRA DE ZOOTECNIA, 33., Fortaleza, 1996. Anais. Viçosa: SBZ, 1996. p.99.

ELER, J.P.; FERRAZ, J.B.S.; GOLDEN, B.L. et al. Influência da interação touro x rebanho na estimação da correlação entre efeitos genéticos direto e materno em bovinos da raça Nelore. Revista Brasileira de Zootecnia, v.29, n.6, p.1642-1648, 2000. 
ELER, J.P.; FERRAZ, J.B.S.; LOBO, R.B. et al. Estimação simultânea de parâmetros genéticos para características de importância econômica na raça nelore, com a utilização de modelos animais. In: REUNIÃO ANUAL DA SOCIEDADE BRASILEIRA DE ZOOTECNIA, 28, João Pessoa, 1991. Anais. Viçosa: SBZ, 1991. p.553.

ELER, J.P.; FERRAZ, J.B.S.; LÔBO, R.B. et al. Genetic antagonism between growth and maternal ability in Nellore cattle. Revista Brasileira de Genética, v.17, n.1; p.59-64, 1994. /Resumo em CAB Abstracts on CD-ROM, 1995/.

ELZO, M.A.; MANRIQUE, C.; OSSA, G. et al. Additive and noadditive genetic variability for growth traits in the Turipana Romosinuano-Zebu multibreed herd. Journal of Animal Science, v.76, n.6, p.1539-1549, 1998. /Resumo em CAB Abstracts on CD-ROM, 1998-00/.

FARIA, C.U. de; MAGNABOSCO, C.U.; REYES, A. de los et al. Importância da utilização de valores iniciais informativos e período de descarte amostral na implementação de uma análise bayesiana para estimação de parâmetros genéticos no peso ao desmame na raça Nelore (compact disc). In: REUNIÃO ANUAL DA SOCIEDADE BRASILEIRA DE ZOOTECNIA, 39., Recife, 2002. Anais. Recife: SBZ, 2002.

FERRAZ-FILHO, P.B.; RAMOS, A.A.; SILVA, L.O.C. da et al. Herdabilidades e correlações genéticas para características de crescimento de animais da raça Tabapuã (compact disc). In: REUNIÃO ANUAL DA SOCIEDADE BRASILEIRA DE ZOOTECNIA, 37., Viçosa, 2000. Anais. Viçosa: SBZ, 2000.

FERRAZ-FILHO, P.B.; RAMOS, A.A.; SILVA, L.O.C. et al. Tendência genética dos efeitos direto e materno sobre os pesos à desmama e pós-desmama de bovinos da raça Tabapuã no Brasil. Revista Brasileira de Zootecnia, v.31, n.2, p.635-640, 2002. 
FERREIRA, V.C.P., PENNA, V.M., BERGMANN, J.A.G. et al. Interação genótipoambiente em algumas características produtivas de gado de corte no Brasil. Arquivo Brasileiro de Medicina Veterinária e Zootecnia, v.53, n.3, p.385-392, 2001.

FORNI, S. Estimação de parâmetros genéticos e fenotípicos para a característica dias para o parto em bovinos da raça Nelore. Jaboticabal, 2003. 58 p. Dissertação (Mestrado) - Faculdade de Ciências Agrárias e Veterinárias, Universidade Estadual Paulista “Júlio de Mesquita Filho”.

GARNERO, A.V.; CABRERA, M.; LÔBO, R. B. et al. Incorporação da covariância direta-materna nas análises de características de crescimento na raça Nelore. In: REUNIÃO ANUAL DA SOCIEDADE BRASILEIRA DE ZOOTECNIA, 38., Piracicaba, 2001. Anais. Piracicaba: FEALQ, 2001b. p.615.

GARNERO, A.V.; FERNANDES, M.B.; FIGUEIREDO, L.F.C. et al. Influência da incorporação de dados de progênies na classificação de touros da raça Nelore. Revista Brasileira de Zootecnia, v.31, n.2, p.918-923, 2002. Suplemento.

GARNERO, A.V.; GUNSKI, R.J.; SCHWENGBER, E.B. et al. Comparación entre criterios de selección para características de crescimiento correlacionados con edad al primer parto en la raza Nelore. Livestock Research for Rural Development, v.13, n.2, p.1-10, 2001c.

GARNERO, A.V.; LÔBO, R. B.; BEZERRA, L. A. F. et al. Comparação entre alguns critérios de seleção para crescimento na raça Nelore. Revista Brasileira de Zootecnia, v.30, n3, p.714-718, 2001a.

GONÇALVES, J. N.S.; FIGUEIREDO, L.A.; RAZOOK, A.G. et al. Prova de ganho de peso de Sertãozinho: efeitos genéticos e de ambiente sobre características de crescimento. In: REUNIÃO ANUAL DA SOCIEDADE BRASILEIRA DE ZOOTECNIA, 33., Fortaleza, 1996. Anais. Viçosa: SBZ, 1996. p.121. 
GROENEVELD, E.; MOSTERT, B.E.; RUST, T. The covariance structure of growth traits in the Afrikaner beef population. Livestock Production Science, v.55, p.99107, 1998.

GUERRA, D.; RODRIGUEZ, M.; PLANAS, T. et al. Evaluación genética de las razas vacunas de carne en Cuba (compact disc). In: REUNIÓN DE LA ASOCIACIÓN LATINOAMERICANA DE PRODUCCIÓN ANIMAL, 17., La Habana: ALPA, 2001.

GUNSKI, R.J.; GARNERO, A.V.; BEZERRA, L.A.F. et al. Idade ao primeiro parto, período de gestação e peso ao nascimento na raça Nelore. Ciência Agronômica, v.32, n.1/2, p.46-52, 2001.

KHOMBE, C.T.; HAYES, R.I.; WADE, K.M. Estimation of direct additive and maternal additive genetic effects for weaning weight in Mashona cattle of Zimbabwe using na individual animal model. Animal Science, v.60, p.41-48, 1995.

KIPPERT, C.J.; WEBER, T.; GHELLER, D.G. et al. Estimativas de parâmetros genéticos, fenotípicos e correlação genética entre os pesos de animais da raça Nelore (compact disc). In: REUNIÃO ANUAL DA SOCIEDADE BRASILEIRA DE ZOOTECNIA, 40., Santa Maria, 2003. Anais. Santa Maria: SBZ, 2003.

KOURY FILHO, W.; FERRAZ, J.B.S.; ELER, J.P. et al. Correlações entre escores de umbigo e características de produção em bovinos da raça Nelore (compact disc). In: REUNIÃO ANUAL DA SOCIEDADE BRASILEIRA DE ZOOTECNIA, 37., Viçosa, 2000. Anais. Viçosa: SBZ, 2000.

KOURY FILHO, W.; FERRAZ, J.B.S.; ELER, J.P. et al. Estimativas de herdabilidades e correlações genéticas entre escores de avaliações visuais e características de desenvolvimento ponderal em uma população da raça Nelore (compact disc). In: SIMPÓSIO NACIONAL DE MELHORAMENTO ANIMAL, Campo Grande, 2002. Anais. Campo Grande: SBMA, 2002. 
LÔBO, R.B.; OLIVEIRA, H.N de; BEZERRA, L.A.F. et al. Estimativa de componentes de (co)variância e herdabilidade para peso aos 120 dias de idade da raça nelore usando estatística bayesiana. . In: REUNIÃO ANUAL DA SOCIEDADE BRASILEIRA DE ZOOTECNIA, 34., Juiz de Fora, 1997. Anais. Viçosa: SBZ, 1997. p.186.

LÔBO, R.B.; REYES, A. de los; BEZERRA, L.A.F. et al. Parâmetros fenotípicos e genéticos de pesos e perímetro escrotal às idades-padrão em animais da raça Nelore. In: REUNIÃO ANUAL DA SOCIEDADE BRASILEIRA DE ZOOTECNIA, 32., Brasília, 1995. Anais. Viçosa: SBZ, 1995. p.625-627.

MACHADO, P.F.A.; AQUINO, L.H. de; GONÇALVES, T.M. Estimativas de parâmetros genéticos e critérios de seleção em características ponderais em bovinos Nelore. Ciência e Agrotecnologia, v.23, n.1, p.197-204, 1999. /Resumo em CAB Abstracts on CD-ROM, 2000-01/.

MAGNABOSCO, C.U.; FAMULA, T.; LÔBO, R. B. et al. Componentes de variância e covariância para características de crescimento em um rebanho da raça Nelore mocho no estado de São Paulo. In: REUNIÃO ANUAL DA SOCIEDADE BRASILEIRA DE ZOOTECNIA, 32., Brasília, 1995. Anais. Viçosa: SBZ, 1995. p.677-679.

MAGNABOSCO, C.U.; FAMULA, T.; LÔBO, R.B. et al. Estimativas de parâmetros genéticos e de ambiente de características de crescimento em bovinos da raça Nelore. In: REUNIÃO ANUAL DA SOCIEDADE BRASILEIRA DE ZOOTECNIA, 33., Fortaleza, 1996. Anais. Viçosa: SBZ, 1996. p.142.

MAGNABOSCO, C.U.; FARIA, C.U.; REYES, A. et al. Inferência bayesiana para peso ao desmame em bovinos da raça Nelore (compact disc). In: REUNIÓN DE LA ASOCIACIÓN LATINOAMERICANA DE PRODUCCIÓN ANIMAL, 17., La Habana: ALPA, 2001. 
MAGNABOSCO, C.U.; LÔBO, R.B; REYES, A. et al. Inferência bayesiana na estimação de parâmetros genéticos para peso aos 205 dias de idade em bovinos da raça Nelore. In: REUNIÃO ANUAL DA SOCIEDADE BRASILEIRA DE ZOOTECNIA, 34., Juiz de Fora, 1997. Anais. Viçosa: SBZ, 1997. p.165.

MAGNABOSCO, C.U.; REYES, A.; McMANUS, C. et al. Estudo genéticoquantitativo de características de crescimento em bovinos da raça Nelore nos Estados Unidos da América. In: REUNIÃO ANUAL DA SOCIEDADE BRASILEIRA DE ZOOTECNIA, 35., Botucatu, 1998. Anais. Viçosa: SBZ, 1998. p.165.

MARCONDES, C.R.; BERGMANN, J.A.G.; ELER, J.P. et al. Análise de alguns critérios de seleção para características de crescimento na raça Nelore. Arquivo Brasileiro de Medicina Veterinária e Zootecnia, v.52, n.1, p.83-89, 2000.

MARCONDES, C.R.; GAVIO, D.; BITTENCOURT, T.C.C. et al. Estudo de modelo alternativo para estimação de componentes de (co)variância e predição de valores genéticos de características de crescimento em bovinos da raça Nelore. Arquivo Brasileiro de Medicina Veterinária e Zootecnia, v.54, n.1, p.93-99, 2002. /Resumo em CAB Abstracts on CD-ROM, 2002/.

MARTINS, G.A.; MARTINS-FILHO, R.; LIMA, F.A.M. et al. Influência dos fatores genéticos e de meio sobre o crescimento de bovinos da raça Nelore no estado do Maranhão. Revista Brasileira de Zootecnia, v.29, n.1, p.103-107, 2000.

MARTINS-FILHO, R.; BIFFANI, S.; LOBO, R.N.B. et al. Genetic parameters of growth traits in Nellore cattle reared in northeast of Brazil. (compact disc). In: WORLD CONGRESS ON GENETICS APPLIED TO LIVESTOCK PRODUCTION, 7., Montpellier, 2002. Proceedings. Montpellier: WCGALP, 2002. 
MARTINS-FILHO, R.; LÔBO, R.B.; LIMA, F.A.M. Parâmetros genéticos e fentípicos de pesos e ganhos de pesos em bovinos zebus no Estado do Ceará. In: REUNIÃO ANUAL DA SOCIEDADE BRASILEIRA DE ZOOTECNIA, 34., Juiz de Fora, 1997. Anais. Viçosa: SBZ, 1997. p.248.

MARTINS-FILHO, R.; LÔBO, R.N.B.; LIMA, F.A.M. Características de crescimento em bovinos zebus criados nos estados do Ceará, Piauí e Maranhão. In: SIMPÓSIO NACIONAL DE MELHORAMENTO ANIMAL, 1., Ribeirão Preto, Anais. Ribeirão Preto: SBMA, 1996. p.266-269.

MERCADANTE, M.E.Z.; LÔBO, R.B. Estimativas de (Co) variância e parâmetros genéticos dos efeitos direto e materno de características de fêmeas de um rebanho Nelore. Revista Brasileira de Zootecnia, v.26, n.6, p.1124-1133, 1997.

MERCADANTE, M.E.Z.; LÔBO, R.B.; REYES, A. Parámetros genéticos para características de crescimiento en cebuínos de carne. Archivos Latinoamericanos Producción Animal, v. 3, n. 1, p.45-89, 1995.

MERCADANTE, M.E.; PACKER, I.U.; RAZOOK, A.G. et al. Direct and correlated responses to selection fou yearling weight on reproductive performance of Nelore cows. Journal of Animal Science, v.81, p.376-384, 2003.

MUCARI, T.B.; OLIVEIRA, J.A. de Estimativas de herdabilidades para efeitos genéticos diretos e maternos de pesos em um rebanho Guzerá (compact disc). In: REUNIÃO ANUAL DA SOCIEDADE BRASILEIRA DE ZOOTECNIA, 39., Recife, 2002. Anais. Recife: SBZ, 2002.

MUCARI, T.B.; OLIVEIRA, J.A. Estimates og genetic parameters and annual trends for weights at weaning and at 18 montths of age in a Guzerát herd. (compact disc). In: WORLD CONGRESS ON GENETICS APPLIED TO LIVESTOCK PRODUCTION, 7., Montpellier, 2002. Proceedings. Montpellier: WCGALP, 2002b. 
NOBRE, P.R.C.; MISZTAL, I.; TSURUTA, S. et al. Analyses of ggrowth curves of Nellore cattle by multiple-trait and random regression models. Journal of Animal Science, v.81, p.918-926, 2003.

OLIVEIRA, C.A.L. de; SILVA, L.O.C. da; MARTINS, E.N. et al. Avaliação genética para características de crescimento em animais da raça Nelore utilizando inferência bayesiana (compact disc). In: SIMPÓSIO NACIONAL DE MELHORAMENTO ANIMAL, Campo Grande, 2002. Anais. Campo Grande: SBMA, 2002.

OLIVEIRA, J.A. de; LÔBO, R.B.; GONÇALVES, A.A.M. Estimativas de parâmetros genéticos e fenotípicos de pesos e ganhos em peso do nascimento aos 365 dias de idade em um rebanho da raça Guzerá. Boletim de Indústria Animal, v.50, p.119123, 1993.

OLIVEIRA, J.A. de; LÔBO, R.B.; GONÇALVES, A.A.M. Correlações genéticas e fenotípicas entre pesos e produção de leite na primeira lactação em fêmeas da raça Guzerá. Boletim de Indústria Animal, v.51, n.1, p.7-11, 1994.

OLIVEIRA, J.A.; ISEPON, O.J.; ALVES, J.B. et al. Fatores ambientais e genéticos relacionados com o peso aos 18 meses e ganho diário de peso ao nascimento a essa idade em bovinos da raça Guzerá. In: REUNIÃO ANUAL SOCIEDADE BRASILEIRA DE ZOOTECNIA, 27., Campinas, 1990. Anais. Viçosa: SBZ, 1990. p.476.

PELICIONI, L.C.; QUEIROZ, S.A.; ALBUQUERQUE, L.G. Estimates of genetic parameters for body weights of Guzerát cattle. (compact disc). In: WORLD CONGRESS ON GENETICS APPLIED TO LIVESTOCK PRODUCTION, 7., Montpellier, 2002. Proceedings. Montpellier: WCGALP, 2002.

PIMENTA FILHO, E.C.; MARTINS, G.A.; SARMENTO, J.L.R. et al. Estimativas de herdabilidade de efeitos direto e materno de características de crescimento de bovinos Guzerá, no estado da Paraíba. Revista Brasileira de Zootecnia, v.30, n.4, p.1220-1223, 2001. 
PLASSE, D.; VERDE, O.S.; ARANGO, J. et al. (Co)variance components, genetic parameters and annual trends for calf weights in a Brahman herd kept on floodable savanna. Genetics and Molecular Research, v.1, n.4, p.282-297, 2002.

REYES, A. de los; LÔBO, R.B.; OLIVEIRA, H.N. de et al. Estimation de (co)varianzas y DEP's por modelo animal bicaracter para pesos y perimetro escrotal de ganado nelore en Brasil. Revista Argentina de Producción Animal, v.15, n.3/4, p.926930, 1995.

RIBEIRO, M.N.; PIMENTA FILHO, E.C.; MARTINS, G.A. et al. Herdabilidade para efeitos direto e materno de características de crescimento de bovinos nelore no estado da Paraíba. Revista Brasileira de Zootecnia, v.30, n.4, p.1224-1227, 2001.

RICO, C.; PLANAS, T.; MENCHACA, I. et al. Parametros geneticos del crescimento a diferentes edades en ganado Cebu. Archivos Latinoamericanos de Producción Animal, v.2, n.1, p.1-8, 1994.

ROSA, A.N.; SILVA, L.O.C. da; NOBRE, P.R.C. Avaliação do desempenho de animais nelore em controle de desenvolvimento ponderal no Estado de Mato Grosso do Sul, Brasil. Revista da Sociedade Brasileira de Zootecnia, v.15, n.6, p.515532, 1986.

SAKAGUTI, E.S. Funções de covariâncias e modelos de regressão aleatória na avaliação genética do crescimento de bovinos jovens da raça Tabapuã. Viçosa, 2000. 86p. Tese (Doutorado) - Universidade Federal de Viçosa.

SALLES, P.A. Critérios de seleção para características de crescimento em machos da raça nelore. Ribeirão Preto, 1995. 69p. Dissertação (Mestrado) - Faculdade de Medicina de Ribeirão Preto, Universidade de São Paulo. 
SARMENTO, J.L.R.; PIMENTA FILHO, E.C.; RIBEIRO, M.N. et al. Estudo genético quantitativo do peso pós-desmama de bovinos Nelore e Guzerá no Estado da Paraíba (compact disc). In: REUNIÃO ANUAL DA SOCIEDADE BRASILEIRA DE ZOOTECNIA, 37., Viçosa, 2000. Anais. Viçosa: SBZ, 2000.

SCARPATI, M.T.V.; LÔBO, R.B. Modelos animais alternativos para estimação de componentes de (co)variância e de parâmetros genéticos e fenotípicos do peso ao nascer na raça Nelore. Revista Brasileira de Zootecnia, v.28, n.3, p.512-518, 1999.

SILVEIRA, J.C. da; SOUZA, A.P. de; McMANUS, C. et al. Parâmetros genéticos e ambientais de características produtivas em animais da raça Nelore no Mato Grosso do Sul (compact disc). In: REUNIÃO ANUAL DA SOCIEDADE BRASILEIRA DE ZOOTECNIA, 37., Viçosa, 2000. Anais. Viçosa: SBZ, 2000.

SIQUEIRA, R.L.P.G.; OLIVEIRA, J.A.; LÔBO, R.B. et al. Análise da variabilidade genética aditiva de características de crescimento da raça Nelore. Revista Brasileira de Zootecnia, v.32, n.1, p.99-105, 2003.

SOUZA, J. C. de; RAMOS, A.A. Efeitos de fatores genéticos e do meio sobre os pesos de bovinos da raça nelore. Revista da Sociedade Brasileira de Zootecnia, v.24, p.164 - 172, 1995.

SOUZA, J.C. de; EUCLIDE FILHO, K.; SILVA, L.O.C. da et al. Estimativa de parâmetros genéticos para o peso ao desmame de animais da raça Nelore. In: REUNIÃO ANUAL DA SOCIEDADE BRASILEIRA DE ZOOTECNIA, 34., Juiz de Fora, 1997. Anais. Viçosa: SBZ, 1997. p.251.

SOUZA, J.C. de; EUCLIDES FILHO, K.; SILVA, L.O.C. da et al. Estudo dos parâmetros genéticos em bovinos da raça Guzerá na micro-região mata e agreste (RP26), no Nordeste do Brasil. In: REUNIÃO ANUAL DA SOCIEDADE BRASILEIRA DE ZOOTECNIA, 38., Piracicaba, 2001. Anais. Piracicaba: FEALQ, 2001. p.611. 
SOUZA, J.C de; SILVA, L.O.C. da; FERRAZ FILHO, P.B. et al. Estimativas de parâmetros e da tendência genética para o peso aos 205 dias de idade de zebuínos da raça Guzerá (compact disc). In: REUNIÃO ANUAL DA SOCIEDADE BRASILEIRA DE ZOOTECNIA, 37., Viçosa, 2000. Anais. Viçosa: SBZ, 2000.

SOUZA, J.C. de; SILVA, L.O.C. da; PINHEIRO, V.G. et al. Estimativas de parâmetros genéticos dos pesos aos 205, 365 e 550 dias de idade em bovinos da raça Guzerá na micro-região de Araraquara (compact disc). In: SIMPÓSIO NACIONAL DE MELHORAMENTO ANIMAL, Campo Grande, 2002. Anais. Campo Grande: SBMA, 2002.

VAN MELIS, M.H.; SILVA, J.A.V.; ELER, J.P. et al. Relação genética entre peso ao nascimento e peso à desmama em bovinos da raça Nelore. In: REUNIÃO ANUAL DA SOCIEDADE BRASILEIRA DE ZOOTECNIA, 38., Piracicaba, 2001. Anais. Piracicaba: FEALQ, 2001. p.515. 